\title{
Non-Energy Benefits of \\ Industrial Energy Efficiency \\ Roles and Potentials
}

\section{Therese Nehler}




\title{
Non-Energy Benefits of Industrial Energy Efficiency
}

Roles and Potentials

\author{
Therese Nehler
}

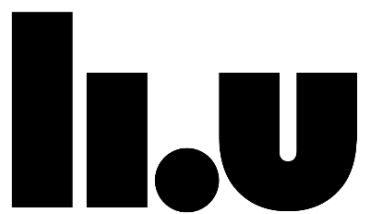

LINKÖPING UNIVERSITY

Division of Energy Systems

Department of Management and Engineering

Linköping University, SE-581 83 Linköping, Sweden

Linköping May 2019 
Non-Energy Benefits of Industrial Energy Efficiency

Roles and Potentials

(C) Therese Nehler, 2019

Linköping Studies in Science and Technology, Dissertation No. 1980

ISBN: 978-91-7685-106-7

ISSN: 0345-7524

Printed in Sweden by LiU-Tryck, Linköping, Sweden, 2019

Published articles have been reprinted with the permission of the copyright holders.

Cover illustration by Therese Nehler

Distributed by:

Linköping University

Department of Management and Engineering

Linköping University, SE-581 83 Linköping, Sweden

Tel.: +4613281000 


\section{Abstract}

Climate and environmental targets place significant requirements on energy efficiency and improved industrial energy efficiency is viewed as one of the most important means of reducing $\mathrm{CO}_{2}$ emissions and mitigating climate change. Even though efforts have been undertaken to improve energy efficiency there is still the potential for further improvements to be made. The potential is a result of that proposed energy efficiency improvement measures are not implemented, even if judged as cost-effective.

Besides improving energy efficiency, the implementation of energy efficiency improvements in industrial firms can generate additional beneficial effects: so-called nonenergy benefits. Examples of non-energy benefits are: improved productivity, lower operation and maintenance costs, a better work environment, decreased waste and fewer external effects, such as lower emissions. This thesis has investigated the roles and potential of non-energy benefits in decisions on energy efficiency improvements from three perspectives: energy efficiency measures, energy efficiency investments and energy management activities.

The results of the studies presented in this thesis demonstrated that different types of non-energy benefits were observed in various areas within industrial firms due to the energy efficiency measures, energy efficiency investments and energy management activities they have implemented. Studying energy efficiency measures and investments revealed that implementing one single energy efficiency measure or investment can generate several non-energy benefits. The studies also uncovered a relationship between the non-energy benefits, i.e. chain reactions of primary, secondary and further effects, in which one benefit can generate other types of benefits. Consequently, some non-energy benefits were observed immediately after the implementation of energy efficiency measures, direct effects, while others were perceived later on, indirect effects. Furthermore, extending the perspective by including energy management activities led to the recognition of novel non-energy benefits.

The results of this thesis demonstrated that non-energy benefits were seldom acknowledged in decisions on energy efficiency improvements. However, the non-energy benefits' character, diversity and relations among them enabled opportunities for the non-energy benefits to be included in decisions on energy efficiency in various ways. For instance, based on the results of these studies, monetised non-energy benefits could be included in investment calculations contributing to cost-effectiveness, while certain effects that are difficult to measure and quantify could be utilised qualitatively in investment evaluations as extra arguments, or, if important to the firm, as objectives for making the investment. Hence, depending on their type, non-energy benefits seemed to have different roles in decisions on industrial energy efficiency improvements. 
This thesis contributed with a comprehensive approach by investigating energy efficiency improvements and the related non-energy benefits through three perspectives. By combining the results from each perspective, the view on industrial firms' decisions on energy efficiency improvements was widened. In this thesis it is concluded that the potential of non-energy benefits in decision-making on industrial energy efficiency improvements lies in the utilisation of all types of non-energy benefits and to consider all the roles that non-energy benefits may have. By utilising knowledge on non-energy benefits along with their roles observed in relation to previous implementations of energy efficiency improvements, non-energy benefits can impact decisions on new implementations. 


\section{Sammanfattning}

Effektivisering av industrins energianvändning ses som ett av de viktigaste redskapen för att minska koldioxidutsläppen i syfte att mildra klimatpåverkan och nå uppsatta klimatoch miljömål. Konkurrens och resursbrist driver industrin till att effektivisera och kopplingen mellan energi och tillverkningsprocesser i företagen betyder att energieffektivisering är av vikt då den även bidrar till effektivisering generellt inom företaget. Trots detta genomförs inte alla föreslagna åtgärder även om de är kostnadseffektiva, vilket gör att det finns en potential till ytterligare industriell energieffektivisering.

Förutom energibesparing och energikostnadsbesparing kan implementering av energieffektiviserande åtgärder även ge ytterligare positiva effekter för företaget, så kallade mervärden (eng. non-energy benefits), exempelvis i form av ökad produktivitet, ökad livslängd för maskiner och utrustning, förbättrad arbetsmiljö samt minskad mängd utsläpp och avfall. Denna avhandling har studerat mervärdens roller och potential i beslut kring energieffektiviserande åtgärder och investeringar samt energiledningsaktiviteter.

Resultaten visade att implementering av energieffektiviserande åtgärder och investeringar samt energiledningsaktiviteter gav flera olika typer av mervärden observerade på olika nivåer och inom olika delar av verksamheten i industriföretag. Genom att studera mervärden ur flera perspektiv synliggjordes nya typer av mervärden samt att implementering av en enstaka energieffektiviserande åtgärd kan generera ett flertal mervärden av olika typ. Vidare sågs även samband mellan olika mervärden, dvs att ett mervärde gav upphov till ett flertal andra mervärden.

Resultaten av dessa studier visade att användningen av mervärden vid beslut kring energieffektivisering begränsas av att många mervärden är svåra att mäta och kvantifiera. Trots att många mervärden var svåra att värdera i pengar och inkludera i investeringskalkyler, visade resultaten att mervärden ibland användes kvalitativt i investeringsunderlag som extra argument. Om mervärdet var av stor vikt kunde det till och med anses vara del utav syftet med en energieffektiviserande investering. Detta visade på mervärdens olika roller beroende på deras karaktär samt hur viktiga de ansågs vara för företaget.

Denna avhandling har studerat energieffektiviseringar och relaterade mervärden ur tre perspektiv. Genom att kombinera resultaten från varje perspektiv erhölls en bredare syn på beslut kring energieffektivisering. Resultaten i denna avhandling visade att mervärden kan bidra på olika sätt i beslut kring energieffektiviseringar beroende på deras olika roller samt att mervärdens potential i sådana beslut beror på om och hur mervärdens olika roller beaktas och används. Genom att använda kunskap om mervärden och deras olika roller som observerats i samband med tidigare energieffektiviserande implementeringar, 
kan mervärden bidra till att påverka beslut vid planering av nya energieffektiviserande implementeringar. 


\section{List of papers}

This thesis is based on the work described in the papers listed below. In the thesis the six papers are referred to by Roman numerals, and the papers are appended at the end of the thesis.

I. Nehler, T., Thollander, P., Ottosson, M., Dahlgren, M. (2014). Including non-energy benefits in investment calculations in industry - empirical findings from Sweden. In Proceedings ECEEE Industrial Summer Study - Retool for a Competitive and Sustainable Industry, 711-719.

II. Nehler, T., Rasmussen, J. (2016). How do firms consider non-energy benefits? Empirical findings on energy-efficiency investments in Swedish industry. Journal of Cleaner Production, 113, 472-482.

III. Nehler, T. (2018). Linking energy efficiency measures in industrial compressed air systems with non-energy benefits - A review. Renewable and Sustainable Energy Reviews, 89, 72-87.

IV. Nehler, T., Parra, R., Thollander, P. (2018). Implementation of energy efficiency measures in compressed air systems: barriers, drivers and non-energy benefits. Energy Efficiency, 11 (5), 1281-1302.

V. Andersson, E., Nehler, T. (2018). Energy management in Swedish pulp and paper industry - benchmarking and non-energy benefits. In Proceedings ECEEE Industrial Summer Study - Leading the low-carbon transition, 313-322.

VI. Nehler, T. (2018). A systematic literature review of methods for improved utilisation of the non-energy benefits of industrial energy efficiency. Energies, 11(12).

A co-author statement for each paper is presented in sub-chapter 1.3. 


\section{Other publications not included in the thesis}

Björkman, T., Cooremans, C., Nehler, T., Thollander, P. (2016). Energy Management: a driver to sustainable behavioural change in companies. In Proceedings ECEEE Industrial Efficiency Summer Study, 379-387.

Parra, R., Nehler, T., Thollander, P. (2016). Barriers to, drivers for and non-energy benefits for industrial energy efficiency improvement measures in compressed air systems. In Proceedings ECEEE Industrial Efficiency Summer Study, 293-304. Early version of Paper IV.

Wollin, J., Nehler, T., Rasmussen, J., Johansson, P-E., Thollander, P. (2016). Idle electricity as energy conservation within Volvo Construction Equipment. ECEEE Industrial Efficiency Summer Study. Extended abstract.

Nehler, T., Thollander, P., Fredriksson, L., Friberg, S., Nordberg, T. (2018). Non-Energy Benefits of Swedish Energy Efficiency Policy Instruments - A Three-Levelled Perspective. In Proceedings ECEEE Industrial Summer Study - Leading the low-carbon transition, 139149. 
To my beloved family 


\section{Acknowledgements}

First, I wish to thank my supervisor, Patrik Thollander. Before I had even started my PhD studies, you encouraged me to submit an abstract for a conference that threw me directly into the field of industrial energy efficiency and its non-energy benefits. This served as a rapid and stimulating start to my doctoral research. Thank you for your guidance, support and never-ending stream of ideas.

Many thanks to my second supervisor, Mats Söderström, for your insight, for sharing your experience, and for your encouraging and humorous spirit.

Thanks to Johanna Mossberg for reading and commenting on an earlier draft of this thesis; your invaluable input helped me to improve it greatly. I would also like to thank all of my colleagues that gave me feedback on the thesis-it was much appreciated.

I would like to thank all the participants in the projects in which I have been involved for their assistance and collaboration in preparing our studies, collecting and analysing empirical data and writing articles. Josefine Rasmussen, thank you for collaborating with me, especially when working on supertvåan (Paper II) and conducting interviews. I miss our road trips and the discussions we had. Elias Andersson, thank you for your excellent teamwork when combining benchmarking and non-energy benefits in Paper V, and thanks for arranging the perfect research trip to Vancouver, Canada. Akvile Lawrence, thank you for your collaboration when writing papers and for your invaluable input on the pulp and paper industry.

The studies in this thesis were carried out under the umbrella of three projects, two of which were funded by the Swedish Energy Agency. The third project was funded by the Swedish Agency for Economic and Regional Growth. I gratefully acknowledge these agencies for their financial support. As a PhD student in a research school administrated by the Department of Management and Engineering (IEI) at Linköping University, additional funding was provided by the department. I would therefore also like to express my gratitude to the IEI for this support.

Without empirical research, this thesis would not have been possible. Therefore, I am very grateful to all the respondents who willingly gave up their time to meet, discuss and answer questions-both in the form of interviews and in responding to the questionnaires. Thank you for your contributions.

Also, my thanks to all my colleagues at the Division of Energy Systems for your meaningful cooperation, inspiring discussions and all the nice coffee breaks-including our lovely Friday-fika. A special thanks to Elisabeth Larsson for all your help with administrative matters. 
As a PhD student in the IEI research school, the first two years of my studies were enriched through annual interdisciplinary workshops as well as through seminars and joint courses with my fellow students. Although we came from diverse research fields and different backgrounds, it seemed that we often struggled with the same issues and mutually benefitted from discussing them. Thank you, all.

I would also wish to thank Friskis \& Svettis, Linköping, for all the energy and endorphins, and a special thanks to all the spinning cyclists who are joining my morning classes. I always leave the F\&S buildings with a happy smile.

Finally, I would like to thank my beloved family. Thank you, Tjalle (alias Henrik), my husband, for always believing in me and giving me the most support. I love you like star crazy! Amanda, Alva and Arvid, our lovely children, I know that sometimes I was not as present as you would have liked when I was completing my studies. Thank you for your patience and for distracting me with your beautiful spirits. When finalising my licentiate thesis, you often asked when my "book" would be finished. You still ask the same question, and finally, book number two is finished! I love you! 


\section{Table of Contents}

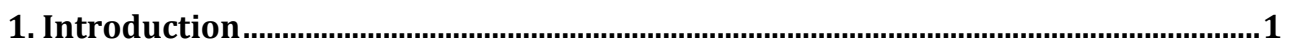

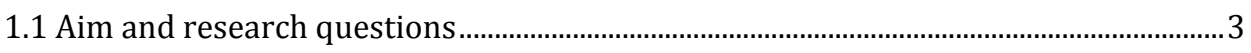

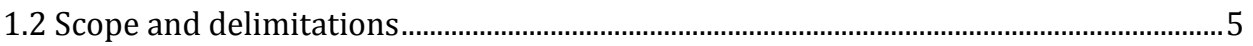

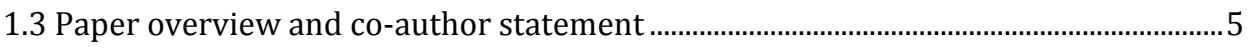

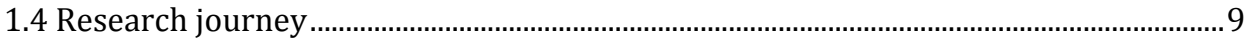

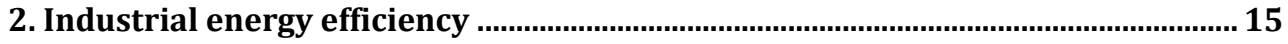

2.1 Industrial energy use and the potentials for improvements....................................... 15

2.2 Energy efficiency improvement measures ............................................................................... 17

2.3 Energy efficiency improvement investments..................................................................... 18

2.4 Energy efficiency improvements by energy management activities .......................... 18

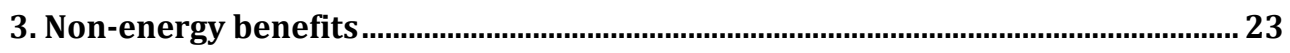

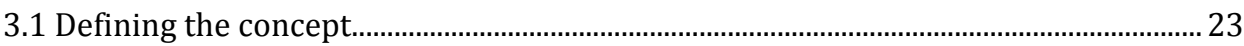

3.2 Industrial non-energy benefits - an overview ................................................................ 24

3.3 Observation and evaluation of industrial non-energy benefits................................... 27

4. Decisions on energy efficiency improvements ....................................................... 31

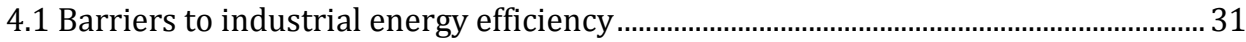

4.1.1 Barriers to cost-effective energy efficiency technology measures ....................... 33

4.1.2 Barriers to specific energy efficiency measures and related processes ............. 33

4.1.3 Barriers to energy management activities.................................................................... 36

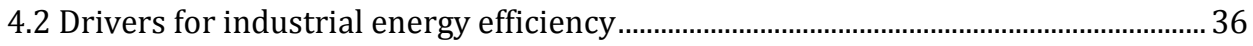

4.2.1 Drivers for cost-effective energy efficiency technology measures ......................... 37

4.2.2 Drivers for specific energy efficiency measures and related processes.............. 38

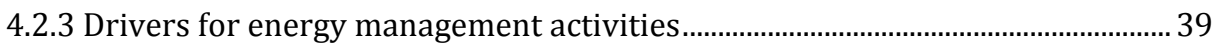

4.3 Decision-making on energy efficiency investments ....................................................... 39

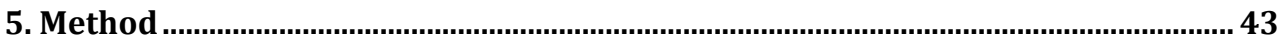

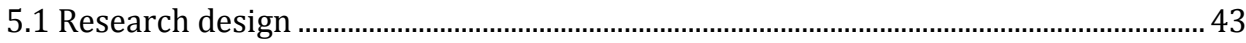

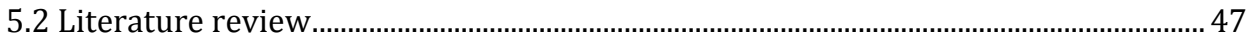

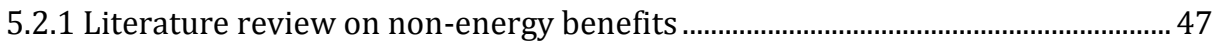

5.2.2 Literature review on compressed air systems .............................................................. 48

5.2.3 Literature review on methods for evaluation of non-energy benefits ................ 50

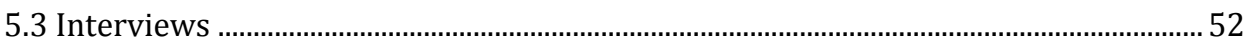

5.3.1 Interviews with Swedish manufacturing firms ...................................................... 52

5.3.2 Interviews with energy managers, energy audit experts and suppliers .............54

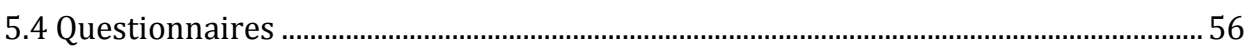

5.4.1 Questionnaires to Swedish industrial manufacturing firms .................................. 57 
5.4.2 Questionnaire to energy auditors (experts) for compressed air systems ......... 57

5.4.3 Questionnaire to Swedish pulp and paper mills .......................................................... 58

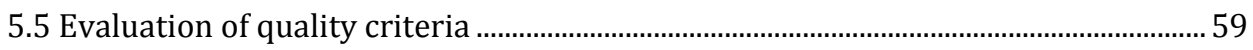

5.6 Methods applied in relation to the appended papers .................................................... 62

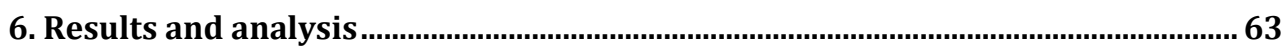

6.1 Non-energy benefits from the perspective of measures: The case of compressed air 63

6.1.1 Energy efficiency measures in compressed air systems........................................ 63

6.1.2 Non-energy benefits of compressed air energy efficiency measures ................... 66

6.1.3 Perceived barriers to compressed air energy efficiency measures........................ 70

6.1.4 Perceived drivers for compressed air energy efficiency measures....................... 72

6.2 Non-energy benefits from the perspective of investments: The case of energy

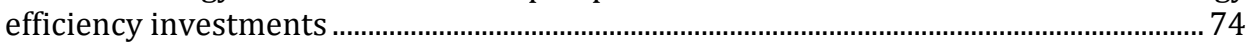

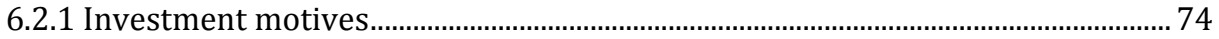

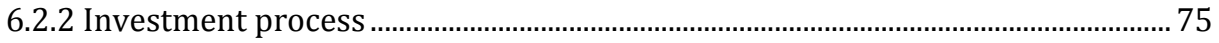

6.2.3 Factors affecting the adoption of energy efficiency investments........................... 75

6.2.4 Non-energy benefits of energy efficiency investments ............................................. 76

6.2.5 Monetisation and inclusion of non-energy benefits in energy efficiency

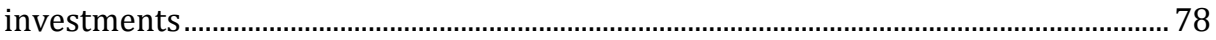

6.2.6 Barriers to inclusion of non-energy benefits in decisions on energy efficiency

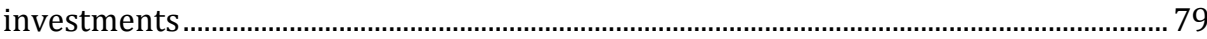

6.3 Non-energy benefits from the perspective of energy management activities: The

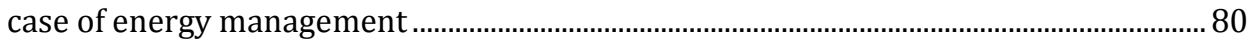

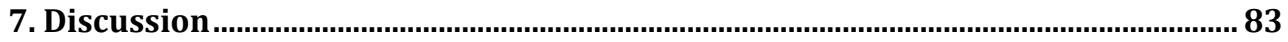

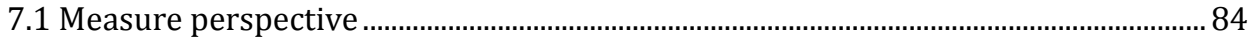

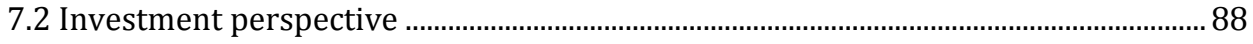

7.3 Energy management perspective.................................................................................. 92

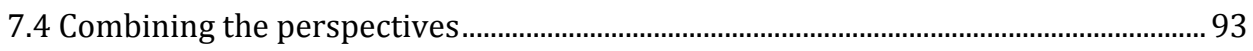

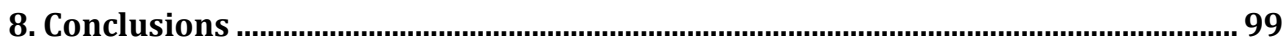

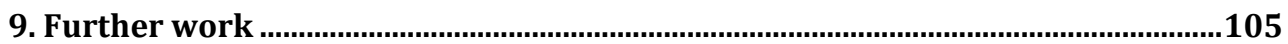

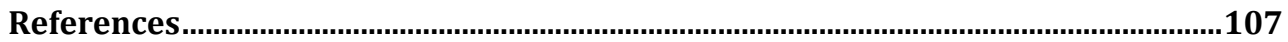




\section{Introduction}

This chapter begins with an introduction to the thesis, including the purpose of the studies and a presentation of the research questions posed. Thereafter, the thesis' delimitations and scope are described and discussed. Then, an overview of the appended papers is provided, together with a co-author statement. The chapter ends with a description of the research journey to give an overview of the study process.

This thesis is situated in the field of energy efficiency, specifically in the area of industrial energy efficiency. However, the studies in this thesis mainly focus on the additional effects that industrial energy efficiency offers beyond the expected energy effects: the nonenergy benefits of energy efficiency. At the beginning of the research process, I read a debate article in which Ulrich Spiesshofer, chief executive officer at ABB, stresses the importance of industrial energy efficiency: "In order to improve competitiveness and reduce environmental impact, industry needs to invest in energy efficiency... it is the most sustainable strategy" (Spiesshofer, 2014, p. 3). At the same time, he emphasises that many industrial firms do not seem to fully understand the linkage between increased competitiveness and other possible beneficial effects of improved energy efficiency: “... we need to work harder to increase knowledge about the opportunities that energy efficiency brings. [...] The industry needs clear examples of energy efficiency" (Spiesshofer, 2014, p. 3).

Around the same time that this debate article was published, my first exploratory interviews with representatives from Swedish industrial firms had just been completed. The respondents gave several examples of the additional effects beyond energy savings and energy cost savings that they perceived as a result of their implemented energy efficiency improvements. Hence, the industrial firms interviewed seemed to be aware of that energy efficiency might offer additional beneficial effects, but these opportunities were seldom capitalised upon, according to the firms.

What the industrial firms were talking about, and perhaps what Spiesshofer (2014) was also trying to put on the agenda, were the non-energy benefits of industrial energy efficiency. These benefits are commonly explained as the additional effects that go beyond the expected energy effects, such as energy savings and energy cost savings as a consequence of implementing energy efficiency improvements. Non-energy benefits include a wide array of effects that can vary from increased productivity and reduced 
operation and maintenance for equipment to improved indoor work environments and beneficial impacts on the external environment, like a decrease in waste and emissions (e.g. Finman and Laitner, 2001; IEA, 2012a; Pye and McKane, 2000; Rasmussen, 2017). Evaluations of implemented energy efficiency projects have addressed the monetary potential of non-energy benefits; the value of the non-energy benefits can exceed the energy savings of the corresponding projects (e.g. Pye and McKane, 2000; Worrell et al., 2003). However, these additional effects are seldom considered when investing in energy efficiency improvements, which leads to underestimated investments (e.g. Pye and McKane, 2000).

Actions to reduce climate impact have been taken worldwide and by individual countries (e.g. EA, 2016; UN, 2015; UNFCCC, 2015). In 2012, the Energy Efficiency Directive was implemented to comply with the Europe 2020 strategy concerning climate change and energy (EC, 2012), for which the key targets to be reached by 2020 are as follows: greenhouse gas emissions to be reduced by $20 \%$ compared to 1990 levels; the share of renewable energy sources in final energy use to be increased to 20\%; and energy efficiency to be improved by $20 \%$ (EC, 2009a; EC, 2009b). A few years later, in 2016, the European Commission updated the Energy Efficiency Directive with a $30 \%$ energy efficiency target for 2030, including measures for meeting this new target (EC, 2016a). In 2018, new binding targets for energy efficiency were set by the Commission, the European Parliament and the European Council in a political agreement: $32.5 \%$ by 2030 for the EU (EC, 2018).

However, despite the substantial efforts undertaken and demonstrated progress in the areas of climate mitigation and energy improvements (e.g. Eurostat, 2018), the objectives concerning climate impact reductions seem hard to meet. The Intergovernmental Panel on Climate Change (IPCC) states that if global warming is to be limited to 1.5 degrees, rapid and comprehensive changes are required: global carbon dioxide emissions must be reduced by 45 percent from 2010 levels by 2030 and zero net emissions must be achieved by 2050 (IPPC, 2018). Industry is responsible for over $30 \%$ of the total energy end-use worldwide (IEA, 2015), and in Sweden, industrial energy use accounts for almost $40 \%$ of Sweden's energy end-use (SEA, 2017). Energy efficiency in the industrial sector therefore plays an important role in the mitigation of climate impacts. Energy achievements and improved industrial energy efficiency are key factors to abate the long-term environmental impacts of energy use and encompass the targets regarding energy and the environment (EC, 2009a; EC, 2009b; EC, 2012). Without the energy efficiency improvement measures that have been realised since 2000, the 2017 industrial energy use in the member states of the International Energy Agency (IEA) countries, would have been $20 \%$ higher (IEA, 2018). Nonetheless, an unexploited potential remains for further energy efficiency improvements in industry because far from all of the suggested improvement measures have been realised, even if they are considered cost-effective (e.g. Hirst and Brown, 1990; Thollander and Ottosson, 2008). The IEA (2018) states a potential between $15 \%$ and $40 \%$ for improved industrial energy efficiency between now and 2040 , 
depending on the type of manufacturing industry. This difference between the theoretical potentials and the energy efficiency improvement measures that have actually been realised is typically explained by different types of barriers to energy efficiency that impede the adoption of the improvement measures (e.g. Hirst and Brown, 1990; Jaffe and Stavins, 1994a; Sorrell et al., 2004; Weber, 1997). This gap refers to the non-adoption of energy efficiency technology measures. When considering also the improvements measures that are included in energy management practices, for instance, organisational and operational activities, and the factors that hinder them, the gap is even larger which extends the potential for industrial energy efficiency (Backlund et al., 2012a; Lawrence et al., 2018; Paramonova et al., 2015).

Thus, the current levels of implemented and realised energy efficiency improvements are not enough. Even if cost-effective energy efficiency improvement measures exist, and even though cost reductions drive industrial firms, energy efficiency issues are often lower priorities or viewed less strategically by the firms (e.g. Cooremans, 2012; Harris et al., 2000; Sandberg and Söderström, 2003). This picture speaks to the importance of investigating how non-energy benefits can contribute to the further adoption of energy efficiency improvements. Non-energy benefits constitutes a diverse collection, and their effects have been observed in different areas in industrial firms as results of the implementation of various types of energy efficiency improvements. The diversity among the non-energy benefits provides conditions for them to have different roles such as drivers of economic or qualitative character or as motivators in decisions on energy efficiency improvements. Therefore, taking non-energy benefits' roles and potentials into account when making decisions on energy efficiency might be a way to overcome barriers and reinforce or create new driving forces for energy efficiency, making energy efficiency improvements more attractive to industrial firms and resulting in positive decisions on their implementation. This diversity among the non-energy benefits requires that various perspectives on energy efficiency improvements are applied when investigating the possible ways that non-energy benefits can affect decisions on energy efficiency improvements. Therefore, in this thesis, non-energy benefits have been studied and analysed through the following three perspectives: non-energy benefits in relation to specific energy efficiency measures, non-energy benefits in relation to energy efficiency investments and non-energy benefits in relation to energy management activities.

\subsection{Aim and research questions}

Improved industrial energy efficiency, or more precisely, the measures, investments or activities undergone to improve industrial energy efficiency, forms the basis of this thesis. An assumption throughout the studies is that energy efficiency improvements in industrial firms can lead to additional effects-so-called non-energy benefits-beyond energy effects. This thesis seeks to gain new knowledge concerning non-energy benefits and to explore their roles and potentials in relation to decisions on energy efficiency improvements in industrial firms. In the light of this, the proposition throughout the 
studies is that the awareness and utilisation of non-energy benefits can contribute to improved industrial energy efficiency.

Based on this, the aim of this thesis is to investigate the roles and the potentials of nonenergy benefits in firms' decisions on measures, investments or activities to improve energy efficiency in industry through three perspectives on industrial energy efficiency improvements: specific energy efficiency measures, energy efficiency investments, and energy management activities.

This thesis focuses on the following research questions:

1. What are the perceived non-energy benefits of implemented energy efficiency measures, energy efficiency investments and energy management activities in the industrial firms studied?

2. How are non-energy benefits utilised and how could they be utilised in decisions aiming at improving energy efficiency in the industrial firms studied?

3. What are the individual contributions of the three perspectives that have been applied in studying the non-energy benefits of energy efficiency improvements?

4. What are the implications of combining the results of the three perspectives applied in studying the non-energy benefits of energy efficiency improvements?

Table 1 gives an overview of how the appended papers contribute to the research questions posed and which perspectives are addressed in each paper.

Table 1. An overview of the appended papers in relation to the research questions and perspectives applied in the thesis.

\begin{tabular}{clll}
\hline $\begin{array}{c}\text { Research } \\
\text { question }\end{array}$ & $\begin{array}{l}\text { Energy efficiency } \\
\text { measures }\end{array}$ & $\begin{array}{l}\text { Energy efficiency } \\
\text { investments }\end{array}$ & $\begin{array}{l}\text { Energy management } \\
\text { activities }\end{array}$ \\
\hline 1 & Papers I, II, III, IV, VI & Papers I, II & $\mathrm{V}^{*}$ \\
2 & Papers I, II, III, IV, VI & Papers I, II, IV, VI & $\mathrm{V}^{*}$ \\
3 & Papers I, II, III, IV, VI & Papers I, II, IV, VI & $\mathrm{V}^{*}$ \\
4 & Papers I, II, III, IV, VI & Papers I, II, IV, VI & $\mathrm{V}^{*}$ \\
\hline
\end{tabular}

* Since energy efficiency measures and investments are included as activities of energy management, these two perspectives and the included papers will contribute indirectly to the energy management perspective. However, Paper V contributes directly to the third perspective.

In this thesis, the analysing variable is defined as the decisions on energy efficiency measures, energy efficiency investments and energy management activities. 


\subsection{Scope and delimitations}

The scope of this thesis is energy efficiency in the industrial sector, particularly the nonenergy benefits of industrial energy efficiency, i.e. the additional benefits beyond the expected energy effects that may be achieved by implementing energy efficiency improvements in industrial firms. As established in the aim stated above, this thesis seeks to contribute with new insights on decisions on energy efficiency improvements by studying non-energy benefits through three different perspectives on energy efficiency: measures, investments and energy management activities. The view on energy efficiency in this thesis is the output measured for a given input, i.e. energy efficiency is considered as an improvement which lead to less energy used but provides the same amount of product or which uses the same amount of energy to provide more of the product (IEA, 2012). Hence, all energy efficiency improvements will therefore not necessarily save energy in absolute terms. However, in this thesis, all improvements that can be carried out to improve energy efficiency are considered.

The additional effects of energy efficiency improvements in general have been observed on many levels, from their effects on the individual level to their effects on society as a whole (IEA, 2012). In this thesis, the perspective on energy efficiency and related effects are studied, from a detailed level of single industrial processes and related equipment, up to the firm level which is represented by the energy management perspective. The industrial firms' views are central, i.e. what is or is not a benefit to the individual firm. Non-energy benefits such as decreased waste and lower emissions can have impacts beyond the individual firm. However, this thesis focuses on their effects in relation to the firm, and not on what these effects mean for the surrounding society.

While the empirical studies upon which this thesis is based were mainly conducted in a Swedish context with Swedish industrial firms as the respondents, the empirical data has also been collected from global industrial firms (Paper IV). Most of the participating firms in these studies were large firms with high energy use, and the majority of them were also considered to be energy-intensive firms. It seemed relevant to include such firms in studies on non-energy benefits since they would have experience in working with energy efficiency issues. Moreover, this would imply that these firms had already implemented several energy efficiency improvements of various kinds and therefore would have perceived additional effects in relation to them.

\subsection{Paper overview and co-author statement}

This thesis is based on the following six papers. The appended papers are briefly described below, along with a description of my personal contribution to each of them.

\section{Paper I}

Nehler, T., Thollander, P., Ottosson, M., Dahlgren, M. (2014). Including non-energy benefits in investment calculations in industry - empirical findings from Sweden. In Proceedings 
ECEEE Industrial Summer Study - Retool for a Competitive and Sustainable Industry, 711719.

Based on interviews with representatives of Swedish industrial firms, this paper explores how the firms perceive the non-energy benefits of energy efficiency investments and how the benefits are acknowledged in their investment calculations. The results of this study indicated that non-energy benefits had been observed by the Swedish industrial firms participating in the study, but that only a few non-energy benefits were included in their investment calculations for their energy efficiency investments. This non-inclusion seemed to be explained by the difficulties associated with how to undertake the quantification and monetisation of the benefits, which could in turn be explained by factors such as the lack of information on how to monetise the non-energy benefits.

This study was the starting point for my studies on non-energy benefits. The interviewbased study was planned together with Patrik Thollander. All interviews were scheduled and conducted by me, while the interview guide was designed together with Patrik Thollander. The other co-authors provided their input to the interview guide. I was the main author of the paper, but it was planned and written together with Patrik Thollander and the progress of the paper was continually discussed between us during the paperwriting process. All interviews were transcribed and the results from the interviews were analysed by me. Sections covering the theoretical background and the results were mainly written by me, while the remaining parts of the paper were written together with Patrik Thollander. The other co-authors provided their input throughout the paper-writing process.

\section{Paper II}

Nehler, T., Rasmussen, J. (2016). How do firms consider non-energy benefits? Empirical findings on energy-efficiency investments in Swedish industry. Journal of Cleaner Production, 113, 472-482.

This paper explores, based on interviews and a questionnaire, how representatives of Swedish industrial firms view energy efficiency investments and non-energy benefits. The results showed that the main motive behind energy efficiency investments was opportunities for cost savings and that critical factors for adopting energy efficiency investments were related to short payback periods, for instance. These strict investment criteria could not always be met by energy cost savings alone. Furthermore, the results indicated that various non-energy benefits had been observed by the studied firms. However, few were monetised and included in investment calculations. The paper suggests that denoting non-energy benefits in relation to cash flow and at the same time considering quantifiability and when the anticipated benefits will appear, would contribute to enhancing the financial aspects of energy efficiency investments. 
This paper was planned and written together with Josefine Rasmussen, a PhD student at Linköping University. I was the main author of the paper. However, the progress of the paper was continually discussed between us during the paper-writing process. Nine of the interviews were conducted by me and the remaining four were conducted together with Josefine Rasmussen. The interview guide used in the interviews and the questionnaire were designed by me and Patrik Thollander. Josefine Rasmussen contributed her input to both. Except for two, all interview recordings were transcribed by me. The results from the interviews and the questionnaire were analysed together with Josefine Rasmussen. The two sections in the paper presenting the theoretical background were mainly written by Josefine Rasmussen, while I mainly produced the method chapter. The remaining parts of the paper were analysed and written together on an equal basis.

\section{Paper III}

Nehler, T. (2016). Linking energy efficiency measures in industrial compressed air systems with non-energy benefits - A review. Renewable and Sustainable Energy Reviews, 89, pp. 72-87.

This paper reviews the current body of scientific publications on energy efficiency in compressed air systems evaluated in relation to measures for improving energy efficiency and possible non-energy benefits. The paper provides a systematic literature review of reported energy efficiency measures for compressed air systems and the results showed a large variation in the measures that can be undertaken to improve energy efficiency in such systems. However, few publications considered a comprehensive view, including the entire compressed air system. Furthermore, the results showed that few publications addressed additional effects of energy efficiency measures in compressed air systems and only one publication addressed the term 'non-energy benefit'. The paper suggests that energy efficiency measures and related non-energy benefits should be studied at the level of specific measures to fully understand effects of energy efficiency measures in systems for generation of compressed air and to acknowledge possible additional effects, i.e. nonenergy benefits.

The paper was entirely planned and written by me, as was the analysis of the results from the literature review. Patrik Thollander supervised and commented on the work.

\section{Paper IV}

Nehler, T., Parra, R., Thollander, P. (2018). Implementation of energy efficiency measures in compressed air systems: barriers, drivers and non-energy benefits. Energy Efficiency, 11 (5), 1281-1302.

From the perspective of three actors, this study investigates barriers to, drivers for and non-energy benefits of energy efficiency improvement measures in compressed air systems. The aim of this paper was to study the barriers to, drivers for and non-energy benefits of compressed air system energy efficiency measures from the perspectives of 
three actors: the users, audit experts and suppliers of compressed air systems. Carried out as a case study, empirical data was collected by conducting interviews combined with a questionnaire. The findings showed that barriers related to the investment or barriers of an organisational type were what mainly hindered energy efficiency investments and measures in compressed air systems, and that organisational and economic factors were the main driving forces for positive decisions on energy efficiency investments and measures in compressed air systems. Productivity gains and the avoidance of capital expenditure were the major non-energy benefits found for compressed air systems.

Parts of this paper are based on a conference paper (Parra et al., 2016) and the original study described in that paper has been extended with new empirical data (the perspectives of the suppliers) and rewritten before being published as a journal article. This study and paper were planned and written together with Ricardo Parra, a master's student and energy audit expert, who was visiting Linköping University in spring 2016. I was the main author of this paper, but the paper was planned together. Except for the interviews with the suppliers, Ricardo Parra was responsible for the empirical data collection, but input on interview guides and questionnaires was provided by me and Patrik Thollander. The data collection regarding the suppliers was conducted in a later phase, and I planned and conducted the interviews with these actors and analysed the results. Patrik Thollander also provided input on this phase. The results of the interviews and the questionnaire were first analysed by Ricardo Parra for the conference paper and then analysed a second time by me in this paper. I was responsible for the analysis of the results from the interviews with the suppliers. The progress of the paper was continually discussed between us (me and Ricardo Parra) during the paper-writing process. Based on the previous version, the conference paper, this paper has been rewritten by me, and Ricardo Parra and Patrik Thollander has provided their input.

\section{Paper $V$}

Andersson, E., Nehler, T. (2018). Energy management in Swedish pulp and paper industry - benchmarking and non-energy benefits. In Proceedings ECEEE Industrial Summer Study - Leading the low-carbon transition, 313-322.

This study puts non-energy benefits in a wider perspective, i.e. the relationship between additional effects and energy management activities within an industrial firm. The paper studies energy management through the perspectives of non-energy benefits and energy performance benchmarking within the Swedish pulp and paper industry. A mixed methods approach was taken, in which a questionnaire was sent to all operating pulp and paper mills in Sweden, and semi-structured interviews were carried out at six mills, to collect data. The pulp and paper mills have perceived a number of non-energy benefits from their energy management practices, where top management's interest in energy efficiency issues has increased more than expected, was perceived as the most substantial. The most common benchmarking method in the Swedish pulp and paper mills was 
external benchmarking within a company group, while historical benchmarking of energy use was the highest ranked benchmarking method among the mills.

Elias Andersson was the main author of the paper, but the progress of the paper was continually discussed between us during the paper-writing process. The empirical data was collected via a questionnaire and the results concerning non-energy benefits were analysed by me, while the benchmarking results were analysed by Elias Andersson. Moreover, the benchmarking part of the paper was also based on interviews, conducted and analysed by Elias Andersson. I was responsible for writing the Introduction section, the sections presenting the theoretical background on energy management and nonenergy benefits, and the results section on non-energy benefits. We wrote the concluding discussion together. I commented on and provided input on the remaining parts of the paper.

\section{Paper VI}

Nehler, T. (2018). A systematic literature review of methods for improved utilisation of the non-energy benefits of energy efficiency. Energies, 11.

This study systematically reviewed the academic literature on non-energy benefits in respect to methods for the observation, measurement, quantification and monetisation of the benefits. The review findings showed that studies mainly applied case study approaches in which data was collected by interviews or questionnaires in the observation of non-energy benefits. The primary methods used to enable quantification and monetisation of observed non-energy benefits were based on classifications, indexes, relative energy savings or frameworks. Calculation methods, databased tools, classification frameworks and ranking were applied to evaluate the benefits' potential in relation to energy efficiency investments. Based on this, the review findings have been synthesised into a guiding scheme for improved utilisation of the non-energy benefits.

The paper was entirely planned and written by me, as was the analysis of the results from the literature review. Patrik Thollander supervised and commented on the work.

\subsection{Research journey}

The assumption, which is that energy efficiency improvements can have additional beneficial effects for industrial firms, was the starting point for this research and continued to be the main theme of the studies. At the beginning of the studies, the focus was on energy efficiency investments and non-energy benefits in general in industrial firms. Then, the perspective on the non-energy benefits studied was both narrowed and extended. First, the perspective was narrowed, focusing on the energy efficiency measures and the non-energy benefits of a particular energy-using process that is widely used by industrial firms: compressed air. Later on in the process, the perspective was extended by investigating possible additional beneficial effects for industrial firms 
working with energy management practices and related activities. By the end of the studies, the perspective was extended further by studying the non-energy benefits of Swedish policy instruments for industrial energy efficiency, but this perspective has not been included in this thesis. The research ended by emphasising the mapping and utilisation of non-energy benefits by focusing on methods for such purposes.

With a proven energy efficiency gap (e.g. Hirst and Brown, 1990; Rohdin et al., 2007; Thollander and Ottosson, 2008), which has been extended by including energy management (Paramonova et al., 2015), overcoming barriers to industrial energy efficiency improvements and stressing important driving factors has been a motivation for studying non-energy benefits, due to their possible impacts on barriers or their opportunities to drive the adoption of energy efficiency measures. Therefore, drivers and barriers at various levels have also been a common (albeit underlying) thread, throughout the studies.

This research studies started with a literature review on non-energy benefits, followed by an interview study on non-energy benefits and energy efficiency investments conducted with Swedish industrial firms. After that, further empirical data was retrieved by a questionnaire followed by extending the interview study with a few more interviews. Until that point, the concept of non-energy benefits and their role in industrial firms' energy efficiency investments had been the main focus.

When I started my research studies, our non-energy benefits research team was involved in the International Energy Agency's (IEA) work on multiple benefits of energy efficiency. Josefine Rasmussen (a PhD student involved in our research on non-energy benefits) and I contributed by commenting on early drafts of the IEA's work on a handbook (IEA, 2014) for capturing the additional effects of energy efficiency. My experience from this contact with the IEA yielded useful input for my research on non-energy benefits by providing insight into various ways of viewing the concept of benefits of energy efficiency, for instance.

A large energy efficiency investment was then studied in detail. Conducted as a single case study, it deepened the current knowledge on the role of non-energy benefits. In particular, decisions in relation to the investment, the investment process and non-energy benefits were explored among representatives who held different positions at different levels in the case firm's organisation. Josefine Rasmussen was mainly responsible for the case study, but we conducted several interviews together and I provided input into the interview guides and contributed partly to transcription of the interview material. The results of the case study contributed with valuable insights on energy efficiency investments and non-energy benefits. Results of the case study are not included in this thesis, but increased my understanding of the topic which has been relevant in the research process. 
From here, insights on the increased complexity that the combination of several energy efficiency improvements and several non-energy benefits brings, in combination with challenges in the collection of data, the focus was tightened to concentrate on one single energy-using process - compressed air - and the related non-energy benefits. By this shift, the focus changed from a more general perspective on non-energy benefits to non-energy benefits of specific energy efficiency measures targeted for compressed air systems. This detailed perspective begun with conducting a systematic literature review on energy efficiency measures in compressed air systems. Furthermore, the literature review also parsed literature on the topic for possible non-energy benefits of the implemented energy efficiency measures in compressed air systems.

The focus on compressed air was further deepened in a case study that combined the drivers for, barriers to and non-energy benefits of energy efficiency improvements in systems for that industrial process. Empirical data was collected via interviews and questionnaires to study the views of three types of respondents: energy managers in global manufacturing firms, energy audit experts on compressed air systems and suppliers of compressed air systems. The empirical data was mainly collected by a senior audit expert on compressed air systems, but the study was planned together. I was responsible for planning and conducting the interviews with the suppliers.

The results and insights gained from the above were then summarised and analysed in my licentiate thesis. Compiling my research up to this point provided me with an opportunity to reflect on what had been achieved while writing the kappa. It also offered insight into the next steps that my research studies would take and gave me useful experiences from which to draw that contributed to finalising this thesis.

At this point, this study's perspective on non-energy benefits was broadened by my involvement in another project which sought to study the barriers to and drivers for energy management in the Swedish pulp and paper sector. The perspective on non-energy benefits was also included in the project via studying the non-energy benefits of energy management activities. An extensive questionnaire aimed at all pulp and paper mills in Sweden was designed, covering topics such as how the mills work with energy management, benchmarking, non-energy benefits, and barriers to and drivers for their energy management activities. Further insights into energy efficiency in relation to the pulp and paper sector were added by visiting a research group at the Institute for Resources, Environment and Sustainability at the University of British Columbia, and talking to representatives for pulp and paper organisations in Vancouver, Canada.

This extended view on non-energy benefits sparked an interest in further expanding the perspective. An interview-based case study was designed to explore the non-energy benefits of Swedish policy instruments for improving industrial energy efficiency. The study investigated the view on non-energy benefits from three perspectives: the views of 
the administrators of the policy instruments, the industrial firms' views and the energy auditors' views.

During the later phase of my research studies, I had the opportunity to be a panel coleader at a conference on industrial energy efficiency, which provided useful insights regarding the research community by reviewing and discussing research in various ways.

Throughout my research studies, unsuccessful attempts to quantify and monetise nonenergy benefits were made. In the final phase of my research project, my involvement in a third project reignited my interest in methods for studying non-energy benefits, particularly methods for mapping and evaluating non-energy benefits to utilise their potential. The aim of the third project, which is still ongoing, is to evaluate energy efficiency improvement measures implemented by small and medium-sized Swedish firms. The evaluation includes both energy savings and non-energy benefits, which will serve as the basis for the development of a calculation tool. A systematic literature review was conducted and covered the following topics: the types of studies and methods that have been applied in previous research to investigate the existence and observation of non-energy benefits, and on which levels non-energy benefits have been studied and reported; the methods that have been applied to measure, quantify and monetise nonenergy benefits; and the methods and calculation tools that have been applied to study and evaluate the potential of non-energy benefits.

Figure 1 summarises how my perspectives on energy efficiency improvements and related non-energy benefits have evolved over the research period. Furthermore, shifts in the underlying themes in this research, consisting of barriers to and drivers for energy efficiency improvements on various levels, are also displayed. This picture could be extended to also include the non-energy benefits of policy instruments for improved industrial energy efficiency. 


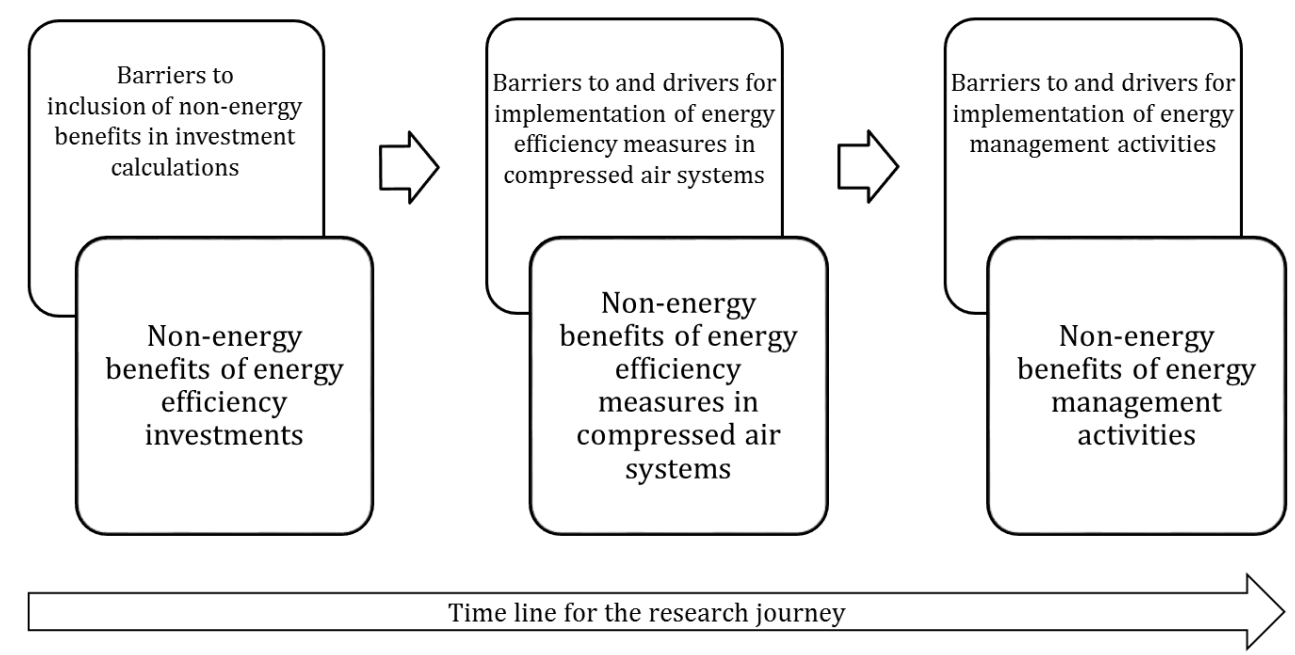

Figure 1. Evolution of perspectives on non-energy benefits throughout the research journey. 


\section{Industrial energy efficiency}

Energy efficiency in the industrial sector and the means by which industrial energy efficiency could be improved represent the background to this thesis. This chapter introduces industrial energy efficiency, potentials for further improvements and means by which industrial energy efficiency can be improved.

\subsection{Industrial energy use and the potentials for improvements}

The activities in the industrial sector account for a large share of the total energy use. Roughly one-third of the world energy end-use originates from the industrial sector (IEA, 2015), and in Sweden, nearly 40\% of the country's total energy end-use is due to industrial activities (SEA, 2018). From a global perspective, industrial energy use has increased between 1990 and 2015, but in Sweden, despite increased industrial production and activities, industrial energy use has been almost the same since 1970 (SEA, 2015 and 2018). In Sweden, a few energy-intensive sectors: pulp and paper, iron and steel, and the chemical sector, dominate the industrial energy use, of which the pulp and paper sector uses half of the industrial energy end-use (SEA, 2018). Industrial energy use is still rising globally, mainly due to increased industrial activity, but the mitigation of climate impact and a reduction in greenhouse gas emissions require further actions to be taken to discontinue increased industrial energy use. Energy efficiency, including industrial energy efficiency, is seen as a key means to reach the set environmental and climate targets (e.g. EA, 2016; EC, 2016a; IEA, 2018).

Without the measures that have been undertaken to improve industrial energy efficiency, the industrial contribution to world energy use in 2017 would have been even higher; IEA (2018) estimates $20 \%$ higher energy use without the implemented measures. Still, IEA (2018) estimates the potential for further industrial energy efficiency improvements to be $15-40 \%$, depending on the type of industry, in the next 20 years. One common explanation for this energy efficiency potential is that a large share of the proposed energy efficiency improvement measures is not implemented, even if the measures are evaluated as cost-effective. Hence, the non-adoption of the energy efficiency measures that theoretically could be implemented exceed the number of energy efficiency measures that actually are realised, which creates a deviation (e.g. Hirst and Brown, 1990). This deviation due to that cost-effective energy efficiency measures are not implemented represents an untapped potential known as the "energy efficiency gap", and the reasons 
for the non-adoption have theoretically been explained by different types of barriers to energy efficiency (e.g. Hirst and Brown, 1990). Furthermore, these barriers have also been empirically demonstrated (e.g. Fleiter et al., 2012; Rohdin et al., 2007; Sorrell et al., 2000; Thollander and Ottosson, 2008).

Knoop and Lectenböhmer (2017) report that an estimated overall energy efficiency potential for all sectors in the EU of at least $27 \%$ by 2030 would be feasible, even though there are significant differences between member states. For Sweden, the authors state an energy efficiency potential of up to almost $40 \%$ depending on which type of measures are included in the estimations (Knoop and Lectenböhmer, 2017). Estimations demonstrate a clear potential for future energy saving opportunities also in the European industrial sector. Despite currently attained efforts to improve energy efficiency, energy saving opportunities which also were considered economically attractive (payback periods of less than two years) by 2030, were assessed for several different types of industrial energy efficiency measures. Even if potentials varied, from $1.6 \%$ to $17.3 \%$ between the different measures, the estimations demonstrated opportunities for improvements (ICF, 2015). The existence of energy efficiency potentials has been emphasised by other studies. For instance, by implementation of energy-efficient and cost-effective (payback periods of less than five years) technologies, energy costs could be reduced by $4-10 \%$ in the European industrial sector (EC, 2016b) and in Sweden, Backlund et al. (2012b) present an energy efficiency potential of 5\% among energyintensive industrial firms by implementing energy-efficiency technologies. Moreover, Brunke et al. (2014), Paramonova et al. (2015) and Thollander and Ottosson (2008) also report on the potential for improved industrial energy efficiency in Sweden.

Despite the actions that have been undertaken to improve industrial energy efficiency, the potential for further improvements seems evident. In light of this, climate and sustainability goals put significant requirements on improved industrial energy efficiency since improved industrial energy efficiency is a key to reduced $\mathrm{CO}_{2}$ emissions and mitigating climate change (e.g. EC, 2016a; IEA, 2018). Paucity of resources together with global competition also trigger industrial firms in improving the overall efficiency. Since energy use and industrial processes typically are closely related in industrial firms, this emphasises the importance of improving energy efficiency also as a means to increase the overall efficiency of the firm.

This creates the background for this thesis, but the focus of this thesis is on the non-energy effects of industrial energy efficiency and how observation and utilisation of these socalled non-energy benefits might offer attractive arguments to motivate further improvements in industrial energy efficiency. With a proven energy efficiency gap and demonstrated energy efficiency potentials in the industrial sector, awareness and utilisation of non-energy benefits might offer new ways to positively impact on firms' and decision-makers' decisions and actions, contributing to reaching climate targets and a sustainable future. 


\subsection{Energy efficiency improvement measures}

Energy efficiency improvements are generally the result of a conducted energy audit in an industrial firm, and in the energy audit, information about how and in which processes energy is used within the firm is mapped and analysed (Rosenqvist et al., 2012). The use of energy in industrial firms varies according to for instance type of production or industrial processes in the firm, but whatever the type of production or process, the energy use is preferably allocated into smaller energy-using parts, unit processes (Söderström, 1996). In respect to the objective of the industrial process, unit processes can be categorised as processes directly related to production or processes that support production (Söderström, 1996). In Table 2, the typical unit processes in an industrial firm are displayed as presented by Söderström (1996) and further developed by Thollander et al. (2012).

Table 2. Categorisation of industrial unit process (Söderström, 1996; Thollander et al., 2012).

\section{Production processes $\quad$ Support processes}

$\begin{array}{ll}\text { Disintegrating } & \text { Ventilation } \\ \text { Disjointing } & \text { Space heating } \\ \text { Mixing } & \text { Compressed air } \\ \text { Jointing } & \text { Lighting } \\ \text { Coating } & \text { Pumping } \\ \text { Moulding } & \text { Tap water heating } \\ \text { Heating } & \text { Internal transport } \\ \text { Melting } & \text { Cooling } \\ \text { Drying } & \text { Steam } \\ \text { Cooling/freezing } & \text { Administration } \\ \text { Packing } & \end{array}$

Analysed information and measurements from the conducted energy audit demonstrate which of the processes that are main energy-using processes, or in which processes energy is wasted or not used in a properly manner (Rosenqvist et al., 2012). Typically, the production processes are the major energy-using processes in the energy-intensive manufacturing firms. In firms not classified as energy-intensive; the major energy-using processes are often processes that support the production, for instance space heating and compressed air.

As stated above, the outcome of an energy audit generates measures for improving energy efficiency in the firm. To systematically allocate the energy use into unit processes further gives a description of in which process, production process or support process, proposed energy efficiency improvements could be carried out (Rosenqvist et al., 2012). The allocation of the energy used in an industrial firm described above also enables an analysis aiming to identify which energy efficiency improvements are relevant to implement in the firm (Rosenqvist et al., 2012). Hence, energy efficiency improvement measures are in 
general aiming at specific processes in industrial firms, and several measures can be proposed for a certain process or technology.

\subsection{Energy efficiency improvement investments}

Adoption and implementation of energy efficiency improvements are required to improve industrial energy efficiency. Measures to improve energy efficiency can be minor changes, for instance changes of operational character, or larger modifications, for instance installations of new technologies. Larger alterations as the latter, often requires an investment to be made which is associated with an investment cost and also involves a process for decision-making on the improvement. Decisions on energy efficiency improvement investments may be complex since investment decisions often are influenced and affected by many factors. Thus, this addresses the importance of the decision-making process and investment process for such measures in order to understand how such decisions are made. Neal Elliott and Pye (1998) and Cooremans (2012) illustrate decisions on energy efficiency investments as dynamic processes. A number of stages have to be passed on the way to a be decided upon, which is displayed in Figure 2. The process for energy efficiency investments according to Cooremans (2012) is described as a process which constitutes five stages: initial idea, diagnosis, build up solution, evaluation and choice, and finally, if a positive decisions on the investment, the implementation.

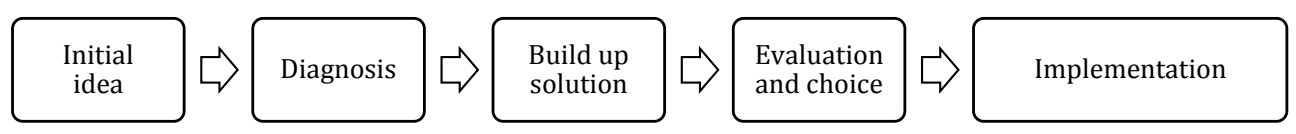

Figure 2. The investment decision-making model by Cooremans (2012).

In all stages of the investment process, from the initiation, and if a positive decision on the investment, to the final stage, which means implementation of it, various factors affect and thus have impacts on the decisions on energy efficiency investments and the investment process for such investments. These factors will be further discussed in Chapter 4.3.

\subsection{Energy efficiency improvements by energy management activities}

Industrial energy efficiency improvements have mainly focused on the diffusion and adoption of energy-efficient technologies (e.g. Lawrence et al., 2018; Thollander and Ottosson, 2008). However, recent studies have demonstrated that if management procedures are added in combination with the implementation of new energy-efficient technology solutions, the industrial energy efficiency potential increases (Backlund et al., 
2012a). Hence, a higher level of energy efficiency can be reached if the perspective on improving industrial energy efficiency is broadened.

Energy management serve as a comprehensive approach to energy efficiency improvements by having a firm level perspective on energy efficiency. However, how energy management is defined seems to vary and the degree of integration of energy management procedures in firms differ among industrial firms (Schulze et al., 2016). Based on results from reviewing energy management literature, Schulze et al. (2016) divide energy management activities in five aggregate dimensions: strategy/planning, implementation/operation, controlling, organisation, and culture (see Figure 3), which are broken down into $2^{\text {nd }}$ order themes and $1^{\text {st }}$ order concepts which describe the various activities that can be included in a firms energy management procedures.

Themes such as energy audits, energy efficiency measures and activities, and investment decisions, are sorted into the implementation and operation area of energy management by Schulze et al. (2016). These themes of energy management are further divided into 1st order concepts, which include non-energy benefits. Moreover, conducting an energy audit and the outcome, the proposed energy efficiency measures and investments, are included in the area of implementation and operation, i.e. these elements represent a portion of all the activities regarded as energy management activities (Schulze et al., 2016). 


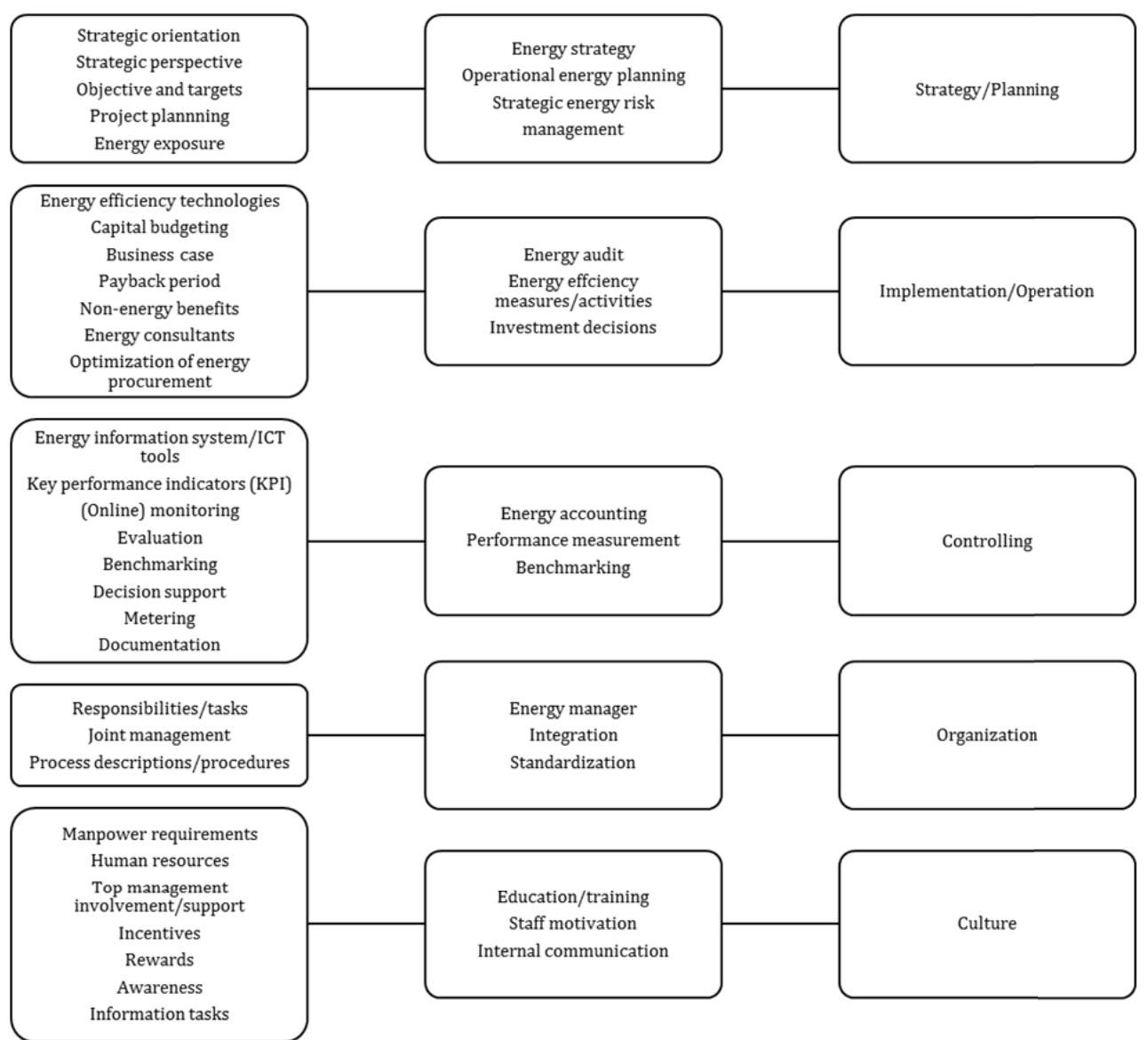

Figure 3. The elements of industrial energy management according to and revised from Schulze et al. (2016).

Energy analysis through energy auditing to gain information of the existing energy flows; set goals for energy efficiency and communicate targets and outcomes within the organisation; implementation of energy efficient technologies; and continuous improvements in operation and maintenance of the technologies and the processes in the company, are examples of common key activities of energy management in an industrial firm (Backlund et al., 2012a). The latter of the examples given include the behavioural energy efficiency changes that can be deployed, for instance measures aiming at managing the processes and technologies in an industrial firm (Paramonova et al., 2015). Moreover, a long-term energy strategy, visualisation, allocation and control of the energy use in the 
firm are other examples of energy management activities, which also have been found to be success factors for improved energy efficiency by in-house energy management (Johansson and Thollander, 2018).

This way, to go beyond the cost-effective measures in energy-efficient technologies by including energy management, extends the energy efficiency gap, thereby denoted the extended energy efficiency gap, by Backlund et al. (2012a). This is exemplified by the results from conducted case studies on electric motor systems in industrial production which demonstrated that the main part of the energy efficiency measures identified were of operational and management character, i.e. measures beyond implementation of new energy-efficient technologies (Svensson and Paramonova, 2017). Moreover, management procedures have also been shown to be important in order to maintain an energy-efficient behaviour over time by continuous improvements (Johansson et al., 2011).

Previous research has demonstrated that energy management procedures deployed by industrial firms can reduce energy use by $4-40 \%$ if both technology measures and management measures are considered (Caffal, 1995). This has been corroborated in later studies; Backlund et al. (2012b) conclude that if investments in energy-efficient technologies are combined with energy management practices, the potential for industrial energy efficiency increases, and energy efficiency can be further improved. Results from studies on Swedish energy-intensive firms have shown that the energy efficiency potential increased from $5 \%$ to $11 \%$ by implementing both technology measures and management practices (Backlund et al., 2012b). 


\section{Non-energy benefits}

The concept of additional effects of energy efficiency and, in particular, industrial nonenergy benefits are introduced in this chapter starting with an overview of the topic and how non-energy benefits have been studied in previous research.

\subsection{Defining the concept ${ }^{1}$}

In addition to energy savings and energy cost savings, energy efficiency improvement measures and investments can lead to other beneficial effects. These benefits have been observed at different levels in society depending on the perspective applied (e.g. Finman and Laitner, 2001; IEA, 2012; Lilly and Pearson, 1999; Mills and Rosenfeld, 1996; Pye and McKane, 2000; Ürge-Vorsatz et al., 2009). The IEA (2012) presents the most wide-ranging term, denoted as multiple benefits, which covers benefits delivered at all societal levels: the individual level, the sectoral level, the national level, and the international level. On the sectoral level (e.g. the industrial and the residential sector) and the individual level (e.g. the firm level), other similar concepts are presented, such as non-energy benefits (e.g. Lilly and Pearson, 1999; Pye and McKane, 2000; Finman and Laitner, 2001; Worrell et al., 2003; Mills and Rosenfeld, 1996; Skumatz and Dickerson, 1997), productivity benefits (e.g. Worrell et al., 2003), ancillary benefits (e.g. Mundaca, 2008; Lung et al., 2005; ÜrgeVorsatz and Metz, 2009), and co-benefits (e.g. Jakob, 2006; Ürge-Vorsatz et al., 2009; ÜrgeVorsatz and Metz, 2009). These terms all occur in, for example, the residential area, the environmental area, and in industrial contexts. There is no clear definition for how these concepts are used (Rasmussen, 2014 and 2017), but non-energy benefits is the most commonly mentioned term in the literature covering industrial energy efficiency improvements (e.g. Lilly and Pearson, 1999; Pye and McKane, 2000; Finman and Laitner, 2001; Hall and Roth, 2003; Worrell et al., 2003). However, in an industrial context, synonyms for non-energy benefits, such as ancillary savings, and productivity and production benefits, are sometimes used (e.g. Worrell et al., 2003, Lung et al., 2005).

\footnotetext{
${ }^{1}$ A version of this sub-chapter was previously published in Nehler (2016).
} 


\subsection{Industrial non-energy benefits - an overview ${ }^{2}$}

Scientific contributions on non-energy benefits have been published since 1999, and contributions on the topic from 1999 to 2005 originated mainly from the US (e.g. Finman and Laitner, 2001; Gordon et al., 1999; Hall and Roth, 2003; Laitner et al., 2001; Lilly and Pearson, 1999; Lung et al., 2005; Pye and McKane, 2000; Skumatz et al., 2000; Worrell et al., 2002; Worrell et al., 2003). Thereafter and until today, publications on non-energy benefits were mainly from various European regions (e.g. Cagno et al., 2016; Christiansen et al., 2016; Gudbjerg et al., 2014; Krutwig and Starosta, 2017; Rasmussen, 2014 and 2017). This may imply that the interest for non-energy benefits was initiated in the US around the year 2000 and then increased later in the European countries. A few of the articles on industrial non-energy benefits concentrate on a certain type of industry, but in general, publications do not have a specific scope regarding the type of industry, or the scope is not clearly defined in the publication. Table 3 below summarises the industrial non-energy benefits previously reported in the literature.

Table 3. A summary of the industrial non-energy benefits reported in the literature, categorised in accordance with Finman and Laitner (2001) and Worrell et al. (2003) (revised and updated from Nehler, 2016).

\section{Non-energy benefits}

Publications

\section{Production}

Increased reliability, fewer production disruptions, improved system performance

Increased productivity, reduced production costs (including labour, operations and maintenance, raw materials), improved product quality (reduced scrap/rework costs, improved customer satisfaction), improved capacity utilisation, improved reliability Improved productivity, greater product life, lower losses of product, better quality

Increased yield of product, shorter processing cycles, improved quality

Increased product output/yields, improved equipment performance, shorter process cycle times, improved product quality/purity, increased reliability in production

Productivity (e.g. less downtime), defect or error rates (e.g. improved lighting gives fewer measurement errors and shipping mistakes, improved temperature control results in products of higher quality, a new compressor gives adequate pressure leading to improved quality) Reduced product waste, increased production, improved product quality, increased production reliability, shorter process/cycle time

Gordon et al., 1999

Pye and McKane, 2000

Skumatz et al., 2000

Laitner et al., 2001

Finman and Laitner, 2001; Worrell et al., 2003

Hall and Roth, 2003

Lung et al., 2005

\footnotetext{
${ }^{2}$ A version of this sub-chapter was previously published in Nehler (2016).
} 
Improved productivity (increased profit, safer working conditions,

IEA, 2012

consistency and improvement in quality and output, reduced capital and

operating costs, and reductions in scrap)

Improved productivity, increased reliability, improved product control and

quality

Cagno et al.,

2016

\section{Operations and maintenance}

Reduced maintenance costs, improved ease of system operation

Gordon et al.,

1999

Reduced operations and maintenance costs, reduced wear, extended

Lilly and

equipment lifetime

Extended life of equipment, reduced cleaning requirements, reduced operating time, reduced ancillary operations (e.g. degreasing, cut-off, swaging, and annealing), reduced downtime

Lower maintenance, better control, longer equipment lifetimes, greater control of equipment and temperatures

Pearson, 1999

Pye and McKane, 2000

Skumatz et al., 2000

Lower operation and maintenance costs, reduced wear and tear on equipment, increased reliability

Laitner et al., 2001

Reduced need for engineering controls, lowered cooling requirements, increased facility reliability, reduced wear and tear on equipment/machinery, reductions in labour requirements

Finman and

Laitner, 2001;

Worrell et al.,

2003

Non-energy operating costs (e.g. decreased staff time), equipment life, maintenance costs

Hall and Roth, 2003

Reduced maintenance costs, reduced purchases of ancillary materials,

Lung et al., 2005 reduced water consumption, lower cooling requirements, reduced labour costs, lower costs of treatment chemicals

Reduced maintenance costs, increased equipment life, reduced wear of equipment

Cagno et al., 2016

\section{Work environment}

Reduced worker safety issues

Gordon et al., 1999

Improved worker safety (resulting in reduced lost work and insurance costs), decreased noise

Better lighting, safety/security, improved work environment, better aesthetics, reduced glare, eyestrain, greater comfort, better air quality, better air flow, reduced noise

Safer conditions, reduced noise, improved lighting, improved air quality, improved temperature control

Reduced need for personal protective equipment, improved lighting, reduced noise levels, improved temperature control, improved air quality

Pye and McKane, 2000

Skumatz et al., 2000

Laitner et al., 2001

Finman and Laitner, 2001; Worrell et al., 2003

Personnel needs, injuries or illnesses (e.g. fewer accidents due to improved Hall and Roth, lighting), employee morale or satisfaction (e.g. improved lighting and 2003 temperature control 
Increased worker safety, reduced noise levels, improved workstation air quality

Health and well-being impacts

Improved lighting conditions, improved thermal comfort, reduced

emissions of noise and vibrations, increased comfort for operators

\section{Waste}

Reduced waste disposal costs, reduced water losses and bills, greater efficiency and control of water use, reduced overwatering of landscaping, reduced water use

Reduced wastes of product, water, and hazardous materials, reduced rawmaterial use, effective reutilisation of waste heat

Use of waste fuels, heat, gas, reduced product waste, reduced wastewater, reduced hazardous waste, materials reduction

Waste generation (e.g. reduced wastewater)

Reduced hazardous waste, reduced wastewater output

Reduced wasted heat, recycling of the wasted heat available

\section{Emissions}

Reduced emissions and reduced fines related to emission exceedances

Reduced cost of environmental compliance, reduced emissions

Environmental benefits, reduced cost of environmental compliance

Reduced emissions of dust and criteria pollutants, cost savings from avoided mitigation expenses or fines

Reduced dust emissions, reduced $\mathrm{CO}, \mathrm{CO}_{2}, \mathrm{NO}_{\mathrm{x}}, \mathrm{SO}_{\mathrm{x}}$ emissions

Reduced emissions of pollutants and other gases, reduced addiction to external conditions, reduced impact on the local community
Lung et al., 2005

IEA, 2012

Cagno et al., 2016

Skumatz et al., 2000

Laitner et al., 2001

Finman and

Laitner, 2001;

Worrell et al.,

2003

Hall and Roth, 2003

Lung et al., 2005

Cagno et al., 2016

Lilly and

Pearson, 1999

Pye and McKane, 2000

Skumatz et al., 2000

Laitner et al., 2001

Finman and Laitner, 2001; Worrell et al., 2003; Lung et al., 2005

Cagno et al., 2016

Gordon et al., 1999

Skumatz et al., 2000

Finman and

Laitner, 2001; Worrell et al., 2003 

charges, reduced/eliminated rental equipment costs, avoided/delayed costs (one-time)

Improved competitiveness, increased asset values, poverty alleviation,

IEA, 2012 energy affordability and access, increased disposable income, energy provider and infrastructure benefits

Improved image in society, increased value of the estate, avoided/delayed costs, increased influence on customers, achievements of rebates or

Cagno et al., 2016 incentives

Following the division of levels outlined by the IEA (2012), the non-energy benefits compiled in the table above are mainly benefits perceived on the individual and sectoral levels. Possible benefits can affect industrial firms in various ways depending on the areas in which the effects arise. For instance, the processes and associated equipment in firms, or the people within an organisation, might benefit from additional effects, but some effects might also translate into positive values outside the firm, which would affect the external environment. The categorisation of Finman and Laitner (2001) and Worrell et al., (2003), which is applied in Table 3 above, divides the benefits according to how and where they are perceived in a firm: waste, emissions, maintenance and operating, production, working environment, and a sixth category consisting of other benefits that do not fit the categories mentioned. This further underlines the diversity among the benefits and shows that energy efficiency improvements might add possible extra value to different areas, on various organisational levels and to various individuals within a firm. Hence, it is apparent that a broad perspective must be applied to understand all the effects that energy efficiency improvements might generate.

It should be noted that certain authors describe some of the stated non-energy benefits as reduced costs, for instance, reduced operations and maintenance costs and reduced production costs. This implies that the benefits have been measured, quantified, and financially evaluated. However, the evaluation of the benefits presents challenges in and of itself.

\subsection{Observation and evaluation of industrial non-energy benefits}

How industrial non-energy benefits have been studied, including the observation, measuring, and quantification of such effects and an evaluation of their impact, was studied in detail in Paper VI. Therefore, this section will only briefly describe how industrial non-energy benefits have previously been studied and evaluated.

As presented in sub-sections 2.2 and 2.3, energy efficiency improvements can be proposed and described on various levels: as specific measures or investments in a certain process, as for a single energy-using process, or as the activities targeted for improved 
energy efficiency overall in a firm, such as energy management activities. The perspective applied on industrial energy efficiency, i.e. the level of energy efficiency applied, impinges on how and on which level non-energy benefits have been studied and reported. Therefore, in order to understand how and from which type of energy efficiency improvement the non-energy benefits are generated, knowledge on how non-energy benefits have been studied and reported in relation to energy efficiency in previous studies is important. The perspective on energy efficiency applied differs somewhat among previous studies conducted on non-energy benefits. However, the studies have typically investigated energy efficiency measures on a specific level (i.e. specific energy efficiency measures), on the process level (i.e. energy efficiency of an energy-using process or technology, such as a compressed air system), or a mix of these two levels (e.g. Cagno et al., 2016; Christiansen et al., 2016; Lilly and Pearson, 1999; Pye and McKane, 2000; Worrell et al., 2003).

Accordingly, in previous studies, industrial non-energy benefits have, in general, been studied and observed mainly on the specific measure level or on the process level (e.g. Cagno et al., 2016; Christiansen et al, 2016; Lilly and Pearson, 1999; Pye and McKane, 2000; Worrell et al., 2003). Many of the previous contributions on industrial non-energy benefits have had a particular focus on the benefits' total monetary impact. i.e. the quantification of non-energy benefits and their role in financial evaluations. Therefore, reported results, for instance, have described how the inclusion of monetised benefits impacts on the total payback period for all implemented measures or investments (e.g. Hall and Roth, 2003; Worrell et al., 2003; Finman and Laitner, 2001). Hence, although nonenergy benefits were studied on a specific measure level or on the process level, these specific non-energy benefits have not always been declared because the results have been reported on a general or aggregated level.

Typically, a case study approach that includes the evaluation of energy efficiency projects or measures has been applied in the studies to identify possible non-energy benefits, but the type and number of cases has varied among studies (e.g. Cagno et al., 2016; Christiansen et al., 2016; Lilly and Pearson, 1999; Lung et al., 2005; Pye and McKane et al., 2000; Worrell et al., 2003). The data collection method applied in the investigation of nonenergy benefits was mainly conducted via interviews with concerned personnel in a firm (e.g. Cagno et al., 2016; Christiansen et al., 2016; Hall and Roth, 2003; Krutwig and Starosta, 2017; Skumatz et al., 2000).

Several studies on non-energy benefits have evaluated energy efficiency measures and projects after they have been implemented. These evaluations have, in particular, demonstrated the benefits' monetary impact on energy efficiency projects; the value of non-energy benefits can exceed corresponding energy savings (e.g. Pye and McKane; Worrell et al., 2003). Despite non-energy benefits' monetary potential, these additional effects are seldom acknowledged in the planning of and investing in energy efficiency improvements, which results in undervalued investments (Pye and McKane, 2000). 
To evaluate the magnitude of the found non-energy benefits as a consequence of energy efficiency improvements, the effects have to be measured and, if possible, also quantified and monetised. The methods for measuring, quantification, and monetisation of industrial non-energy benefits vary among previous studies. A central aspect in many of the previous publications is quantifiability, and in relation to this, several studies have reported that certain non-energy benefits are more difficult to quantify and monetise than others. Benefits related to the work environment, such as safety, noise, and improved air quality, for instance, are more difficult to quantify and monetise than benefits related to operation and maintenance (Lilly and Pearson, 1999).

Knowledge on the non-energy benefits that have been observed as a result of implemented energy efficiency improvements, the benefits' character, and in which area of an industry these additional effects occur, is a prerequisite for the utilisation of these benefits. In addition, the measurement and evaluation of their effects build a basis for the mapping of their effects. The utilisation of the benefits in decisions on energy efficiency improvements requires knowledge on which factors and how these factors affect such decisions. Therefore, factors that may influence decisions on energy efficiency improvements will be discussed in Chapter 4. 


\section{Decisions on energy efficiency improvements}

The adoption and implementation of energy efficiency improvements are required to improve industrial energy efficiency. However, decisions on energy efficiency are not always straightforward; a number offactors might affect such decisions. In this chapter, some of the factors will be described in relation to their impact on decisions on the implementation of energy efficiency measures of energy-using processes, energy efficiency investments, and energy management activities.

\subsection{Barriers to industrial energy efficiency ${ }^{3}$}

The barriers to industrial energy efficiency are often addressed as an approach to explain the energy efficiency gap; i.e. why energy-efficient technologies are not realised despite being economically profitable (e.g. Hirst and Brown, 1990; Jaffe and Stavins, 1994; Sorrell et al., 2004; Stern and Aronson, 1984). Decision-making on energy efficiency improvements in industrial firms may be complex, involving several actors and affected by various factors. Possible factors that hinder energy efficiency improvement measures from being implemented have been extensively studied, theoretically and empirically, in previous research on energy efficiency. Hence, to understand and explain what hinders energy efficiency improvements, barrier theory provides a comprehensive approach in that it combines various parameters from different fields, such as economics, behavioural and organisational sciences (Thollander and Palm, 2013). However, there is no common approach to classifying barriers. Previous literature has presented different ways of categorising barriers, depending on which perspective has been applied (e.g. Cagno et al., 2013; Hirst and Brown, 1990; Sorrell et al., 2000; Weber, 1997). Hirst and Brown (1990) present barriers as two groups, structural barriers and behavioural barriers, while Sorrell et al. (2000), as displayed in Table 4, divide barriers into market failure, nonmarket failure, behavioural and organisational, of which the first two constitute economic barriers.

\footnotetext{
${ }^{3}$ A version of this sub-chapter was previously published in Nehler (2016).
} 
Table 4. Categorisation of barriers to energy efficiency (based on Sorrell, 2000).

\begin{tabular}{|c|c|}
\hline Category & Barrier \\
\hline Economic: Market failure & $\begin{array}{l}\text { Imperfect information, adverse selection, split } \\
\text { incentives, principal-agent relationships }\end{array}$ \\
\hline Economic: Nonmarket failure & Heterogeneity, hidden costs, risk, access to capital \\
\hline Behavioural & $\begin{array}{l}\text { Bounded rationality, form of information, credibility } \\
\text { and trust, inertia, values }\end{array}$ \\
\hline Organisational & Power, culture \\
\hline
\end{tabular}

Weber (1997) classifies barriers in four groups: institutional, economic, organisational, and behavioural, whereof institutional barriers are caused by political institutions, such as the national government. Cagno et al. (2013) add other dimensions to the previous taxonomies by dividing barriers into external and internal with respect to the industrial firm as such and the actors within the firm which are affected by the barriers. In addition, the authors relate these barriers to steps in the decision-making process for energy efficiency investments.

Barriers to energy efficiency have also been studied empirically to further understand why the implementation of energy efficiency improvements are not realised, despite being evaluated as cost-effective. The identification of the major barriers to industrial energy efficiency in various contexts and through different perspectives is important in order to develop strategies to overcome barriers since one type of barrier may require a certain strategy to be overcome. Studies on empirical barriers have mainly concentrated on the barriers to cost-effective energy efficiency technology measures (e.g. Thollander and Ottosson, 2008; Trianni et al., 2013). A few publications have addressed barriers to specific measures of certain energy-using processes (detailed perspective) (e.g. Fleiter et al., 2012), and barriers to energy management activities (comprehensive perspective) is a topic that is even less studied. Depending on their specific character, the consideration of additional benefits from energy efficiency improvements could be a means to overcome certain barriers, which also underscores the importance of studying the non-energy benefits of industrial energy efficiency from various perspectives. In the following sections, previous literature on barriers to energy efficiency improvements will be described from the three perspectives applied in this thesis: sub-section 4.1.1 describes the barriers in relation to the investment perspective, followed by a description of barriers in relation to the measure perspective (sub-section 4.1.2) and the energy management perspective (sub-section 4.1.3). 


\subsubsection{Barriers to cost-effective energy efficiency technology measures ${ }^{4}$}

Empirical studies on barriers to industrial energy efficiency technology measures have been conducted in various contexts. Fleiter et al. (2012) have investigated small- and medium-sized manufacturing enterprises in Germany, and the major barriers found were high investment costs and lack of capital. Small- and medium-sized Italian enterprises have also been studied, and Trianni and Cagno (2012) found that major barriers to energy efficiency perceived by the firms were access to capital, lack of (or imperfect) information on cost-efficient energy efficiency interventions, and the form of information. Based on studies in the Netherlands, de Groot et al. (2001) have stated that other investments are more important as a main barrier. This has been acknowledged by Venmans (2014) who studied the ceramic, cement, and lime sector in Belgium and found that major barriers were other priorities for capital investments and hidden costs. In an Australian study including all manufacturing sectors, Harris et al. (2000) have identified firms' perceptions of low rates of return and long payback periods to be major barriers. In Sweden, barriers to industrial energy efficiency have been investigated in various sectors, and the perceived barriers to energy efficiency in the Swedish context have recently been compiled by Johansson and Thollander (2018). Based on about 300 interviews and questionnaires, the authors report the following main barriers: other priorities for capital investments (behavioural barrier), lack of time or other priorities (organisational barrier), technical risk, such as risk of production disruption, and lack of access to capital (economic barriers).

The results of the studies described above to some extent demonstrate a variation between different regions and sectors among the perceived main barriers, which has previously been stressed by, for instance, Sorrell et al., (2000). Trianni and Cagno (2012) address that barriers also can vary due to firm size. Nonetheless, these findings show that the main empirical barriers represent the theoretical barriers of economic, behavioural, and organisational nature. Hence, financial aspects are important in decisions on energy efficiency measures, but the adoption of measures also faces other obstacles, for instance, of organisational and behavioural nature.

\subsubsection{Barriers to specific energy efficiency measures and related processes ${ }^{5}$}

The previous literature on energy efficiency that has investigated the factors that hinder the implementation of energy efficiency measures has, with the exception of a few studies (Fleiter et al., 2012; Cagno and Trianni, 2014), reported on the barriers to energy efficiency measures in general and the barriers to the adoption of energy-efficient technologies. Hence, the barriers to energy efficiency improvements for specific energyusing processes or the barriers to implementation of the specific energy efficiency measures of a certain process have been scarcely explored.

\footnotetext{
${ }^{4}$ A version of this sub-chapter was previously published in Nehler (2016).

${ }^{5}$ A version of this sub-chapter was previously published in Nehler (2016).
} 
The characteristics of the measures play an important role to understand and explain the non-adoption of specific energy efficiency measures, but this aspect is normally not considered according to Fleiter et al. (2012). The types and characteristics of energy efficiency improvement measures seem to affect their adoption (Fleiter et al., 2012; Trianni et al., 2014). Fleiter et al. (2012) emphasise that it is rather the characteristics of a measure that hinder its implementation, not the energy efficiency measure as such. Consequently, the adoption of energy efficiency measures faces different obstacles that depend on the characteristics of the specific measure. The characteristics and associated attributes provided by Fleiter et al. (2012) are presented in Table 5.

Table 5. Characteristics of energy efficiency measures and their associated attributes according to Fleiter et al. (2012).

\title{
Characteristics \\ Attributes*
}

\section{Relative advantage:}

Internal rate of return

Payback period

Initial expenditure

Non-energy benefits
Low $(<10 \%)$, medium $(10-30 \%)$, high $(>30 \%)$

Very long ( $>8$ years), long (5-8 years), medium (2-4 years), short $(<2$ years)

High ( $>10 \%$ of inv.budget), medium ( $0.5-10 \%$ of inv.budget), low ( $<0.5 \%$ of inv.budget)

Negative, none, small, large

\section{Technical context:}

Distance to core process

Type of modification

Scope of impact

Lifetime

\section{Close (core process), distant (ancillary process)}

Technology substitution, technology replacement, technology add-on, organisational measure

System (system-wide effects), component (local effects)

Long, medium, short, not relevant

\section{Information context:}

Transaction costs

Knowledge for planning

and implementation

Diffusion progress

Sectoral applicability

\author{
High, medium, low \\ Technology expert, engineering personnel, maintenance personnel \\ Incubation, take-off, saturation, linear \\ Process-related, cross-cutting
}

\footnotetext{
* The adoption rate depends on the attribute and increases from left to right, for instance, low internal rate of return and long payback periods are expected to lead to a lower rate of adoption.
}

Based on literature on the adoption of energy efficiency measures, innovation, and manufacturing technology, Fleiter et al. (2012) have derived 12 characteristics divided into three areas: relative advantage, technical context, and information context. Energy efficiency measures' attributes, such as long payback period, high initial expenditure, 
close to core business, and process-related are, according to the authors, associated with lower rates of adoption.

The importance of the characteristics of energy efficiency improvement measures has in later research been acknowledged by Trianni et al. (2014). The authors have presented 17 categorised attributes that characterise industrial energy efficiency improvements, see Table 6.

Table 6. The characteristics and associated attributes of industrial energy efficiency measures according to Trianni et al. (2014).

\begin{tabular}{ll} 
Characteristics & Attributes \\
\hline Economic & Payback time, implementation cost \\
Energy & Resource stream, amount of saved energy \\
Environmental & Emission reduction, waste reduction \\
Production-related & Productivity, operation and maintenance, working environment \\
Implementation-related & $\begin{array}{l}\text { Saving strategy, activity type, ease of implementation, likelihood of } \\
\text { success/acceptance, corporate involvement, distance to core business }\end{array}$ \\
$\begin{array}{l}\text { Interaction-related } \\
\text { attributes }\end{array}$ & Indirect effects \\
\hline
\end{tabular}

The classification by Trianni et al. (2014) shares common features with the classification scheme provided by Fleiter et al (2012), such as payback time, implementation cost, activity type, and distance to core business. However, the way in which additional effects, such as non-energy benefits, are tackled differs. Trianni et al. (2014) have incorporated the various benefits into attributes, while Fleiter et al. (2012) have allocated a specific characteristic attribute to the benefits.

Barriers to energy efficiency have also been addressed on the process level for some of the industrial processes and technologies that are often involved in firms' production. Cagno and Trianni (2014) have studied what hinders energy efficiency improvements for lighting, compressed air, motors, heating, ventilation, and air conditioning among manufacturing SMEs in Italy. Their findings illustrate differences in perceived barriers between the investigated processes and technologies. The authors also reported that these differences might be due to the characteristics of the specific measures. Cagno and Trianni (2014) report that the main barriers to measures aimed at improving energy efficiency in compressed air systems, such as lack of information on costs and benefits, unclear information from technology providers, and uncertain trustworthiness of the information source, i.e. main barriers, were of an informational character. 
Hanna and Baker (2000) add other hindering factors to energy efficiency measures for compressed air systems: compressed air systems are only prioritised by operations and financial managers when production is threatened; lifecycle costs are not considered when investing in new energy-efficient improvements for the systems; compressed air system measures are not seen as potential cost savers; a lack of understanding of the system by operations and maintenance managers (they lack a comprehensive view of the system and are unaware of the parameters that affect system efficiency; therefore, new equipment is installed instead of optimising an existing system); lack of expertise on implementation and maintenance of compressed air systems by operations and maintenance staff; and lack of time.

\subsubsection{Barriers to energy management activities}

Energy management applies a comprehensive approach to improving energy efficiency by including several activities, of which the decisions on adopting energy efficiency improvement measures and investments are one element (Schulze et al., 2016). As described in sub-section 4.1.1, previous literature has studied barriers to cost-effective energy-efficiency measures for various industrial sectors and types of industrial firms in different geographical regions (e.g. De Groot et al., 2001; Harris et al., 2000; Thollander and Ottosson, 2008; Trianni et al., 2013; Venmans, 2014). Sa et al. (2017) have studied what hinders the adoption of energy management programs in energy-intensive industrial sectors, but studies with a wider scope that include obstacles to energy management activities in industry, in general, are lacking. For instance, in reviewing the academic literature on the barriers to improved energy efficiency by energy management in the pulp and paper industry, Lawrence et al. (2018) concluded that the previous studies have mainly focused on the part of energy management that Schulze et al. (2016) have described as implementation/operation, for instance, the implementation of energyefficient technology measures, which was described in sub-section 4.1.1.

\subsection{Drivers for industrial energy efficiency}

Previous literature has addressed factors that foster the adoption of energy efficiency improvements in industrial firms. Unlike the identification of barriers to industrial energy efficiency, the drivers of industrial energy efficiency have not been subject to as much thorough research. Nevertheless, an understanding and analysis of what drives and fosters the adoption of industrial energy efficiency improvements is important in order to improve industrial energy efficiency. In the following sections, drivers for energy efficiency improvements will be described from the three perspectives applied in this thesis: sub-section 4.2.1 describes the drivers in relation to the investment perspective, followed by the drivers in relation to the measure perspective (sub-section 4.2.2) and the energy management perspective (sub-section 4.2.3). 


\subsubsection{Drivers for cost-effective energy efficiency technology measures ${ }^{6}$}

Drivers to industrial energy efficiency have been empirically studied for the industrial sector in various regions (e.g. Brunke et al., 2014; Cagno and Trianni, 2013; Hasanbeigi et al., 2010; Rohdin and Thollander, 2006; Rohdin et al., 2007; Thollander and Ottosson, 2008; Venmans, 2014). Hasanbeigi et al. (2010) have studied the Thai industry and showed that commitment from top management and cost reduction resulting from lowered energy use were the main drivers. Venmans' (2014) study of the ceramic, cement, and lime sector in Belgium showed that increasing energy prices and commitment by top management were perceived as the main drivers. Studies in the US have demonstrated that investment costs, payback time, and cost reduction from lowered energy use were important in driving energy efficiency in that region (Abadie et al., 2012; Anderson and Newell, 2004). Blass et al. (2014) add managerial aspects, such as the involvement of the operational manager and the position of management, as important drivers. Based on their studies of the Dutch energy-intensive sector, Groot et al. (2001) have found that having a green corporate image is a main driver. Johansson and Thollander (2018) have compiled studies (published 2004 to 2016) that have investigated driving forces for improved industrial energy efficiency in Sweden. The review found that people with real ambition (behavioural) and long-term energy strategy (organisational) were the main drivers in the Swedish industrial context.

Solnørdal and Foss (2018) provide a comprehensive take on previous studies on drivers by systematically reviewing and compiling the empirical contributions to the notion of drivers for energy efficiency in industrial firms. Categorised as economic drivers, organisational drivers, market drivers, and policy instruments, their findings demonstrated organisational drivers, $45 \%$, as the most important, and economic drivers, $30 \%$, as the second most important. The organisational drivers include organisational structure, management, and competence (e.g. awareness of energy efficiency, energy audits, performance indicators, long-term energy strategy, commitment and support, environmental company profile). Economic drivers, in contrast, comprise technology, operating costs, and finance (e.g. cost reduction from lowered energy use, investment cost, and payback period). Policy instruments and market drivers were found to be of less importance in driving energy efficiency in the manufacturing industry. The findings of Solnørdal and Foss (2018) are in accordance with the review results in the Swedish context; main drivers were for instance of organisational character (Johansson and Thollander, 2018).

Hence, the previous literature described above has emphasised organisational, management and behavioural factors as important for driving industrial energy efficiency together with economic drivers, such as cost reduction from lowered energy use, investment costs, and payback time.

\footnotetext{
${ }^{6}$ A version of the first part of this sub-chapter was previously published in Nehler (2016).
} 


\subsubsection{Drivers for specific energy efficiency measures and related processes ${ }^{7}$}

Possible drivers for the implementation of specific energy efficiency measures are even less investigated than the corresponding specific barriers. However, similar to the specific barriers, the characteristics of energy efficiency measures might have an important role in driving and motivating their adoption. As described in sub-chapter 4.1.2, the adoption of energy efficiency improvement measures can be hindered by their characteristics, but the characteristics have also been found to drive their implementation and adoption (Fleiter et al., 2012; Trianni et al., 2014). Thus, the characterisation scheme (Table 5) according to Fleiter et al. (2012) could be applied to understand what pushes the adoption and implementation of specific energy efficiency measures; i.e. sufficient attractive characteristics may be viewed as driving effects in the adoption of energy efficiency measures. Organisational measures with attractive payback periods are, for instance, suggested to have a positive impact on the adoption rates of such energy efficiency measures (e.g. Fleiter et al., 2012).

Non-energy benefits, one of the characteristics that Fleiter et al. (2012) group into relative advantage, have been considered as one of the characteristics that can have an impact on the adoption rate of energy efficiency measures; large non-energy benefits are expected to yield a higher adoption rate (Fleiter et al., 2012). The magnitude of non-energy benefits, in respect to adoption rate, will naturally vary due to how important the benefits are perceived by the firms, i.e. the firms' perception of, for instance, the benefits' quantifiability and the strategic character of the benefits (e.g. Cooremans, 2011). As regards the remainder of the characteristics classified as relative advantage, Fleiter et al. (2012) have considered a high internal rate of return, a short payback period, and low initial expenditure to positively influence the adoption rate. However, if non-energy benefits are quantified and included in investment calculation, the benefits will also influence and lower the PB periods. As can be seen in Table 5, Fleiter et al. (2012) also address attributes of a technical and informational character as factors that have an impact on the adoption rate of energy efficiency improvement measures. For instance, the distance to the core process and the type of modification, which have previously been stressed by Cooremans (2012) and Paramonova et al., (2015) respectivelely as important factors in relation to rate of adoption.

Trianni et al. (2014) have applied their proposed characterisation framework in order to understand what drives the adoption of energy efficiency measures. The authors concluded that characteristic attributes among energy efficiency measures can contribute to a higher level of adoption of energy efficiency measures if the attributes provide driving effects to the measures for energy efficiency. Many of the attributes are similar to nonenergy effects or benefits, for instance, impacts on payback periods, reductions of emissions and waste, factors affecting productivity, operation and maintenance, and the

\footnotetext{
${ }^{7}$ A version of this sub-chapter was previously published in Nehler (2016).
} 
work environment (Trianni et al., 2014). In a recent study by Trianni et al. (2018), operational, economic, energetic, and contextual parameters were found to be vital to the decision-making processes on energy efficiency measures to foster an effective adoption of energy improvements in compressed air systems. The authors further divided the contextual parameters into three factors: complexity, compatibility, and observability, of which the latter consists of possible additional effects observed after the implementation of a certain measure, i.e. the non-energy benefits as a consequence of the implementation. The additional effects considered by Trianni et al. (2018) were, for instance, improved safety, better air quality, less wear and tear, and less noise.

\subsubsection{Drivers for energy management activities}

Sa et al. (2017) have studied drivers for the adoption of energy management programs in energy-intensive industrial sectors, but studies investigating what drives energy management activities in industry, in general, seem scarce. Publications on the topic illustrate drivers for energy efficiency, in general, or factors that drive energy efficiency investments and measures, but not which factors that comprehensively drive energy management activities as such (e.g. Lee, 2015; May et al., 2017; Sivill et al., 2013). Previous literature has focused mainly on drivers for specific elements of energy management, for instance, driving factors for energy efficiency technology improvements (Thollander and Ottosson, 2008), which may explain why studies on drivers for energy management practices seem to be lacking (Lawrence et al., 2018). Lawrence et al. (2018) have reviewed previous literature for factors for improved energy management in the pulp and paper industry and found that studies on what drives and hinders energy management procedures in the pulp and paper sector are missing. However, as described in sub-section 4.2.1, the review of Solnørdal and Foss (2018) has revealed the importance of drivers related to organisation and management which are typical elements of energy management. Hence, based on this finding, such drivers may contribute to the adoption of energy management activities.

\subsection{Decision-making on energy efficiency investments ${ }^{8}$}

Improved energy efficiency requires the adoption and implementation of energy efficiency measures and investments. Similar to any improvement requiring an investment, economic evaluation plays a key role in making decisions on energy efficiency investments. An economic evaluation should provide adequate economic information to make a decision. Short et al. (1995) state that a complete analysis involves forecasting each year of an investment's lifetime and should include costs relevant to the decision. However, it is important to let the objective of the analysis and decision-making criteria dictate how detailed the evaluation must be (Short et al., 1995), because this will also influence the choice of evaluation method applied. Common methods (or capital budgeting tools) for economic evaluations and analysis of investments, in general, applied

\footnotetext{
${ }^{8}$ A version of this sub-chapter was previously published in Nehler (2016).
} 
by firms are the net present value (NPV), the internal rate of return (IRR), and the calculation of the payback period (PB). The same methods are used in the evaluation and analysis of investments in energy efficiency (e.g. Harris et al., 2000).

NPV considers the discount rate and accounts for the time perspective by including the lifetime of an investment; it is, therefore, viewed as a method that provides the most correct basis for decision making of these three methods (e.g. Brooks, 2016). IRR is more complex to use; therefore, it is more difficult to obtain accurate evaluations when it is applied (Brooks, 2016). PB, however, is regarded as a simple method to use in the economic evaluation of investments as well as in general decision-making on investments; the method is commonly applied by firms despite its limitations (Olve and Samuelson, 2008). For instance, the PB method does not account for the time aspect of a return, hence, cash flows that arise at a later stage are not considered (e.g. Brooks, 2016). This well-known deficit in not being able to sort short-lived investments from long-lived investments has been acknowledged by Jackson (2010), and that author also emphasises that the use of the PB method can lead to the rejection of profitable investments. In their study conducted among the largest corporations in Sweden, Sandahl and Sjögren (2002) have found that PB is the most commonly applied capital budgeting tool in all types of industries, and most frequently used in the industrial engineering sector $190 \%$ of the studied firms stated that they use the PB method). The PB method is also a commonly applied tool for the evaluation of energy efficiency investments (e.g. Harris et al., 2000; Sandberg and Söderström, 2003; Bunse et al., 2009). However, firms, in particular larger firms, occasionally complement their evaluation methods with NPV and IRR, for instance (Sandahl and Sjögren, 2003). As regards energy efficiency improvement investments, findings from Sandberg and Söderström (2003) and Cooremans (2012) have shown that firms use the PB method along with IRR and NPV, especially when it comes to making larger investments (Sandberg and Söderström, 2003). Similar to the PB method, IRR and NPV are also applied as single evaluation methods by firms; however, as a single evaluation tool, these methods are not as common as the PB method (e.g. Brunke et al., 2014; Harris et al., 2000).

As regards investment criteria that guide the investment decision, research has shown that shorter payback periods are required, and higher discount rates are charged for energy efficiency investments to pass to a positive decision, compared to, for instance, investments in production efficiency (Qiu et al., 2015). Jackson (2010) stresses that lower PB times are applied by firms to account for possible uncertainties, such as future energy prices. Previous literature on energy efficiency investments indicates that PB periods of 3.5 years or less (e.g. DeCanio, 1998; Harris et al., 2000; Thollander and Ottosson, 2010; Brunke et al., 2014; Venmans, 2014) and an average discount rate of $13 \%$ are required to make the investments (Harris et al., 2000). To this, Qiu et al. (2015) add companies' views of energy efficiency projects as cost centres, meaning that energy efficiency investments are not often associated with an increase in revenue or profit. In a study on energy efficiency investments in manufacturing enterprises in the US, Abadie et al. (2012) 
corroborate the role of the PB method as the most decisive factor, together with investment cost, in decisions on energy efficiency investments.

Economic evaluation and cost-effectiveness are hence important for the adoption and implementation of such investments, but these are not always determining factors in positive decisions; decisions on energy efficiency investments are also influenced and affected by several other factors (e.g. Cooremans, 2012; de Groot et al., 2001). Studies by Sandberg and Söderström (2003) have reported that energy efficiency improvements are seldom pure energy efficiency investments; these investments are often initiated by other objectives, and energy efficiency is, thereby, one factor among others. Cost savings are an important driving force behind positive investment decisions, but this is not always true for energy efficiency investments; cost-effective investments in energy efficiency exist but are not decided upon (e.g. Thollander and Ottosson, 2008). Other more attractive investment opportunities are, for instance, chosen instead of investing in energy saving technologies (e.g. Cooremans, 2012). These findings have been acknowledged in recent studies by Trianni et al. (2016); decisions based on the financial analysis in the investment process for energy efficiency investments might face economic barriers, but there are also other factors, such as behavioural barriers and lack of awareness, that can have impact on the decision-making process mainly in the first part of the process (Trianni et al., 2016).

In addition, recent studies by Cooremans (2011, 2012) have shown that the result of financial evaluation is often viewed as secondary. Instead, it is the strategic character of the investment that is decisive in investment decisions. Examples of strategic investments are capital investments linked to a firms' core business, for instance, investments that improve productivity and capacity (Cooremans $(2011,2012)$ ). This is related to previous findings on energy efficiency investments; the absence of a link between energy efficiency investments and core business is argued to contribute to the non-adoption of energy efficiency investments because other more attractive investment alternatives are chosen and decided upon (e.g. Harris et al., 2000; Sandberg and Söderström, 2003). Apart from core business, Cooremans (2011) defines an investment as strategic "if it contributes to create, maintain, or develop a sustainable competitive advantage" (p. 483). In this definition, the term competitive advantage is defined with three parameters; costs, value, and risks, and these parameters have been applied by the author to evaluate the strategic character of investments (Cooremans, 2011). Into this characterising framework, Cooremans (2011) incorporates the role of non-energy benefits, i.e. how can these benefits contribute to costs, value, and risk (competitive advantage). Based on the benefits reported by Worrell et al. (2003), Cooremans (2011) argues that non-energy benefits contribute to all three dimensions of competitive advantage; reduced waste, reduced material, and reduced wear and tear on equipment decrease costs. Improved product quality and improved public image increase value, and reduced hazardous waste and reduced $\mathrm{CO}, \mathrm{CO}_{2}, \mathrm{NO}_{\mathrm{x}}, \mathrm{SO}_{\mathrm{x}}$ emission reduce risks. 
Findings by Cooremans (2012) also stress the role of investment categories; investigated firms confirmed the existence of investment categories, which implies competition between investments within a firm. Moreover, the most common investment categories stated by the firms were related to core business, which further contributes to the relation between strategic investments and positive investment decisions. Findings by Cooremans (2012) also address the lack of category for energy efficiency investments as an explanation for the non-adoption of energy efficiency investments, which corroborates earlier findings from de Groot et al. (2001). The investment decision and, hence, the adoption, or non-adoption, of energy efficiency investments are affected by several factors. Moreover, according to Cooremans (2012), the investment process is also surrounded and, thereby, influenced by the actors involved.

To conclude, economic evaluation has an important role in determining energy efficiency investments. However, strict criteria seem to be applied in decision making on these types of investments. Furthermore, several other factors seem to affect the phases of the investment process for energy efficiency investments, i.e. financial evaluation is just one factor among others. 


\section{Method}

This chapter describes the overall methodological approach, i.e. the research design, the methods applied in the papers appended to this thesis and ends with a discussion on quality aspects of these studies.

\subsection{Research design}

After their implementation, industrial energy efficiency improvement measures and investments can give rise to the spread of additional effects (e.g. IEA, 2012; Pye and McKane, 2000; Worrell et al., 2003). As described earlier, there are several different types of these so-called non-energy benefits that can be observed at various levels and by various actors in an industrial firm, and they can affect a variety of actors and processes (e.g. IEA, 2012; Worrell et al., 2003). Furthermore, the perspective on non-energy benefits has been broadened throughout these studies to also include an investigation of the nonenergy benefits of energy management activities. Central in studies of non-energy benefits are the decisions made on energy efficiency measures and investments; such decisions often involve several actors and require them to consider multiple aspects. Similarly, various actors interact in making decisions on energy management activities. This paints a complex picture, and the view of the actors involved therefore plays an important role in understanding and describing non-energy benefits as a phenomenon.

Since non-energy benefits may be of several different types, and their effects may be observed in many different areas in industrial firms as results of the implementation of various types of energy efficiency improvements, different perspectives on energy efficiency improvements are required when investigating the possible ways that nonenergy benefits can affect decisions on energy efficiency improvements. Therefore, in this thesis, non-energy benefits have been studied and analysed through the following three perspectives: non-energy benefits in relation to specific energy efficiency improvement measures, non-energy benefits in relation to energy efficiency investments and nonenergy benefits in relation to energy management activities.

The perspective on energy efficiency in previous research on industrial energy efficiency, on drivers for and barriers to energy efficiency, and on non-energy benefits, have typically been based on improving energy efficiency mainly by investments in new technology (e.g. Sorrell et al., 2000; Thollander and Ottosson, 2008; Worrell et al., 2003). Therefore, the 
decision to study non-energy benefits from the investment perspective, i.e. non-energy benefits in relation to energy efficiency investments, seemed relevant also in these studies. The diversity among the non-energy benefits and that their effects sometimes were difficult to recognise and measure motivated studying non-energy benefits also from a more detailed perspective; non-energy benefits in relation to specific energy efficiency measures aiming at a single energy-using process - compressed air. If investments in new energy-efficient technology is combined with operational and organisational activities, i.e. energy management, the potential for improved energy efficiency is extended (Backlund et al., 2012; Paramonova et al., 2015). In order to investigate if also the perspective on non-energy benefits also could be extended, a third perspective was applied: non-energy benefits in relation to decisions on energy management activities.

All types of energy efficiency improvements that can be undertaken may be viewed as measures, but many measures could also be regarded as investments. In this regard, energy efficiency investments are measures associated with an investment cost and an investment process including an investment evaluation, i.e. investments are measures that require a more thorough assessment. Hence, energy efficiency investments can be seen as a sub-set of all measures that can be undertaken. Furthermore, according to Schulze et al. (2016), the implementation of energy efficiency measures is also included as an element in energy management, along with other dimensions such as strategy and planning, operation, control, organisation and culture. Hence, similar to the above, energy efficiency measures and investments comprise a sub-set of the possible energy management activities that can be undertaken in an industrial firm.

Many of the previous publications on industrial non-energy benefits were published in and around the year 2000, and they primarily originated in the US. In recent years, the concept of non-energy benefits has begun to appeal to additional geographical areas, such as to European countries, for instance (e.g. IEA, 2012; IEA, 2014). However, research on non-energy benefits may still be seen as an emerging research field, i.e. studies on nonenergy benefits can be judged as explorative.

Ahrne (2011) emphasises that when studying a phenomenon or a problem involving various actors, a qualitative approach to the description, explanation and interpretation is considered suitable. A detailed understanding when exploring problems is also favoured by a qualitative approach (Creswell, 2013). This understanding, as emphasised by Creswell (2013), can be established by studying the research problem in the participants' normal context by talking to them and conducting interviews. This further enables the context to be studied and described, which is typically important and requires attention in qualitative studies, according to Creswell (2013). Furthermore, Creswell (2009) stresses that a qualitative approach is applicable to exploratory studies.

A quantitative approach normally emphasises objective measurements and statistical analysis in order to test hypotheses and generalise the results across larger populations 
(Bryman, 2011). Also, quantitative data collection (such as via questionnaires), as opposed to gathering qualitative data, typically collects large amounts of data relatively quickly (Bryman, 2011). However, small sample sizes will yield less empirical material which limits statistical analysis or statistical generalisation; nonetheless, such quantitative data can be analysed in a descriptive or qualitative way (Bryman, 2011).

Case study research, according to Yin (2014), is defined as empirical research conducted in a real-world context that investigates a contemporary phenomenon in depth. According to Yin (2014), using case studies is a suitable research design when "how" and "why" questions prevail among the research questions posed. Case study research is often recognised as a qualitative research method, but Yin (2014) argues that case studies can rely on quantitative evidence or a mixture of qualitative and quantitative data, depending on the data collection method employed. Furthermore, this design also suits studies with an explorative nature (Yin, 2014).

Hence, studying different aspects of non-energy benefits on various levels promotes a comprehensive research design that can handle both a narrow perspective and a broader perspective, i.e. a design that is capable of grasping all the aspects and views that have to be considered in relation to the studied problem. Moreover, the research design's capacity to capture the views of various actors involved in relation to the context in which nonenergy benefits are likely to be found is also required. At the same time, the explorative elements of the studies have to be considered in the design. Therefore, in order to explore the role of non-energy benefits, a research strategy including both qualitative and quantitative approaches has been applied in the studies conducted for this thesis. Various case study designs have been applied in the research in which interviews and questionnaires have been the main methods used for data collection. In the studies on which this thesis is based, the rather small sample sizes of the empirical material collected did not allow for statistical analysis or statistical generalisation; however, they were not intended to. Rather, the quantitative data was mostly descriptively and qualitatively analysed. The qualitative approach is mainly evident in Papers I, II and IV, and the studies described in Papers I and II formed the basis for the studies conducted later on. Papers II and IV also contained quantitative elements based on the use of questionnaires, and in Paper V, the same method was applied for the empirical data collection. The research design was also supported by systematic literature reviews.

Overall, the research design for this thesis can be considered as having a mixed methods approach. Mixed methods research describes a strategy that combines methods, such as using both quantitative and qualitative methods (Bryman, 2011). Combining research methods can be done for several reasons: to triangulate (e.g. a quantitative method is applied to confirm qualitative results and vice versa), to support (e.g. one research strategy is applied as support in conducting the other strategy) and to complement (e.g. both research strategies are applied in order to reveal different aspects of a study which are then fit together) (Bryman, 2011). Combining different types of samples and using 
different data collection methods strengthens validity (e.g. Creswell, 2009). The mixed methods approach in this thesis (Papers II and IV) was applied for triangulation purposes: more than one type of method was used to investigate the problem. For instance, data on observed non-energy benefits were collected by both interviews and questionnaires, which contributed to confirmation of the results.

The interpretive framework applied to the studies reflects what Creswell (2013) describes as a pragmatic approach, meaning that the research is permeated with usefulness, both inductive and deductive elements and both qualitative and quantitative methods of data collection and analysis. Moreover, knowledge creation and related values reflect the views of both the researcher and the participant(s) (Creswell, 2013). The views on theory and how theories are generated and challenged are influenced by the aim of the study and the problem studied. A deductive approach starts from existing theory, hypotheses are formulated and tested and, depending on the result, new theories will be formulated (Bryman, 2011). However, Bryman (2011) explains that the last step (the formulation of new theories) may be viewed inductively, which is the opposite of deduction. In induction, new theories are formulated after generating results from observation or empirical study. The inductive approach may also have deductive elements. For instance, a researcher may want to collect additional empirical data after analysing the results (Bryman, 2011).

As a topic of research, non-energy benefits have been scarcely studied, especially in industrial contexts. However scarce it may be, previous literature on the subject has deductively guided the studies. The analysis of the empirical data has inductively increased the understanding of non-energy benefits. Since the studies presented in this thesis have been of an exploratory nature, an inductive view has dominated the theoretical process. Hence, the empirical results have been the basis for acquiring new knowledge, even though the inductive approach also had deductive components. For instance, the analysis of the results generated new questions that were explored in further empirical data collection, which is an example of this deductive component. In the studies described in this thesis, there has been a continuous interaction between theory and empirical data. Bryman and Bell (2011) describe this interaction as an iterative approach. Even if research studies are often described as a process, there may be an iterative loop after the theoretical work in which a new theoretical approach might be created (Bryman, 2011). The new theory may require the collection of additional data, which also creates an interrelationship between the interpretation of data and the conceptual and theoretical work. According to Bryman (2011), for qualitative methods it is typical that a new theory - the inductive generation of a theory-is formulated from the results.

Elements of the research presented in this thesis were conducted as part of two interdisciplinary research projects spanning energy systems and business administration. In the project on non-energy benefits in Swedish manufacturing firms, the interdisciplinary approach was most apparent by my collaboration with Josefine 
Rasmussen, a doctoral candidate in the field of business and administration, in working on Paper II. The perspectives of our two research fields were shared and combined through our interactions and discussions throughout the entire research process, which provided input to my studies. This interdisciplinary collaboration continued in the second project (energy management in the Swedish pulp and paper industry), mainly through regular meetings and discussions with the research group. These collaborations and continuous interdisciplinary discussions enriched the research in various ways, including in the creation of new knowledge. According to Creswell (2009), reviewing and discussing your research is also a means of strengthening the reliability of the research.

\subsection{Literature review 9}

Prior literature often forms the basis for understanding a research field, and what is known about a topic and what has been done before creates the background and sets the prerequisites for generating a new theory (Bryman, 2011). To become acquainted with the field of industrial energy efficiency and non-energy benefits, in particular, the research process began with a literature review. According to Bryman (2011), a literature review could focus on the context and the connections between earlier studies, describing their build-up and contributions. On the other hand, Bryman (2011) also states that a literature review can be based on problematisation and the gaps in previous literature in order to search for certain aspects that have not yet been studied or presented. During the studies carried out for this thesis, three literature reviews were conducted. The first considered industrial non-energy benefits in general, and the intention was to become acquainted with and create an initial background to the field of non-energy benefits. The other two aimed at systematically reviewing the literature on energy efficiency measures for compressed air systems and also the literature on industrial non-energy benefits in relation to the methods applied for the mapping and evaluation of the benefits. In sections 5.2.1-5.2.3 below, the literature reviews will be further described.

\subsubsection{Literature review on non-energy benefits}

The objective of carrying out the literature review on non-energy benefits was mainly to create an overview of non-energy benefits, particularly an overview of industrial nonenergy benefits. The literature review did not intend to cover the entire field of nonenergy benefits and their related concepts, since a comprehensive and systematic literature review had previously been conducted by our research project on non-energy benefits (Rasmussen, 2014, 2017). Therefore, the review mainly focused on industrial non-energy benefits, even if some of the non-energy benefits described in other areas and related concepts were included to some extent. The literature review summarised the previous literature rather than filled in the gaps-even if it did demonstrate some elements of the latter. Keywords such as "non-energy benefits", "industrial energy efficiency", "energy efficiency investments" and "energy efficiency measures" were

\footnotetext{
${ }^{9}$ A version of this sub-section was previously published in Nehler (2016).
} 
applied in the search process. Moreover, citations and reference lists found in previously published studies were also gleaned for relevant publications.

\subsubsection{Literature review on compressed air systems}

The aim of the literature review on compressed air was twofold. First, it was conducted to systematically review previous academic contributions on energy efficiency in compressed air systems, particularly energy efficiency measures for compressed air systems. Second, it also aimed to explore possible contributions on non-energy benefits in relation to energy efficiency measures for compressed air systems.

The systematic search for literature on energy efficiency measures in compressed air systems involved identifying relevant publications, i.e. studies published in peerreviewed journals and peer-reviewed conference proceedings; other publication types were omitted. Further inclusion criteria were: English as the language of publication, available as full-text, related to energy as a research domain, related to the industrial sector, published from 1960-2016 and relevant to the studied topic. The literature search was performed during autumn 2016 and the main resource that was used to search for relevant literature on the subject was the scholarly database Scopus. The search settings were set to search within the article title, abstract and keywords. In addition to searching online databases, both journal articles and conference papers were identified by checking the citations and reference lists in articles that were found earlier. Three search strings were applied: "compressed air" was combined with "energy efficiency", "energy saving" or "energy conservation". The search process and the selection process are visualised in the flow chart below (Figure 4). 


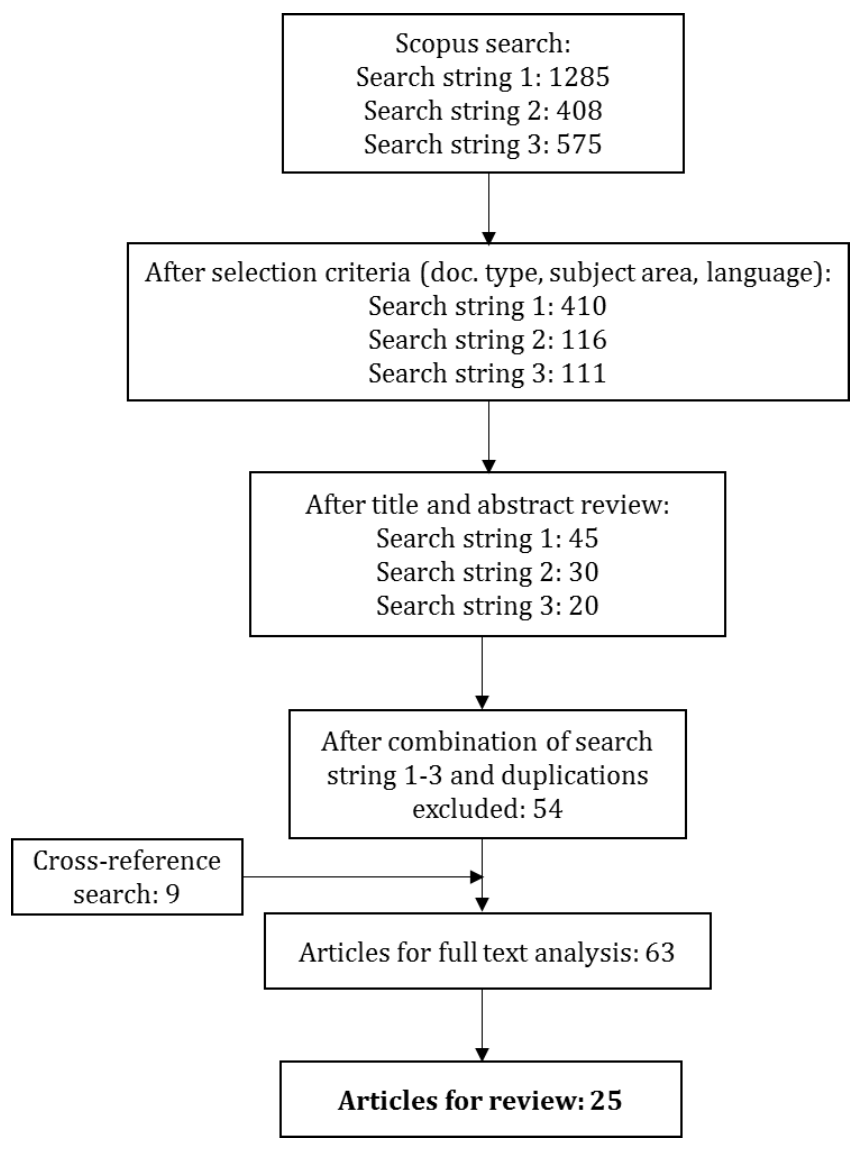

Figure 4. Mapping of the literature search and selection process (Nehler, 2018a, Paper III).

The articles reviewed were coded according to their bibliographic character and study type and then analysed. The analysis focused on the energy efficiency strategies applied in the reviewed articles and the possible non-energy benefits in relation to the energy efficiency measures mentioned. The measures were first categorised as demand-side measures or supply-side measures, based on the sub-part of the compressed air system at which the measure was aimed.

The relevant publications uncovered during the literature review were also analysed with respect to the possible non-energy benefits of the energy efficiency measures described. Furthermore, the possible relationships between non-energy benefits and energy efficiency measures in compressed air systems were also approached from the opposite direction, i.e. previous literature on non-energy benefits was parsed for implemented energy efficiency measures in compressed air systems which had generated non-energy benefits. 


\subsubsection{Literature review on methods for evaluation of non-energy benefits}

The aim of the literature review on methods for the evaluation of non-energy benefits was to systematically review previous academic contributions on the non-energy benefits of industrial energy efficiency improvements and the methods applied in the mapping and evaluation of the benefits in particular.

The systematic search for literature on methods for the evaluation of non-energy benefits was performed during summer 2018 using the scholarly database Scopus. Publications relevant for inclusion in the review were articles in peer-reviewed journals and conference proceedings, and other types of publications, like reports, were omitted. Inclusion was also based on the following criteria: articles, conference papers or reviews as the document type; available as full-text; research domains related to energy, engineering, environmental science, business, management, accounting or social sciences; related to the industrial sector; and relevant to the studied topic. The following four search strings were applied when parsing the articles' titles, abstracts and keywords: "energy efficien*" was combined with 1) "non-energy benefits"; 2) "co-benefits"; 3) "multiple benefits"; and 4) "ancillary". The search process and the selection process are displayed in the flow chart below (Figure 5). 


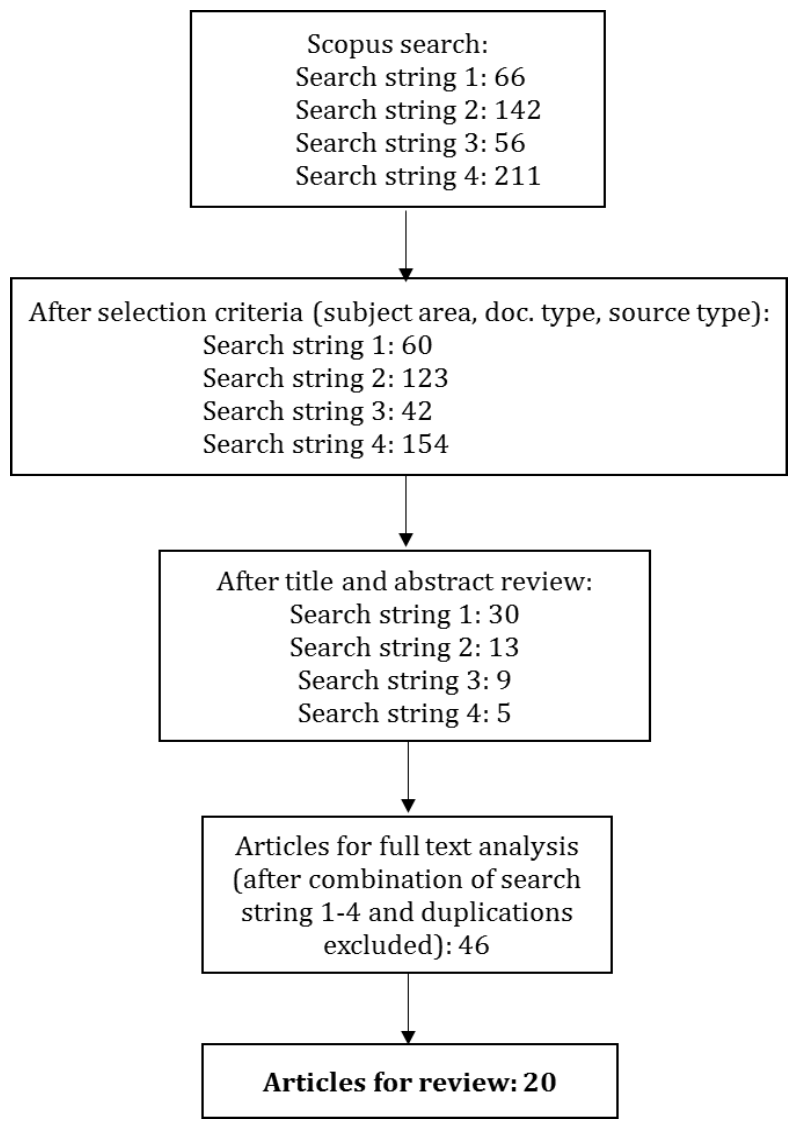

Figure 5. Mapping of the literature search and selection process (Nehler, 2018b, Paper VI).

The articles that were identified and reviewed were coded with respect to their bibliographic character and the type, geographic origin and geographical scope of the study (i.e. in which geographical area the study was conducted). In addition, the articles were also coded with respect to the type of study and which methods were applied in collecting data on non-energy benefits.

Since the level of the energy efficiency perspective applied affects how and on which level non-energy benefits are studied, the level of energy efficiency was included in the descriptive analysis as well as the level of non-energy benefits. Furthermore, the level on which the non-energy benefits have been observed and the level on which they have been reported were also distinguished. The articles were also analysed with respect to the time perspective (i.e. if measures were evaluated after implementation, the articles had an expost perspective, or if estimations or calculations were applied to forecast the non-energy benefits' potential, the article had an ex-ante perspective). The distinction made between these perspectives was important since methods for the evaluation of the non-energy benefits may differ according to whether the studies regard evaluations after implementation or if the objective is planning and estimating the implementation. In 
addition, other suggestions on how to evaluate non-energy benefits were included, such as how the characteristics of non-energy benefits could be utilised in making decisions on energy efficiency investment, i.e. their roles as drivers.

\subsection{Interviews ${ }^{10}$}

In Papers I, II and IV, data were mainly collected by conducting interviews. In qualitative research, interviews aim to understand a certain phenomenon from the perspective of the study subject (Kvale and Brinkmann, 2009). Hence, interviews are suitable for gaining a greater understanding of a certain topic and uncovering how people perceive the topic, in particular. Qualitative interviews were thus a suitable method in these studies to collect the study subjects' experiences with non-energy benefits and related topics. The conversation and the interaction between the interviewee and researcher is central in interview-based research because the conversation, characterised as a professional talk, intends to create new knowledge through that interaction (Kvale and Brinkmann, 2009).

Before the interviews were conducted, interview guides were developed. As described by Kvale and Brinkmann (2009), the interview guide normally structures the interview. The interview guides were developed based on the scientific literature on the topic and on the research questions posed in the studies. The guides consisted of questions to be asked during the interview. However, the order in which the questions were asked varied, and there were also opportunities to ask follow-up questions. Most questions were openended, but some of them were formulated as closed questions asking for straightforward yes or no answers. As discussed by Kvale and Brinkmann (2009), this semi-structured approach to formulating the interview guide encourages the researcher to start analysing the data during the interview which thus permits valuable follow-up and clarifying questions to be asked. Before the interview guides were used, the guides were reviewed by senior colleagues, as suggested by Yin (2014).

\subsubsection{Interviews with Swedish manufacturing firms ${ }^{11}$}

The empirical data in Papers I and II were mainly collected by conducting interviews with Swedish manufacturing firms. In total, 13 interviews with representatives from Swedish industrial firms were conducted in these studies. The results from eight of the interviews have been analysed and presented in Paper I. These interviews were complemented by five more interviews in Paper II. Hence, Paper II are based on analysis of results of all 13 interviews.

The interviews, that built the empirical material in Papers I and II, sought to explore the perceived non-energy benefits of the firms' implemented energy efficiency investments

\footnotetext{
${ }^{10}$ A version of this sub-section was previously published in Nehler (2016).

${ }^{11}$ A version of this sub-section was previously published in Nehler (2016).
} 
and how the benefits were acknowledged in their investment evaluations. In addition, the interviews tried to find explanations for what hinders the monetisation of non-energy benefits and their inclusion in investment evaluations. In Paper I, the interviewed representatives of Swedish industrial firms were asked if and how non-energy benefits were included in their investments related to energy efficiency. If they were not included, the respondents were further asked about the factors inhibiting the inclusion of nonenergy benefits in their investment calculations. The interviews investigated firms' views on the investment process, investment motives, investment evaluations and capital budgeting tools in relation to energy efficiency investments and non-energy benefits. In addition, the interviews also focused on the participants' views on measuring, quantifying and monetising non-energy benefits.

Selection of the participating firms was based on energy use, assuming that high energyuse firms probably have sufficient experience with energy efficiency improvements. Moreover, the majority of the firms had also joined the Swedish Programme for Energy Efficiency in Energy-Intensive Industry (PFE), a voluntary long-term agreement ${ }^{12}$ meaning that the firms would have experience in implementing energy efficiency measures and possibly additional effects in relation to the measures. The energy use in the firms was 40-5000 GWh per year and the participating firms covered the following sectors: pulp and paper (three firms); engineering (five firms); chemical (two firms); iron and steel (two firms); and another type of manufacturing industry (one firm). The representatives interviewed were energy managers or similar, i.e. the interviewees were responsible for handling energy issues and related energy efficiency improvements realised at the firm. Nine of the interviews were carried out over the telephone by the author of the thesis, while the other four were conducted on-site together with Josefine Rasmussen. The interviews lasted between 50 minutes and two hours. All interviews were recorded and transcribed, and the material was mainly qualitatively analysed on the basis of posed research questions. The transcripts were also quantitatively analysed in a descriptive way. In the analysis of the interview answers provided by the first eight interviews conducted, six barriers outlined by Sorrell et al. (2004) were applied to analyse the non-inclusion of non-energy benefits into investment decisions: risk, split incentives, access to capital, imperfect information, hidden costs and bounded rationality. Since barriers might be ambiguous, overlaps might exist between them. Hence, empirical findings may be sorted into several of these barriers.

The same interview guide was used for all 13 interviews. However, it was extended for the last four interviews by including four questions regarding firms' views on their investments and related processes. The questions were mainly open-ended, but some were closed questions. The interviews focused the following subjects: general

\footnotetext{
${ }^{12}$ A voluntary long-term agreement programme aimed at Swedish energy-intensive industries. The programme was operated by the Swedish Energy Agency (SEA). Firms received a tax rebate if they worked with energy efficiency efforts in a structured way; i.e. if they performed energy audits, energy analyses and implemented the proposed energy efficiency measures and investments (SFS, 2004).
} 
information on the firms and interviewees, investments (e.g. investment motives, the investment process, energy efficiency investments, investment evaluations and calculations and capital budgeting tools) and non-energy benefits (e.g. observed nonenergy benefits, inclusion of non-energy benefits in investment decisions and quantification and monetisation of non-energy benefits).

\subsubsection{Interviews with energy managers, energy audit experts and suppliers}

The empirical data in Paper IV were mainly based on the interviews conducted with industrial energy managers, independent energy audit experts and suppliers of compressed air systems. The interviews sought to understand what hinders and drives energy efficiency measures for compressed air systems. The research design included the energy managers' and the auditors' views based on their experiences of energy efficiency improvements in compressed air systems. In addition, the views of the suppliers of compressed air systems were studied by conducting interviews with salespersons of compressed air systems and related equipment. Sixteen interviews were conducted in total, of which five were with energy managers, five were with energy audit experts and six were with suppliers.

The energy managers were corporate-level representatives from multinational industrial manufacturing firms. Their views reflected their experience with energy-related issues in general and their knowledge of their firms' energy-using processes, which includes the process of compressed air. Table 7 outlines the positions of the interviewees, their firms' business types and the numbers of employees.

Table 7. Background information on the interviewees and firms (revised from Nehler et al., 2018).

\begin{tabular}{clll} 
Interviewee & Position & Type of business & Number of employees \\
\hline 1 & Global energy manager & Meat casing & $>5000$ \\
2 & $\begin{array}{l}\text { Regional project manager, } \\
\text { Bellevue, OH, US (former } \\
\text { energy manager) }\end{array}$ & $\begin{array}{l}\text { PET beverage } \\
\text { containers }\end{array}$ & $>37800$ \\
& $\begin{array}{l}\text { Regional engineering director, } \\
\text { US (former energy manager) }\end{array}$ & $\begin{array}{l}\text { Paints and } \\
\text { coatings } \\
\text { Chemical } \\
\text { company }\end{array}$ & $>28000$ \\
4 & $\begin{array}{l}\text { Global energy manager, } \\
\text { Europe }\end{array}$ & $\begin{array}{l}\text { Fogional energy and } \\
\text { sustainability manager, US }\end{array}$ & $>110000$ \\
\hline
\end{tabular}

Interviews were also done with independent energy audit experts of compressed air systems from a number of consultancy firms in the US. The rationale for interviewing this group was that their focus on auditing compressed air systems meant that they had experience analysing and proposing energy efficiency improvement measures specifically targeted at compressed air systems. Table 8 outlines general information on the energy 
audit experts along with their accumulated experience as reflected in the records (number) of energy audits conducted.

Table 8. Background information on the energy auditor experts for compressed air systems (revised from Nehler et al., 2018).

\begin{tabular}{lllll}
\hline Interviewee & Position & Firm & $\begin{array}{l}\text { Affiliated with } \\
\text { equipment suppliers }\end{array}$ & $\begin{array}{l}\text { Records of } \\
\text { audits }\end{array}$ \\
\hline 1 & $\begin{array}{l}\text { System } \\
\text { auditor/owner }\end{array}$ & Crowsnest Ltda. & No & $<50$ \\
2 & $\begin{array}{llll}\text { System auditor } \\
\text { System }\end{array}$ & IZ Systems LLC & No & $<100$ \\
3 & IZ Systems LLC & No & $<300$ \\
4 & $\begin{array}{l}\text { System auditor } \\
\text { auditowner }\end{array}$ & $\begin{array}{l}\text { Southern Corporation } \\
\text { of SC }\end{array}$ & No & $>300$ \\
5 & $\begin{array}{l}\text { Compressed Air } \\
\text { System }\end{array}$ & No & $>200$ \\
\hline
\end{tabular}

The interviews with the users and the energy audit experts were based on an interview guide that included both open-ended questions and a structured part (following, e.g. Kvale and Brinkmann, 2009). For instance, aspects of improving energy efficiency in compressed air systems and the interviewees' experiences of measures for such improvements were covered. The structured part sought to investigate their views on the factors that hinder or drive the implementation of cost-effective energy efficiency improvement measures for compressed air systems. The barriers and drivers that were tested among the respondents in the structured part were influenced by previous studies by Rohdin and Thollander (2006) and Brunke et al. (2014).

In total, six interviews were carried out with salespeople or representatives with similar roles from four firms supplying compressed air systems. The objective of these interviews was to consider the suppliers' perspectives, in particular their views on and experiences of non-energy benefits. Table 9 provides background information on the interviewees. 
Table 9. Background information on compressed air systems salespeople (revised from Nehler et al., 2018).

\begin{tabular}{lll}
\hline Interviewee & Position & Supply company \\
\hline 1 & Sales project engineer & A \\
2 & Sales engineer & A \\
3 & Sales engineer & B \\
4 & Sales engineer & B \\
5 & Business developer & C \\
6 & Energy efficiency project engineer & D \\
\hline
\end{tabular}

The interviews were structured around an interview guide that focused on the perceived non-energy benefits related to energy efficiency measures for compressed air systems. Non-energy benefits were first addressed by asking open questions, followed by questions on the non-energy benefits of specific energy efficiency measures for compressed air systems. The energy efficiency measures covered in the interviews were selected based on a taxonomy of energy efficiency measures (Blomqvist and Thollander, 2014; Söderström et al., 1994). In addition, three more measures were includedmaintenance of ancillary equipment, air inlet measures and measures related to end-use equipment-in order to include all parts of the compressed air system. The interviewees were asked to share their experiences of possible non-energy benefits in general based on their sales role but also based on their views of non-energy benefits with respect to specific energy efficiency measures for compressed air systems. Finally, questions on the factors driving or hindering energy efficiency measures for the process of compressed air were asked.

\subsection{Questionnaires}

In Papers II and IV, the interviews were complemented by questionnaires to collect data on non-energy benefits and other topics, whereas in Paper V, questionnaires were the main method applied to collect empirical data. One advantage of using questionnaires is that several respondents can be reached and extensive data can be collected in one single opportunity (Bryman, 2011; Trost and Hultåker, 2016). However, using questionnaires in research as opposed to interviews, for example, has certain drawbacks. For instance, Bryman (2011) stresses that if questions are unclear there is no one for the respondent to ask for clarification, and as a researcher, you do not have the opportunity to ask followup questions. Hence, there are parameters that you as a researcher cannot control. Often the response rate is lower for questionnaires, which may create errors and skews because there will often be differences between those who answered and those who did not 
(Bryman, 2011). However, the empirical data collection in these studies did not intend to collect extensive data for the purposes of quantitative and statistical analysis; rather, the use of questionnaires was for more exploratory purposes. Hence, the characteristics of the results from the questionnaires were mainly descriptive.

The aim of using questionnaires in these studies was twofold. First, the objective was to use this method, in addition to the interviews, to collect further data on non-energy benefits. Second, it deepened our understanding by studying the problem from another perspective, but it also contributed to data triangulation by combining different datasets. In Paper V, a questionnaire was sent out to collect Swedish pulp and paper mills' views on the barriers to and drivers of energy management and to investigate how the mills have worked with and continue to work with energy management procedures. The questionnaire was designed to also include questions on the respondents' views on the possible non-energy benefits of energy management activities. Lessons learned from from the use of questionnaires in Papers II and IV were applied to the design of the part concerning non-energy benefits.

\subsubsection{Questionnaires to Swedish industrial manufacturing firms ${ }^{13}$}

In Paper II, the interview study was complemented by a questionnaire to collect data on non-energy benefits. The questions were intended to collect the respondents' experiences of non-energy benefits. The respondents were asked which benefits they had perceived in relation to the energy efficiency investments and measures implemented in their firms. The following questions concerned if and how non-energy benefits were included in the firms' investment assessments. These questions were formulated based on a table in which examples of non-energy benefits were given. Moreover, the respondents were also asked which capital budgeting tools were normally applied by the firm in its investment evaluations. The responses were mainly quantitatively analysed in a descriptive way, but the answers were also qualitatively analysed according to the research question posed.

The questionnaire was distributed to representatives of industrial firms during a one-day workshop for the firms participating in the PFE. Representatives participating in the workshop were working with PFE- and energy-related issues. The responses were collected on the same day by representatives from the Swedish Energy Agency, which organised the workshop.

\subsubsection{Questionnaire to energy auditors (experts) for compressed air systems}

The interviews conducted with the users of and the experts on compressed air systems sparked an interest in studying the possible non-energy benefits of the energy efficiency measures implemented for compressed air systems. Due to their experiences in auditing, implementing and evaluating energy efficiency projects of various types and sizes, energy

${ }^{13}$ A version of this sub-section was previously published in Nehler (2016). 
audit experts were chosen as respondents. To collect data on observed non-energy benefits, a questionnaire was constructed and distributed to independent energy audit experts (for background information on the respondents, see Table 8 above). The nonenergy benefits included and tested by the respondents were selected based on observed and reported industrial non-energy benefits in the previous studies on the topic (e.g. Finman and Laitner, 2001; Hall and Roth, 2003; Laitner et al., 2001; Lilly and Pearson, 1999; Lung et al., 2005; Nehler and Rasmussen, 2016; Pye and McKane, 2000; Worrell et al., 2003). All the non-energy benefits included in the questionnaire are listed in Paper IV.

The perceived non-energy benefits after the implementation of energy efficiency projects were investigated using a five-point Likert scale ranging from 1 ("strongly disagree") to 5 ("strongly agree"), including 0 if "indifferent". The first question asked about the benefits: "According to your aggregated experience of auditing plants and implementing energy savings projects in compressed air systems of all sizes and characteristics, to what extent do you agree or disagree with the following as perceived non-energy benefits as a result of the implementation of energy savings retrofit projects?" Further, to study the role of non-energy benefits as drivers, the respondents were also asked: "To what extent do you agree or disagree that non-energy benefits complement energy savings in the decisionmaking process?" This question was formulated on the same basis as the first question, i.e. by using the same five-point Likert scale and testing the same non-energy benefits.

\subsubsection{Questionnaire to Swedish pulp and paper mills}

In Paper V, data were collected by a questionnaire aimed at Swedish pulp and paper mills. The questions covered several topics, such as an assessment of the maturity of the mill's work with energy management (inspired by Carbon Trust, 2001), barriers to and drivers of energy management practices, benchmarking and the non-energy benefits of energy management. Utilising a questionnaire for the empirical data collection created an opportunity to retrieve the views of representatives from almost all of the pulp and paper mills in Sweden. In previous studies on barriers and drivers, the unit of analysis has been the decisions on cost-effective energy efficiency improvement measures. Since energy management comprises several other components as well, the unit of analysis in this study was broadened to include decisions on all energy management activities, including decisions on energy efficiency measures. At the beginning of the questionnaire, a definition of energy management was provided to ensure that all the respondents answered from the same viewpoint in terms of the concept of energy management. The definition was similar to the one offered by Schulze et al. (2016), but slightly shortened.

The additional effects of implemented industrial energy efficiency measures have been observed and demonstrated within and outside of industrial firms (e.g. IEA, 2012; Nehler and Rasmussen, 2016; Worrell et al., 2003), but the non-energy benefits of energy management activities have not been investigated. Björkman et al.'s (2016) study describes the additional effects observed by firms participating in the PFE. The 
participating firms were required to work with energy management and energy efficiency issues in a structured way, and their experiences formed the basis of the selection of benefits to test in the questionnaire. Statements were formulated based on the following additional effects: top management's and the organisation's interest in energy efficiency issues; energy performance measurement and evaluation; access to investment capital; additional/new personnel categories involved in energy efficiency issues; and employees' knowledge of energy efficiency. However, since these effects may also be viewed as parts or objectives of the energy management activities and not additional effects, the statements formulated sought to investigate if these additional effects had changed more than expected. This method of constructing the statements was used to enable these effects to be counted as additional effects, i.e. non-energy benefits.

Energy management activities consist of several components, and according to Schulze et al. (2016), one of these components considers the implementation of energy efficiency improvement measures. Therefore, the possible non-energy benefits of energy management might include the non-energy benefits of implemented energy efficiency measures. Hence, an overlap exists. Consequently, a few of the previously observed benefits of implemented energy efficiency measures were included in the questionnaire. These "classic" non-energy benefits were of various types to cover a range of benefit categories. The following non-energy benefits were tested among the respondents: improved external environment; cost reductions beyond energy cost reductions; improved corporate image; increased productivity; and improved work environment.

In total, using a Likert scale, 13 statements concerning non-energy benefits were included in the questionnaire to investigate the mills' perceptions of the observed benefits of their energy management activities. The scale ranged from 1 ("no change at all") to 7 ("substantial change").

The empirical data collection process started in March 2017 and ended in September 2017. During this period, 50 pulp and paper mills were operating in Sweden and initial contact was made with all the mills before sending out the questionnaire that aimed at finding the most relevant representative at the responding mills. The appointed respondents could thereafter choose between completing the questionnaire themselves or answering the questions in a structured interview over the telephone. Twenty-eight of the mills completed the questionnaire and one firm responded to certain parts, which gave a response rate of $56 \%$. For comparison, the response rate is similar to that of previous studies on barriers and drivers (e.g. Brunke et al., 2014; Thollander and Ottosson, 2010).

\subsection{Evaluation of quality criteria}

The quality of research is often evaluated according to quantitative criteria and concepts. General aspects to consider in this sense are: reliability, replication and validity 
(measurement validity, internal validity, external validity and ecological validity) (Bryman, 2011). Qualitative research methods have been criticised as subjective, difficult to replicate, not transparent in how they have been conducted and that qualitative results are difficult to generalise (e.g. Bryman, 2011; Denzin and Lincoln, 2013). Therefore, as a qualitative researcher, it is important to carefully describe how the research has been conducted and to describe the sampling and cases in detail. Bryman (2011) suggests that evaluating reliability, replication and validity by assessing the trustworthiness of a qualitative study would be more suitable. The aspects of trustworthiness can be divided into: credibility (similar to internal validity), transferability (similar to external validity), dependability (similar to reliability) and confirmability (similar to the role of objectivity) (Bryman, 2011). The methodological approach of the research presented in this thesis was both qualitative and quantitative. In this chapter, the quality aspects of the studies conducted in this thesis will be evaluated and discussed.

How qualitative research is defined has been vigorously disputed (Bryman, 2011). A qualitative researcher strives to capture reality in the most accurate way, and therefore he or she must be open to changes, which means that a flexible approach has to be taken (Bryman, 2011). Bryman (2011) further stresses that qualitative researchers strive to see and understand the world through the eyes of the study subjects and that their behaviour and views are affected by the surrounding environment. Therefore, the context of the study is very important and should thus be described thoroughly (Bryman, 2011; Creswell, 2013).

To grasp all these aspects, qualitative research typically applies more than one method in a study. Due to this diversity, it may be difficult to define a qualitative research process that holds for all qualitative studies, which might have created difficulties in explaining and defining qualitative research (Bryman, 2011). The use and combination of methods, i.e. the triangulation of methods, is one way to confirm that the research yields the "correct" interpretation of the context studied. For instance, triangulation can be applied to validate results by combining one quantitative method and one qualitative method (Bryman, 2011). In this thesis, data were collected through both interviews and questionnaires. The empirical data collection has been complemented with literature reviews. The application of such an approach, combining different samples and methods in the collection of data, is argued to strengthen the (internal) validity and the reliability (which corresponds to credibility and dependability in a qualitative research evaluation) (e.g. Creswell, 2009; Patton, 2015). In Paper IV, the concept of non-energy benefits was investigated among different actors, both energy audit experts and suppliers of compressed air systems, to capture their views on the perceived benefits with respect to energy efficiency measures for compressed air systems. Viewing the problem from several perspectives yields a deeper understanding, and since different datasets were combined, it also contributes to data triangulation. Furthermore, the experience gained by conducting several types of case studies with various types of data collection methods 
enriched the studies methodologically, which contributes to the confirmation of the results.

The generalisation of qualitative research, especially case studies, is often difficult since such research designs are often limited to a few cases which cannot represent all similar cases or situations. Qualitative studies rather consider the transferability of the results to other situations or contexts instead of generalisation. Since parts of the research presented in this thesis concerned firms with similar characteristics, for instance, energy use and affiliation with the Swedish industrial sector, it might be possible to transfer the results to other firms with similar characteristics in similar contexts. Furthermore, one element of the studies presented in this thesis has concentrated on a specific energy-using process: compressed air. This might be considered as a narrow scope, and the results may be difficult to generalise and transfer to other contexts. However, compressed air is a widely used industrial process among most industrial manufacturing firms. Although compressed air systems are adjusted to the situation and context in the specific firm, measures to improve efficiency and energy efficiency are the same and may to some extent generate similar non-energy benefits. Therefore, the findings in relation to compressed air may be transferable to other contexts in which compressed air is used.

The researcher's own values influence the research process. Even if objectivity is the goal, it is difficult to avoid subjectivity entirely and it may influence all steps taken in the research process. Hence, as a researcher, it is important to be aware of this and, if required, describe how subjectivity might affect the results. Bryman (2011) states that even if the findings should not be shaped by the values of the respondents or the researcher, absolute objectivity can be difficult to achieve. In this study, objectivity (described as confirmability in qualitative contexts) has been ensured by the parallel analysis of parts of the results, for instance. Furthermore, asking open questions in the interviews might be a way to minimise the transfer of the researcher's own values and influences on a topic. For example, in the interviews conducted, the respondents were given the opportunity to speak freely about non-energy benefits to avoid being affected by the researcher's bias on what is considered a benefit.

Although choices of methods are adjusted to fit the problem being studied, there will always be limitations. Non-energy benefits comprise a wide range of effects. In these studies, the respondents were (with a few exceptions) mainly energy managers or people in similar positions. The role of an energy manager is comprehensive as such, but collecting the views of people in other organisational roles (such as those responsible for financial issues or the work environment) in industrial firms may have provided additional or other types of results in relation to capturing the non-energy benefits. This might have limited the results with respect to the observation or evaluation of non-energy benefits. 
The studies of one energy-using process-compressed air-provided detailed knowledge on that specific process. However, knowledge on the non-energy benefits of that specific process may not be representative of or transferable to other types of specific industrial processes. An investigation of additional industrial processes would have broadened the scope of knowledge and enabled further opportunities for comparing different processes in relation to non-energy benefits.

Empirical data on the non-energy benefits of energy management activities were collected by questionnaires. The respondents answering questionnaires are constrained by the alternatives provided in them, which might have limited the results in these studies. The use of interviews as a data collection method, in which respondents could speak freely about the possible additional effects of practising energy management, may have offered a more comprehensive view of the results by indicating other types of nonenergy benefits.

\subsection{Methods applied in relation to the appended papers}

Table 10 below summarises the methods applied in relation to the appended papers.

Table 10. The methods applied in the papers appended to this thesis

\begin{tabular}{|c|c|c|c|}
\hline Paper & Literature review & Interviews & Questionnaire \\
\hline I & $\mathrm{X}$ & $\mathrm{X}$ & \\
\hline II & & $\mathrm{X}$ & $\mathrm{X}$ \\
\hline III & $\mathrm{X}$ & $\mathrm{X}$ & $\mathrm{X}$ \\
\hline IV & & & $\mathrm{X}$ \\
\hline V & & & \\
\hline VI & $\mathrm{X}$ & & \\
\hline
\end{tabular}

The literature reviews conducted in Papers III and VI were systematically conducted (as defined by Tranfield et al., 2003, for instance), whereas the literature review in Paper I should not be viewed as a systematic literature search. 


\section{Results and analysis}

In this chapter, selected results from the appended papers are presented and analysed. The presentation of the results is structured based on the three perspectives applied in the thesis: energy efficiency measures, energy efficiency investments and energy management activities.

\subsection{Non-energy benefits from the perspective of measures: The case of compressed air}

This perspective aimed to investigate industrial non-energy benefits in detail by focusing on one industrial energy-using process-compressed air-and the specific energy efficiency measures that can be undertaken to improve energy efficiency in compressed air systems. Firstly, the results regarding energy efficiency improvements and related non-energy benefits from Papers III and IV are provided. Thereafter, these results are complemented by results pertaining to the factors that may hinder and drive energy efficiency improvement measures in compressed air systems (from Paper IV).

\subsubsection{Energy efficiency measures in compressed air systems}

A compressed air system consists of several interconnected sub-parts. The sub-parts can be divided into supply-side parts and demand-side parts. Supply-side parts are involved in the generation or production of compressed air, some examples of which are the air inlet, compressor, ancillary equipment (e.g. filters) and heat recovery. Demand-side parts are involved in the use of air, some examples of which are the distribution system (piping) and equipment for end-use and systems management. Hence, compressed air systems are complex systems and alterations in one part of the system will often impact other parts of the system. Nonetheless, this complexity creates several opportunities for improving the energy efficiency of the system.

Paper III, which is appended to this thesis, reviewed the scientific literature with respect to energy efficiency measures for compressed air systems. The review discovered a number of various measures that could be undertaken to improve energy efficiency. The measures were divided into supply-side measures and demand-side measures and then further categorised according to the parts of the compressed air system targeted by the measures, i.e. the parts primarily impacted by the measures. In Figures 7 and 8, the energy 
efficiency measures identified in the review have been compiled for the demand side and the supply side, respectively.

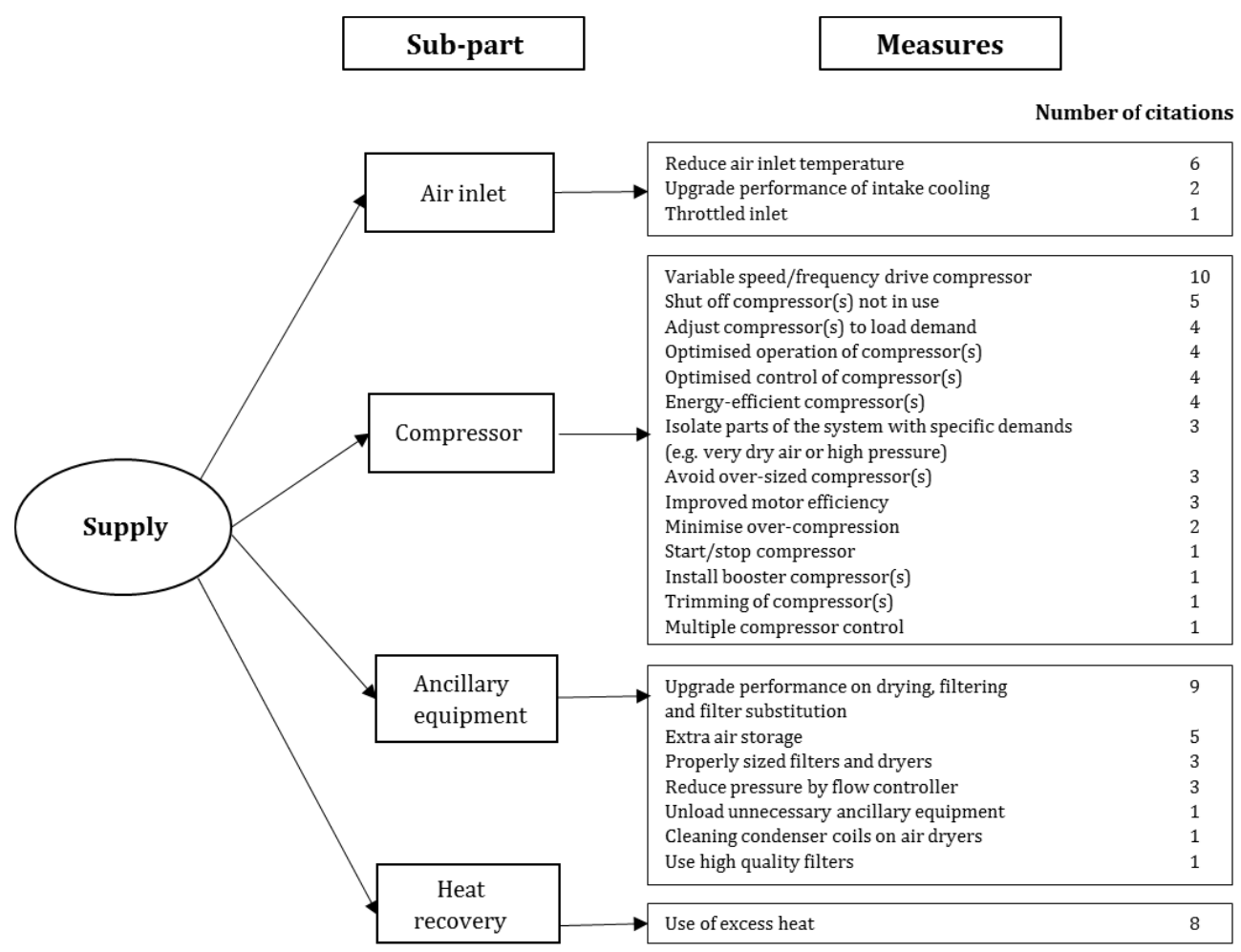

Figure 7. Energy efficiency measures on the supply side in relation to the targeted sub-parts of the compressed air system (revised from Nehler, 2018a, Paper III).

Moreover, the measures have also been quantified, i.e. by showing how many of the reviewed publications addressed specific measures. This is demonstrated in the numbers of citations displayed to the right in Figures 7 and 8. As can be seen in Figure 7, most of the measures on the supply side aimed at the compressor, with the variable speed drive compressor being the most frequently cited measure. Other commonly described supplyside measures were upgrading the drying and filter performance and the use of excess heat. Figure 8 shows that most of the demand-side measures were related to the distribution, with the reduction of leaks being the most frequently proposed measure for improving energy efficiency in compressed air systems. 


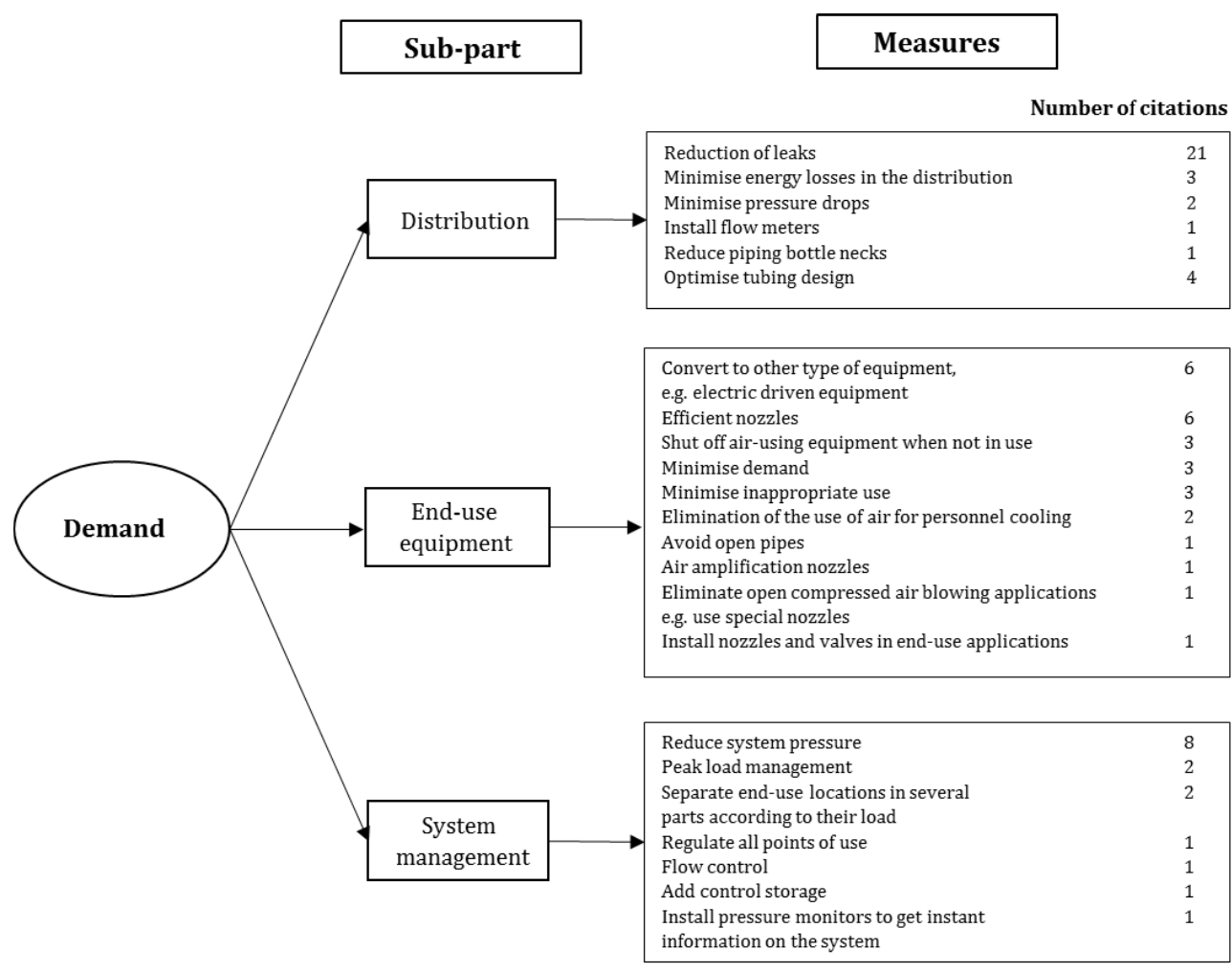

Figure 8. Energy efficiency measures on the demand side in relation to the targeted sub-parts of the compressed air system (revised from Nehler, 2018a, Paper III).

In general, measures carried out on the demand side aim at lowering the demand for compressed air. The supply side and the demand side-as well as all the sub-parts of the system-are interrelated. Therefore, demand side measures will affect the supply side and its sub parts. As a consequence, the demand on the compressor will for instance be lowered by carrying out demand side measures. The demand on the compressor will also be affected by measures undertaken on the supply side, for instance measures in air inlets and ancillary equipment. A lowered demand on the compressor and thereby a lowered working pressure obtained by the compressor will in turn decrease the amount of excess heat which further affect the amount of heat that can be recovered. Hence, the energy efficiency measures that can be implemented in a compressed air system are connected in various ways and will therefore have an impact on other measures and on other parts of the compressed air system.

The results of the literature review in Paper III thus revealed a variety of measures that can be carried out to improve energy efficiency in compressed air systems, but the studies included in the review did not address in which order measures should be implemented (cf. Björk et al., 2003). Since compressed air systems consists of many interrelated subparts and that measures can affect other parts of the system, this is may be an important 
aspect to consider. For instance, an analysis of artificial demand or reduction of air leakages is preferable made before the initiation of an investment in a new energyefficient compressor In addition, a comprehensive approach covering the entire compressed air system, was generally lacking in the reviewed publications. One explanation to the lack of a comprehensive approach could be that the studies focused on case-specific conditions. However, the categorisation of the measures as supply-side measures and demand-side measures and the division of the specific energy efficiency measures according to which sub-part of the compressed air system the measures are aimed, provides a comprehensive perspective which includes effects in the entire system. In addition, including the interrelations between sub-parts and between measures contributes to the perspective and to an understanding of where in the system the measures' effects will appear, which may minimise the risk of concentrating on certain parts when improving energy efficiency in compressed air system. Furthermore, these conditions also depict how, where and by whom the possible non-energy benefits of implemented energy efficiency measures in compressed air systems are observed.

\subsubsection{Non-energy benefits of compressed air energy efficiency measures}

In Paper IV, compressed air systems' energy efficiency measures were studied with respect to the process and the non-energy benefits of such measures. Empirical data on non-energy benefits were retrieved from energy audit experts on compressed air systems and from suppliers (salespersons) of compressed air systems and their related equipment. 


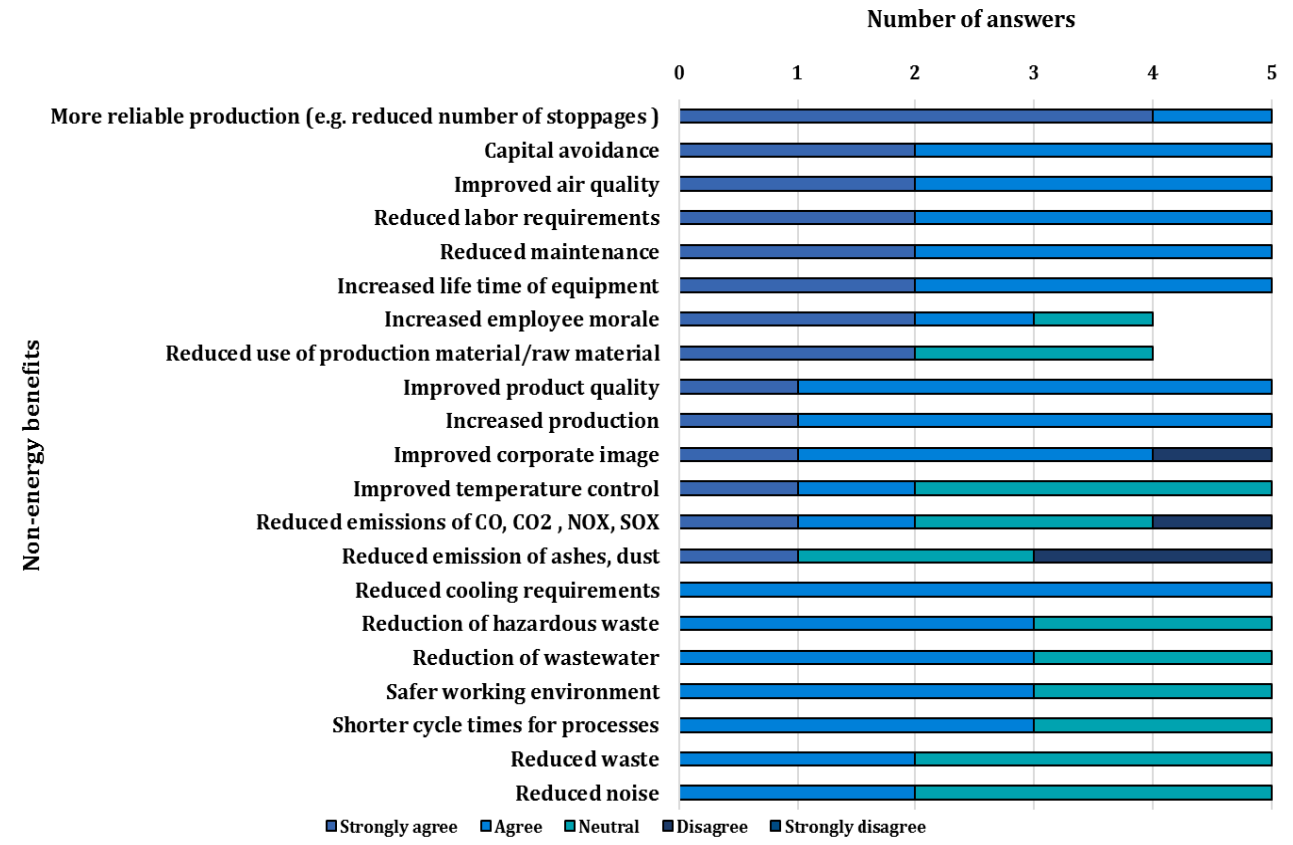

Figure 9. Ranked non-energy benefits of energy efficiency measures in compressed air systems as perceived by energy audit experts (revised from Nehler et al., 2018, Paper IV).

As shown in Figure 9, the experiences of the energy audit experts revealed that the main non-energy benefits of improving energy efficiency in compressed air systems were: more reliable production (e.g. a reduced number of stoppages), capital avoidance, improved air quality, reduced labour requirements and reduced maintenance. The energy audit experts were not asked to relate the benefits to specific measures, but all of them agreed that these were important additional effects resulting from the energy efficiency measures implemented in compressed air systems. The experts saw capital avoidance as the secondmost important benefit. Handling the workload on the compressor by implementing energy efficiency measures might be a means to circumvent investment in new compressors, for instance. The three other main non-energy benefits are in many ways related to the operation of a compressed air system and indicate a well-functioning system. For instance, regular maintenance of ancillary equipment is an energy efficiency measure that leads to both an energy efficient process and an efficient system, which may deliver non-energy benefits such as improved air quality, reduced labour requirements and reduced maintenance. Indirectly, these benefits may also lead to a more reliable production of air, which might have contributed to the high ranking of that effect. Other benefits ranked highly by the experts were: increased lifetime of equipment, increased employee morale, reduced use of production/raw materials, improved product quality, increased production and improved corporate image. 
From this collection of perceived non-energy benefits it can be seen that many of them have an impact on production, i.e. the production of compressed air, but a wellfunctioning air production system affects the reliability of a firm's production in general, which in turn can improve the firm's overall productivity. The same applies for the benefits that are related to the operation and maintenance of the system. Capital avoidance is an economic non-energy benefit, while the remainder of the benefits are related to the equipment (increased lifetime), to behaviour (increased employee morale) or are impactful in other ways outside of the firm (improved corporate image). To conclude, the perceived non-energy benefits were of various kinds and affect different parts of the operating system and various actors in relation to the compressed air system or the firm.

The suppliers of compressed air systems and related equipment were interviewed and asked about their experiences of the possible non-energy benefits of specific measures aimed at improving energy efficiency in various parts of the compressed air system. In Table 13, the measures considered and the related non-energy benefits (as perceived by the interviewees as a consequence of the implementation of the measures) are presented. 
Table 13. Non-energy benefits of specific energy efficiency measures for compressed air systems as perceived by the suppliers of compressed air systems (revised from Nehler et al., 2018, Paper IV).

\section{Measure Perceived non-energy benefits}

Convert to electric-driven tools

Sealing of leaks

Heat recovery

System management (e.g. VSD)

Reduced system pressure (e.g. avoidance of oversized system pressure)

Maintenance of ancillary equipment (filters, dryers, etc.)

Air inlet (lower temperature, better air quality, etc.)

End-use equipment
Improved positioning and power management Improved control of acceleration/deceleration

Decreased demand on the compressor

Less compressor back-up capacity

No need to invest in a new compressor due to demand or an increased demand is managed by sealing leaks Less noise, i.e. an improved work environment Stable pressure which leads to improved quality of products/production

Fewer cooling requirements Lower temperature, i.e. improved work environment

Less fluctuation in air production

Stable pressure

Improved efficiency in the production of compressed air Increased stability of the system, i.e. a balanced system

Investments in smaller capacity or no need to invest in a new compressor due to demand Fewer unplanned disruptions or stops in the production Less wear and tear on the compressor and on other equipment

Stable pressure, which leads to improved product/production quality

Improved air quality

Fewer disturbances in the operation

Reliable operation/production and fewer unplanned production stops/disturbances

The correct air quality and temperature creates less wear and tear on system equipment

Less noise, i.e. improved work environment

Safer work environment

Increased lifespan of the compressor, i.e. investment in a new compressor will be delayed

The suppliers' perceptions of non-energy benefits add more detail to the results on energy efficiency improvement measures in compressed air systems by relating the benefits to specific measures. Based on the suppliers' experiences, their answers indicate which nonenergy benefits can be observed after the implementation of a specific energy efficiency 
measure in a compressed air system. However, this only reflects the views of the suppliers. Other actors, such as users, might have other experiences of the additional effects of specific energy efficiency measures depending on their role, such as the operators of compressed air systems, and where in the firm the actors are situated. The same applies to the energy audit experts.

Nonetheless, the results on the non-energy benefits of measures in compressed air systems (based on the views of the experts as well as the suppliers) demonstrated a spread among the perceived non-energy benefits and showed that one energy efficiency measure, for instance a reduced system pressure, can not only give rise to several nonenergy benefits in various parts of the compressed air system (e.g. reliable production, less wear and tear and stable pressure) but also offer benefits outside of the system (e.g. improved work environment and capital avoidance). Although only one processcompressed air-was investigated with respect to observed non-energy benefits, the results align with the previous literature on the subject: non-energy benefits comprise a variety of effects that may impact several areas of an industrial firm. Compressed air represents a complex process with several interrelated sub-parts. Consequently, the energy efficiency measures implemented in one part of the system may have an impact on other parts, which might contribute to the variety among perceived non-energy benefits. In addition, the relationships between the sub-parts and corresponding measures for a compressed air system entail relations among the non-energy benefits, i.e. that one benefit gives rise to one or several other benefits. Hence, there are primary nonenergy benefits that yield secondary effects, i.e. secondary non-energy benefits. However, a comprehensive view of energy efficiency improvements in compressed air systems must be applied in order understand how measures and additional effects relate to each other and also to enable recognition of all the benefits.

\subsubsection{Perceived barriers to compressed air energy efficiency measures}

To understand what affects the implementation and adoption of energy efficiency improvements it is important to study the barriers to energy efficiency on various levels. In Paper IV, the barriers to energy efficiency improvements for one industrial process, compressed air, were studied from the perspectives of the users (energy managers) of and experts (energy auditors) on compressed air systems. 


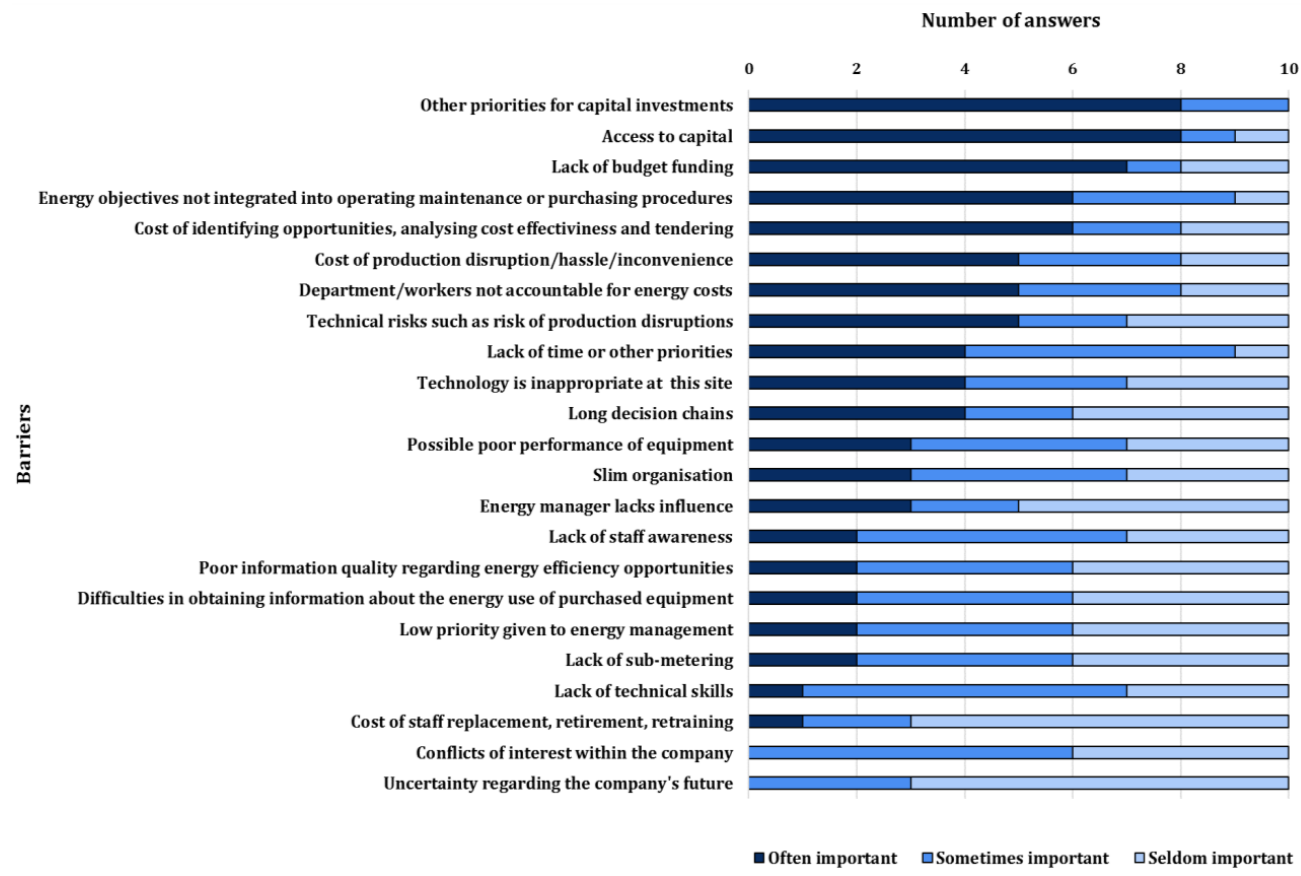

Figure 10. Ranked barriers to the implementation of energy efficiency measures in compressed air systems as perceived by energy managers and energy audit experts (revised from Nehler et al., 2018, Paper IV).

As presented in Figure 10, the main barriers perceived by the respondents were other priorities for capital investments, access to capital, lack of budget funding, energy objectives not integrated into operating maintenance or purchasing procedures, the cost of identifying opportunities, analysing cost effectiveness and tendering and the cost of production disruption, or hassle or inconvenience. With the exception of the energy objectives not integrated into operating maintenance or purchasing procedures, which is of organisational type, all of these barriers have an economic character and are more or less related to investment in energy efficiency measures. In previous research, economic and financial factors have been stressed as hindrances to the implementation of energy efficiency measures in general (e.g. Brunke et al., 2014; Fleiter et al., 2012; Harris et al., 2014; Thollander and Ottosson, 2008; Venmans, 2014), and they have also been found to hamper financial analyses in decision-making processes on energy efficiency improvements (Trianni et al., 2016). Since economic barriers were ranked highly by the respondents, this puts a certain focus on the implementation of measures with behavioural and operational characters, i.e. measures that are typically low-cost measures with short payback periods. The barrier energy objectives not integrated into the operating maintenance or purchasing procedures and the barriers ranked as being of medium importance by the users and the experts, such as department/workers are not accountable for energy costs, long decision chains and slim organisation, were mainly of an 
organisational character. These factors have been emphasised by previous studies as barriers to energy efficiency technology measures in general (e.g. Lee, 2015; Rohdin et al., 2007; Thollander and Ottosson, 2008).

In Paper IV, the suppliers' views of barriers were also explored. According to the suppliers, barriers to the implementation of energy efficiency improvements in compressed air systems were mainly related to organisational issues, stating that energy efficiency is not the core business, a lack of support by top management for energy efficiency projects for compressed air systems, other energy efficiency projects are chosen instead, and lack of foresight on the part of the decision-makers in the firm.

In sum, the views of the users and the experts indicated that measures to improve energy efficiency in compressed air systems seem to be hindered mainly by economic issues, while the suppliers stressed that organisational factors are the most significant hurdles. These results differ from the findings of a recent study which demonstrated that informational factors are the main barriers to implementing specific measures in compressed air systems (Cagno and Trianni, 2014). However, the perception of barriers was shown to vary depending on firm size, region and the type of industrial activity (e.g. Cagno et al., 2013).

\subsubsection{Perceived drivers for compressed air energy efficiency measures}

In Paper IV, the drivers for making energy efficiency improvements to compressed air systems were also studied from the perspectives of users (energy managers) and experts (energy auditors) (see Figure 11). Ranked highest and second highest were organisational drivers: commitment from top management and people with real ambition. The driver ranked third highest was of an economic character-cost reductions from lowered energy use-and was followed by several organisational drivers: long-term energy strategy, energy management system and the threat of rising energy prices. 


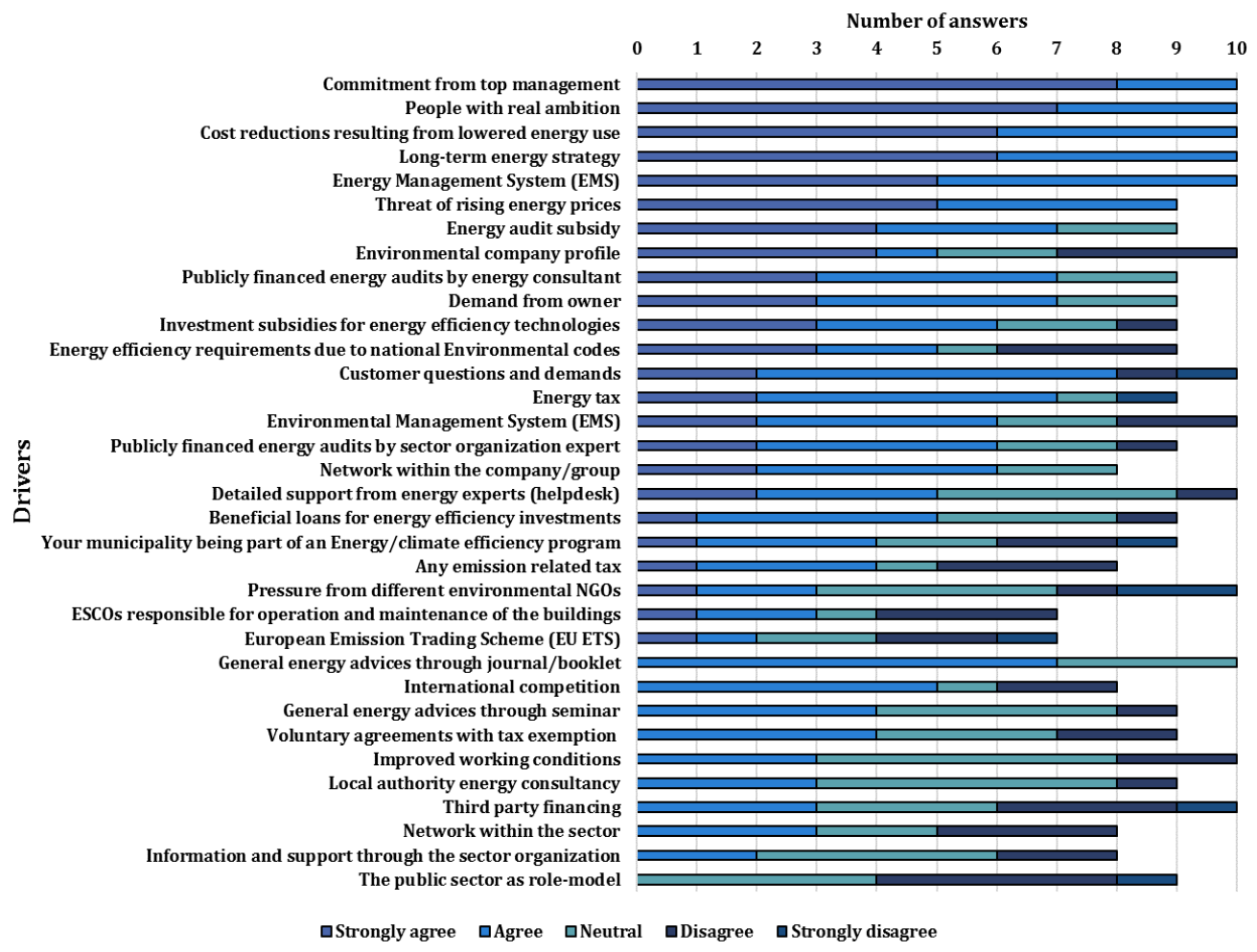

Figure 11. Ranked drivers of the implementation of energy efficiency measures in compressed air systems as perceived by energy managers and energy audit experts (revised from Nehler et al., 2018, Paper IV).

The interviews with the suppliers of compressed air systems revealed similar drivers to those expressed by the users and the experts: people with real ambition, long-term perspective on energy efficiency measures for compressed air systems, high profitability (short payback periods), inclusion of energy efficiency in the budget and understanding the potential of the energy efficiency measures.

People with real ambition, long-term energy strategy and the threat of rising energy prices are drivers that have been ranked high in previous studies on the drivers of energy efficiency technology measures (e.g. Apeaning and Thollander, 2013; Cagno and Trianni, 2013; Hasanbeigi et al., 2010; Lee, 2015; Rohdin et al., 2007; Thollander et al., 2013; Thollander and Ottosson, 2008). Furthermore, economic drivers related to energy efficiency measures for compressed air systems have also been stressed previously (Trianni et al., 2016). 


\subsection{Non-energy benefits from the perspective of investments: The case of energy efficiency investments}

Section 6.2 covers Papers I's and II's findings on energy efficiency investments in Swedish industrial firms based on interviews with representatives from those firms. In addition, this section presents the results on their perceptions of non-energy benefits in relation to energy efficiency investments-specifically, if and how non-energy benefits are acknowledged in the decisions made on energy efficiency investment in large Swedish industrial firms. This section concludes with the findings on what hinders the inclusion of non-energy benefits in making investment decisions on energy efficiency. Versions of the results in sub-sections 6.2.1-6.2.4 have previously been published in Nehler (2016), which had a pronounced investment focus on energy efficiency and non-energy benefits.

\subsubsection{Investment motives}

Paper II explored the motives behind industrial firms' investments. Investments related to production or capacity (for instance, the removal of bottlenecks), were stated as the most common (see Table 14).

Table 14. Frequency of investment categories as stated by the responding firms (revised from Nehler and Rasmussen, 2016, Paper II).

\begin{tabular}{ll}
\hline Investment category & Frequency \\
\hline Production or capacity & 9 \\
Energy efficiency & 6 \\
Work environment, health and safety & 4 \\
Replacement or maintenance & 3 \\
Quality improvements & 2 \\
Change in product or product mix & 2 \\
Environment & 2 \\
\hline
\end{tabular}

Six firms out of 13 stated that energy efficiency could be a motive for making investments in new technology. However, at the same time, three of the 13 firms stated that it was often difficult to base their energy efficiency investments on energy savings alone. Hence, these investments were commonly combined with other motives, such as improvements in production, in order to meet the thresholds for the investment to be approved. This is in line with the work of de Groot et al. (2001), who found that energy is just one of the parameters that is considered when making investments in new technology (i.e. other factors are often included when considering making investments in new technology, such as increased capacity and improved product quality). This also addresses what was previously stressed by Sandberg and Söderström (2003), which is that energy efficiency investments are not always pure energy efficiency investments. Other investment motives stated by the respondents were work environment; health and safety; replacement or maintenance; quality improvements; change in product or product mix; 
and environment. In addition to the investment motives stated above, the firms stressed that cost savings in general was an underlying motive for most of their investment decisions. The importance of the link to core business is also demonstrated in this study's findings - the most commonly stated investment motives relate to production or capacity, followed by a change in the product or product mix, which was also stated as an investment motive. Hence, these results corroborate Cooremans' (2012) previous findings; among the Swiss firms studied, the most common investment categories stated by the firms were related to core business.

\subsubsection{Investment process}

Paper II also investigated the investment processes at the studied firms. Normally, their investments followed the steps of identification, analysis, evaluation and implementation, which is similar to the investment decision-making model described by Cooremans (2012), even if there were some deviations among them. Energy efficiency investments passed through the same phases as other types of investments in the firms; in other words, energy efficiency investments were not handled differently. The initiation of investments varied. They could be initiated by the firm's personnel, or, in the case of energy efficiency investments, they could be initiated by an energy auditor. Most firms stated that the following phase, the analysis of the investment, was often based on a prestudy or a pilot study. In the subsequent phase, the evaluation of the investment, the studied firms normally used one or more evaluation methods, among which the PB method was predominant. The evaluation phase was followed by completing the investment proposal, or deciding the basis for the investment decision, which was then presented to the firm's management.

\subsubsection{Factors affecting the adoption of energy efficiency investments}

From the results of the interviews and the questionnaire reported in Paper II, the PB period appeared to be the method most commonly applied by the firms to evaluate investments. The answers implied that this method was generally used for the screening of investments in the early phases. The PB method was also used in combination with other tools, like NPV. Or, as stated by one of the firms, the PB method was used for smaller investments while other methods, such as NPV, were used for larger investments. As single methods, NPV and IRR were applied by the firms, but to a lesser extent. The findings above describing the firms' use of the capital budgeting tools in relation to energy efficiency investments are similar to previous findings (e.g. Harris et al., 2000; Sandberg and Söderström, 2003). Furthermore, some firms also addressed their use of life cycle cost (LCC). This was a required method for making energy efficiency investments within the PFE, which was a program for improving industrial energy efficiency in the Swedish electricity and energy-intensive sectors in which several of the investigated firms had participated. 
The results showed that investment decisions were made on different levels in the organisation; larger investments often required decisions to be made on a higher organisation level. Hence, the size of the investment seemed to be one factor influencing the adoption of investments, including energy efficiency investments. However, profitability and short PB periods appeared to be the most critical factors determining whether investments would be approved. Several firms stated that a PB period of 1 to 3 years was not an uncommon requirement for investments to be adopted. In some cases, a PB period of one year was required for the investment to pass approval, which underlines the importance of profitability for a proposed investment to pass to the adoption phase. This is in line with Fleiter at al.'s (2012) and Trianni et al.'s (2014) findings that short PB periods increase the adoption rate of energy efficiency investments. Moreover, the use of strict investment criteria for energy efficiency investments has previously been asserted by Qiu et al. (2015) and Abadie et al. (2012) among others.

\subsubsection{Non-energy benefits of energy efficiency investments}

Paper II studied large Swedish manufacturing firms' perceptions of non-energy benefits; i.e. if those firms had perceived any additional effects after their implementation of energy efficiency investments. The study did not aim to relate the benefits to specific measures; rather, the objective was to get an overview of the perceived existence of possible nonenergy benefits. As demonstrated in Figure 12, the results of the interviews conducted (Paper II) showed that a number of non-energy benefits were stated by the respondents. 


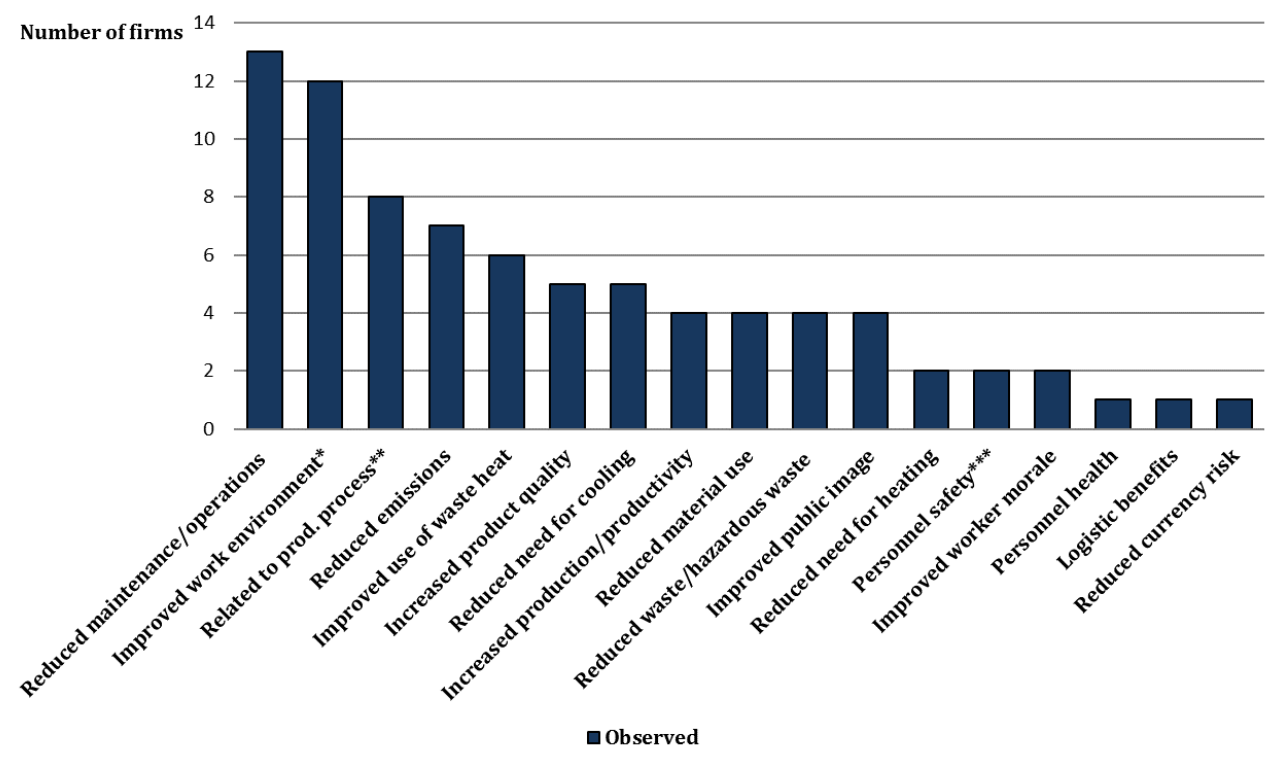

Figure 12. Industrial non-energy benefits as perceived by the interviewed firms (revised from Nehler and Rasmussen, 2016, Paper II). * This benefit includes reduced noise, improved air quality, reduced heat, improved lighting, improved indoor environment and improved temperature control. ** This benefit includes longer equipment lifetime, reduced wear and tear, reduced scrap, fewer production disruptions, process stability and improved reliability in production. ${ }^{* * *}$ This benefit includes fewer accidents due to improvements in the work environment and fire protection.

As Figure 12 shows, the interviewees reported that the most commonly observed benefits were benefits related to operation, maintenance, work environment, emissions and production, of which benefits related to operation and/or maintenance and work environment were observed by almost all of the interviewed firms. The study in Paper II was also based on questionnaire responses, and the results from the questionnaires showed similar results; among the most commonly observed non-energy benefits were, according to the respondents, benefits related to production (e.g. improved productivity and product quality); operation and maintenance (e.g. reduced maintenance); and work environment (e.g. lower noise levels). Although there might have been differences in which types of non-energy benefits were reported and how, the observed non-energy benefits in this study were similar to those observed in the previous literature on the subject (e.g. Finman and Laitner, 2001; Hall and Roth, 2003; IEA, 2012; Lilly and Pearson, 1999; Pye and McKane, 2000; Worrell et al., 2003). Furthermore, the non-energy benefits observed after the firms' energy efficiency implementations also showed similarities with respect to the variety of effects that were perceived to impact several different areas of the firms. 


\subsubsection{Monetisation and inclusion of non-energy benefits in energy efficiency investments}

In Figure 13, the firms' views on monetisation are compiled in relation to the non-energy benefits perceived. As can be seen, even though several non-energy benefits were observed by the interviewed firms, only a few of the interviewees stated that non-energy benefits were monetised.

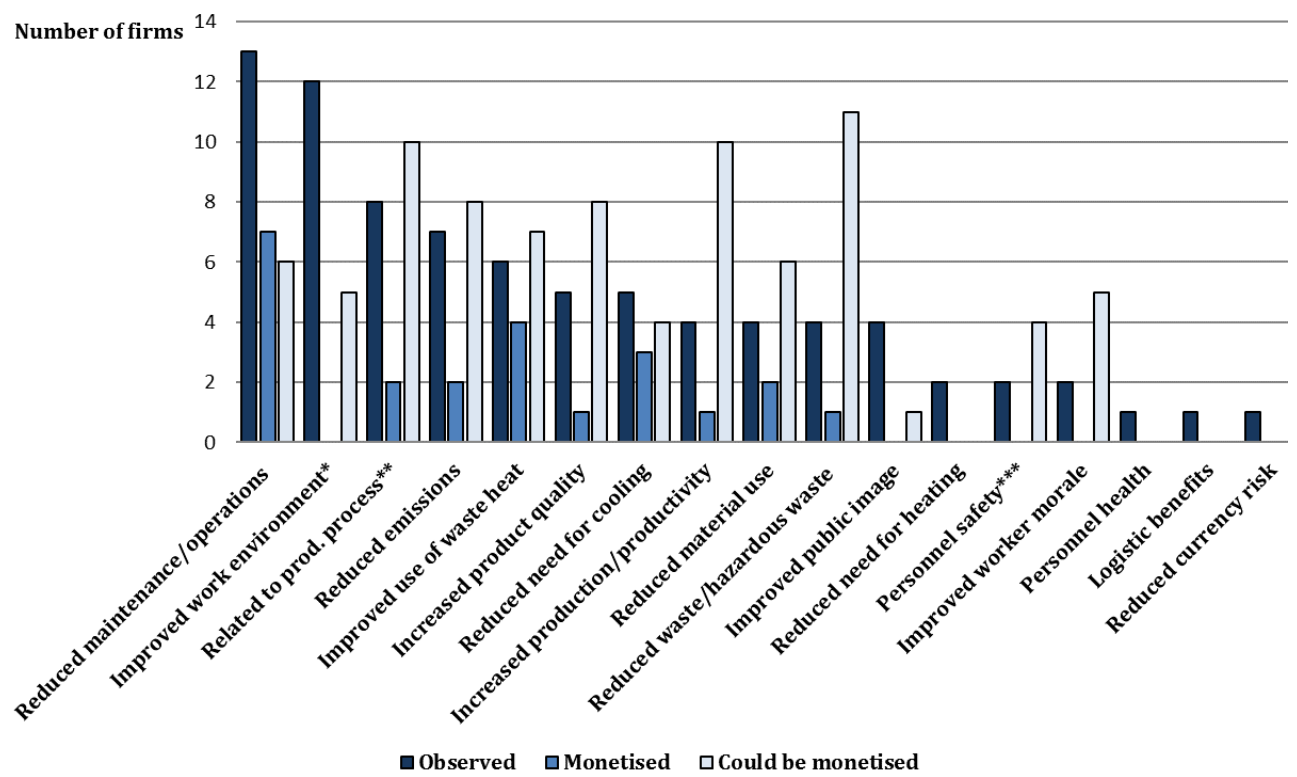

Figure 13. Industrial non-energy benefits and their monetisation as perceived by the interviewed firms (revised from Nehler and Rasmussen, 2016). * This benefit includes reduced noise, improved air quality, reduced heat, improved lighting, improved indoor environment and improved temperature control. ${ }^{* *}$ This benefit includes longer equipment lifetime, reduced wear and tear, reduced scrap, fewer production disruptions, process stability and improved reliability in production. ${ }^{* * *}$ This benefit includes fewer accidents due to improvements in the work environment and fire protection.

Reduced operation and maintenance, improved use of waste heat and reduced need for cooling were the non-energy benefits that firms stated were most frequently monetised. Approximately half of the observed non-energy benefits were not monetised at all, indicating that they were not included in investment calculations, which was also confirmed by the firms. For instance, non-energy benefits related to the work environment and health were not monetised at all by the firms. In addition, the interviewees considered benefits related to health to be difficult to monetise. However, the responding firms were still receptive to monetising other of the observed non-energy benefits; the interviewees frequently stated that it would be possible to monetise many of them. 
In relation to the observed non-energy benefits, the interviewed firms also gave suggestions on how non-energy benefits could be monetised, based on how the benefits could be measured. From their suggestions, it appeared that many of the non-energy benefits can be considered cost reductions, such as reduced material costs and reduced salary costs, but also cost avoidances, for instance, less sick leave and reduced costs for silencers and noise enclosures. On the other hand, according to the respondents, some of the benefits could also be observed and measured through increased revenue such as increased production and increased productivity.

\subsubsection{Barriers to inclusion of non-energy benefits in decisions on energy efficiency investments}

The studies reported in Papers I and II provided insights on whether and how large Swedish firms acknowledge non-energy effects in their investments in energy efficiency improvements. Based on interviews with representatives from the firms, it appeared that even though such effects were recognised, only a few of the non-energy benefits were included in their investment calculations or decisions on energy efficiency investments. The study described in Paper I investigated the reasons for this non-inclusion. In Table 15 , the results on barriers to inclusion are summarised.

Table 15. Barriers to inclusion of non-energy benefits in decisions on energy efficiency investments as perceived by Swedish industrial firms.

\section{Barrier}

Risk

Split incentives

Access to capital

Imperfect information

\section{Interview responses in relation to the barriers}

Low reliability of the data on the monetary value of the nonenergy benefits; calculations are perceived as not credible if based on assumptions and estimations. This barrier was not perceived as a main barrier to inclusion.

One person has relevant information about possible nonenergy benefits, for instance, but others cannot be convinced since the benefits are not translated into monetary value. This barrier was not perceived as a main barrier to inclusion.

This barrier was not perceived as a main barrier to inclusion by any of the respondents.

A lack of data on the monetary value of non-energy benefits or a lack of metering to enable the quantification of non-energy benefits. A lack of metering also contributes to other difficulties, for instance, to refer a benefit to a certain energy efficiency improvement measure. Moreover, a lack of information on how to translate benefits into monetary value regarding benefits related to the work environment, for instance. 
Hidden costs

Bounded rationality
Retrieving information on how to translate the value of nonenergy benefits into monetary terms might be associated with higher costs than the corresponding savings from non-energy effects.

Often, organisations and individuals do not base their decisions on complete information; rather, they act according to a "rule of thumb". For instance, new solutions are not tested, and previous solutions to similar problems are chosen instead.

According to the interviewed firms, the main barriers to inclusion were related to imperfect information, hidden costs and bounded rationality. It should be noted that the barriers above may be related to each other. For instance, comments on imperfect information can also be sorted under the barriers of hidden costs and bounded rationality; a lack of data on how to measure and monetise is due to associated hidden costs and new models for such purposes are not developed. Moreover, searching for information on how to do this is time-consuming and costly. Since any possible gains associated with the nonenergy benefits are then unknown, established procedures are followed instead and the development of new ways to improve decision-making on energy efficiency improvements with the benefits mentioned are hence not prioritised. To conclude, the main factors preventing the inclusion of non-energy benefits in decisions on energy efficiency investments seem to be a lack of information and a lack of metering of nonenergy effects.

\subsection{Non-energy benefits from the perspective of energy management activities: The case of energy management}

In Paper V, the perspective of non-energy benefits was broadened to include not only the benefits of energy efficiency measures and investments but also the possible benefits stemming from other activities aiming at improved energy efficiency, i.e. energy management activities. Swedish pulp and paper mills' perceptions of the possible nonenergy benefits of energy management activities were studied. The study included an investigation of both "classic" non-energy benefits (i.e. the non-energy benefits of implemented energy efficiency measures and investments) and the possible additional effects of the implementation of energy management activities and practices in an industrial firm.

In Figure 14, the mean values for the studied benefits ranged from just above 3 to slightly more than 4 , which shows that the mills generally observed positive changes for all the benefits studied due to the mills' work with energy management practices. 


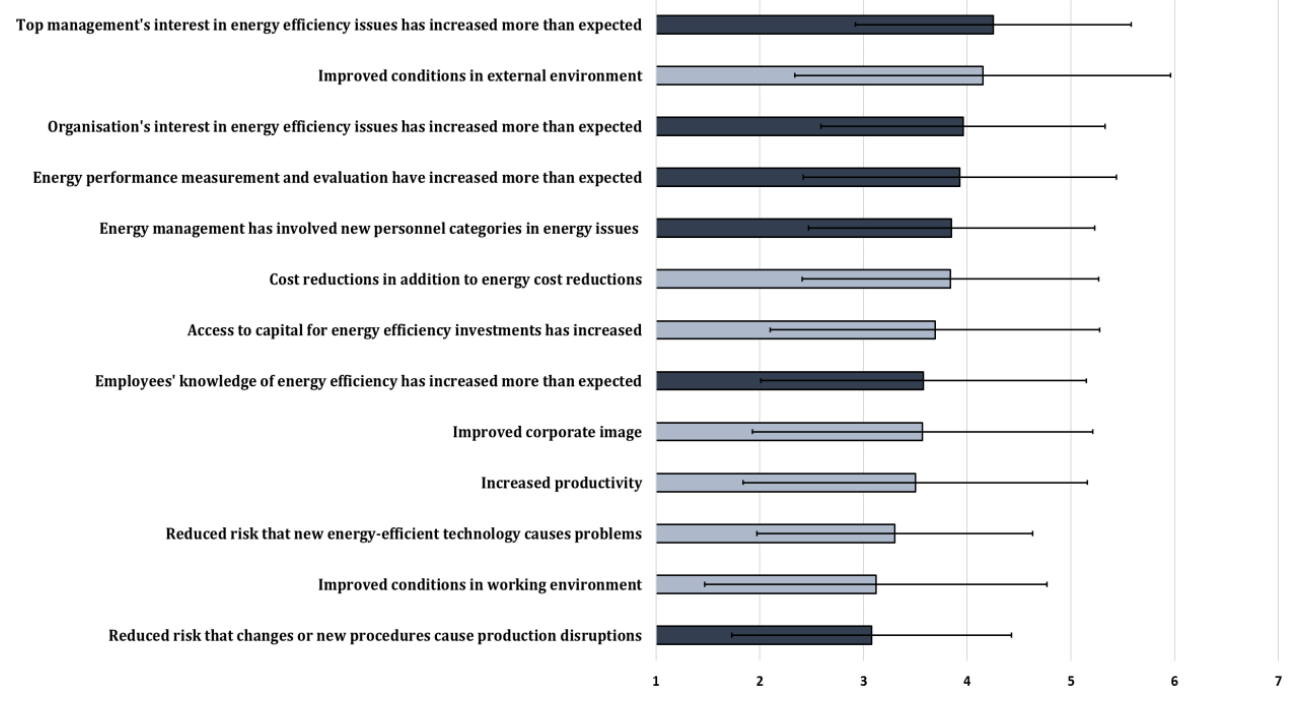

Figure 14. The non-energy benefits of energy management activities as perceived by the pulp and paper mills, using a Likert-type scale ranging from 1 (no change at all) to 7 (substantial change). Dark colour: energy management-related non-energy benefits; light colour: classic non-energy benefits; lines in bars: the standard deviation (revised from Andersson and Nehler, 2018).

The results show that the views of the respondents speak to an increased interest in energy efficiency issues on different levels within the mills' organisations as a consequence of the energy management activities conducted; among the non-energy benefits tested, benefits ranked highly by the mills studied were an increased interest in energy efficiency issues by top management (ranked first), an increased interest in energy efficiency issues in the organisation in general (ranked third) and energy management's involvement of new groups of personnel in energy issues (ranked fifth).

The second highest non-energy benefit stated by the pulp and paper mills was improved conditions in the external environment as a result of energy management. Pulp and paper mills are in various ways restricted and affected by environmental laws and regulations, some of which are related to energy and energy efficiency improvements in particular, which might have contributed to and influenced their greater awareness of the additional effects that improved energy efficiency might have on the external environment. The respondents who filled out the questionnaire were typically responsible for energy issues within the mills, but their roles were sometimes combined with other environmental responsibilities in the company that could have contributed to their particular focus on and awareness of environmental benefits in relation to energy management. Increased energy performance measurement and evaluation due to energy management activities was ranked fourth by the pulp and paper mills, and the benefits related to financial issues were also ranked relatively highly, i.e. cost reductions in addition to energy cost reductions and increased access to capital for energy efficiency investments. 
The results indicate slightly higher values for the energy management-related non-energy benefits (dotted bars) as compared to the values for the classic benefits (white bars). Hence, the mills have perceived not only classic non-energy benefits but also (to a slightly higher degree) novel non-energy benefits due to energy management practices and the energy management activities implemented. It should be noted that the mills' answers varied, i.e. there was a spread with regard to the extent to which the benefits were perceived. This can be seen in the relatively large standard deviations shown in Figure 14. Therefore, some of the mills did not perceive changes in these effects at all, whereas others observed significant changes. The deviations might be explained by the degree of implementation of energy management in the mills or if certain dimensions of the mills' energy management were more prominent than others. The spread might also be affected by the respondents' opinions of what is and what is not a benefit.

The results address a certain focus on two of the dimensions of energy management according to Schulze et al.'s (2016) model: organisation and culture. For instance, top management's involvement and support and the integration of energy efficiency issues in the organisation might have involved and motivated new staff in working with energy efficiency issues due to the implementation of energy management activities and practices. 


\section{Discussion}

In this chapter, the results of this thesis are discussed and analysed through the three perspectives on energy efficiency and non-energy benefits that have been applied throughout the studies: energy efficiency measures, energy efficiency investments and energy management activities. The chapter ends with a discussion on combining the perspectives.

The results of this thesis have demonstrated that energy efficiency improvements yield not only the planned or expected energy effects but also many other additional effects, known as non-energy benefits. Perceptions of these non-energy benefits, including their roles and potential impact on making decisions on energy efficiency improvements, were in this thesis studied from three perspectives: non-energy benefits in relation to the specific energy efficiency measures of one specific energy-using process (compressed air), non-energy benefits in relation to investments in energy efficiency and non-energy benefits in relation to energy management activities. In Figure 15, the relationships between the three perspectives of energy efficiency improvements and non-energy benefits are displayed.

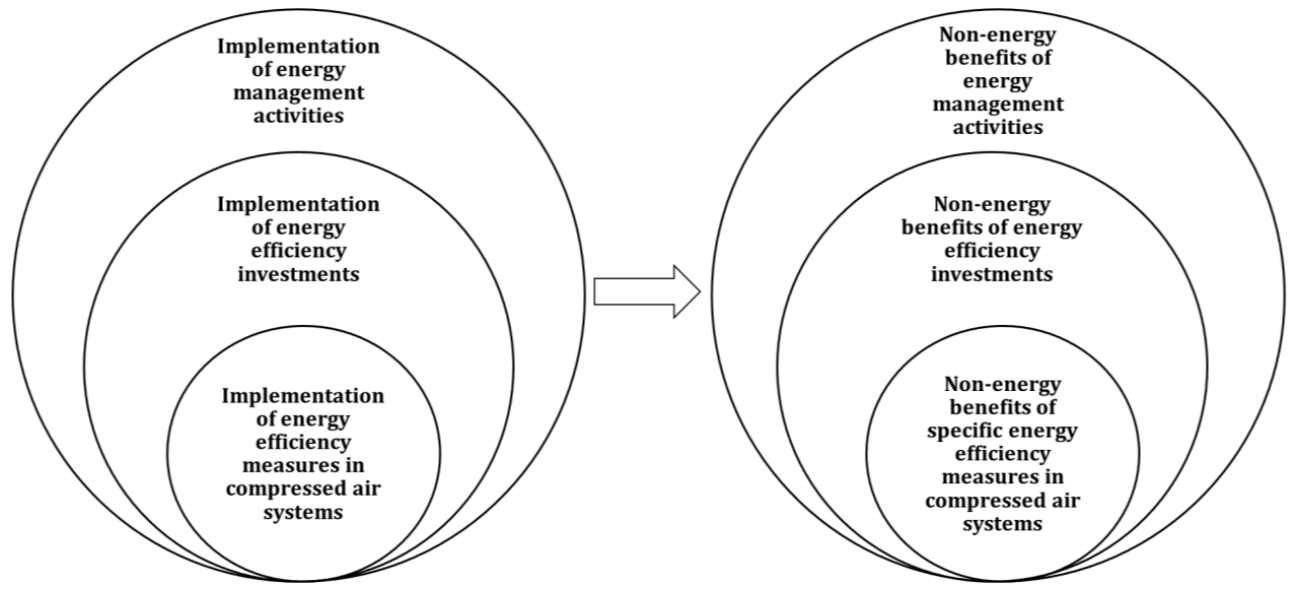

Figure 15. The relationship between the implementation of different energy efficiency improvements and non-energy benefits. 
Energy management practices do not only comprise managing energy efficiency issues by various organisational, strategic and controlling activities, it also involves the implementation of different kinds of energy efficiency measures and investments (Schulze et al., 2016). Therefore, energy efficiency investments and measures can be seen as subsets of energy management activities. However, specific measures for improving energy efficiency, in for instance compressed air systems, are not always investments, i.e. all measures are not associated with an investment cost or require a thorough assessment before the decision on them. Hence, specific energy efficiency measures for compressed air should not be seen as a subset of energy efficiency investments. Instead, the circles displayed in Figure 15 aim to illustrate that the perspectives are different with respect to the detail with which they describe energy efficiency improvements. The same reasoning is applicable to the perspectives on non-energy benefits. Hence, Figure 15 aims to illustrate that different perspectives on energy efficiency improvements lead to different perspectives on non-energy benefits, which is indicated by the arrow in the middle, and hence yield different results regarding perceptions of non-energy benefits.

In the sections below, based on the results presented in this thesis, the roles and potential of non-energy benefits will be discussed from the three perspectives on energy efficiency improvements applied: measures of one specific energy-using process (compressed air), investments and energy management activities.

\subsection{Measure perspective}

This perspective placed a certain focus on energy efficiency measures and in particular the related non-energy benefits of one specific industrial process: compressed air. Even though the investigation of one specific industrial process represents a rather narrow perspective, the case of compressed air nonetheless demonstrated several valuable results and considerations. The results of the study presented in Paper III revealed that many different measures could be undertaken to improve energy efficiency in compressed air systems. The measures were summarised and categorised, which showed that the energy efficiency measures aimed at many zones of the system which created a diversity among which measures that can be undertaken to improve energy efficiency. Systems for compressed air not only consist of various interrelated sub-parts, but compressed air is also, as regards energy, an inefficient process as such. These factors might explain the existence of several opportunities for energy efficiency improvements to be made in compressed air systems and also the diversity among them. Furthermore, since the sub-parts are connected, many energy efficiency measures for compressed air systems also impact other parts of the compressed air system beyond the sub-part subjected to the measure.

The results of Paper III further revealed a scarcity of literature on the perceived nonenergy benefits in relation to compressed air energy efficiency measures. However, the results of the study, which are described in Paper IV, contributed insights on the non- 
energy benefits of improving energy efficiency in the process of compressed air. The respondents' experiences demonstrated the existence of several important non-energy benefits and the results pointed to diversity among the perceived benefits as well. The views of the suppliers of compressed air systems (Paper IV) contributed further by giving examples of the non-energy benefits related to specific energy efficiency measures in compressed air systems. Some of the benefits were observed in the same part of the system where the measure was implemented (e.g. less wear and tear), while others yielded effects that influenced other parts of the system or even led to additional effects outside the compressed air system (e.g. increased productivity, increased worker safety and improved financial prospects). The results also demonstrated that the implementation of just one measure could yield several non-energy benefits of different types. Investigating non-energy benefits from the perspective of specific energy efficiency measures aiming at one industrial process, which has been done in these studies, contributes detailed results on non-energy benefits to the field of study. Since few studies have reported and related non-energy benefits to specific measures, these findings serve to fill a gap, at least partly, by contributing detailed knowledge regarding the non-energy benefits and energy efficiency improvements in compressed air systems. These detailed insights also created a basis for gaining additional understanding on how to observe the non-energy benefits.

The case of compressed air offered several examples of the relations between non-energy benefits, showing that one benefit leads to or has an impact on other benefits. These findings were already shown in the study presented in Paper II. However, in the case of compressed air, this became even more obvious and lent further support to the existence of relations between non-energy benefits. Based on the review findings of Paper III and the interview results presented in Paper IV, examples of possible relations between the non-energy benefits of energy efficiency measures in compressed air systems could be distinguished. For instance, reduction of air leakages in the compressed air system can lead to several additional effects. Except energy savings, this measure can decrease leakage-related noise, which in turn improves the conditions in the work environment for the employees in the production facilities. Improved conditions in the work environment for the employees make them feel better, and they might work better. As a result, productivity may increase.

Thus, as visualised in Figure 16, the implementation of energy efficiency improvements in systems for the generation of compressed air, which consist of several sub-parts, does not only create interrelations and dependencies between various energy efficiency measures, it also generates several non-energy benefits which are related to each other. In other words, the implementation of one specific energy efficiency measure could generate not only primary non-energy benefits, but also many secondary benefits, tertiary benefits and benefits even further distanced from the original non-energy benefit. 


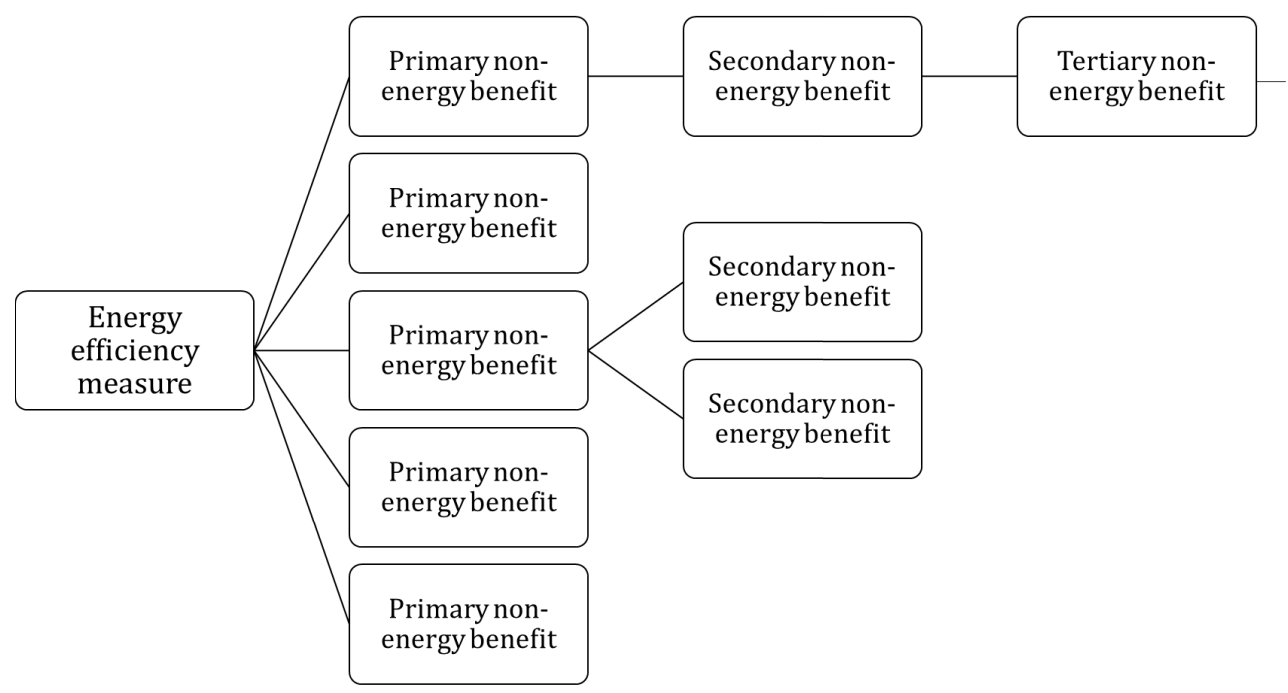

Figure 16. An example of the primary, secondary and tertiary non-energy benefits of one energy efficiency measure implemented in a compressed air system.

Hence, improving energy efficiency by implementing even one measure in a compressed air system can generate several primary non-energy benefits. In addition, some of those can also lead to secondary and tertiary non-energy benefits. Furthermore, several different benefits might be perceived not only in the compressed air system and its related sub-parts but also outside the system, affecting different areas (e.g. those related to production or finances) of an industrial firm. These chain reactions among the non-energy benefits are in the case of compressed air consequences of the compressed air system, as it consists of several interrelated sub-parts, and they are also consequences of the spread and diversity among the non-energy benefits and their ability to affect many different areas and different actors within the industrial firm, but also their ability to affect other non-energy benefits.

Applying a time perspective, the relations among non-energy benefits also mean that secondary effects and the effects that are generated from them will often be observable after the primary effects, i.e. there are direct non-energy benefits and indirect non-energy benefits. However, not all secondary and tertiary effects have to be indirect. For instance, in the example given above, reduction of air leakages reduce leakage-related noise-a primary and direct effect-which in turn lead to improved work environment, which is a secondary and also a direct effect. If this further leads the improved productivity-a tertiary effect-this non-energy benefits will probably be observable later on, i.e. an indirect effect. The time perspective is thus important to consider. In order to improve decision-making on the implementation of energy efficiency measures by increasing the 
utilisation of non-energy effects, industrial firms have to acknowledge not only primary effects, but also secondary and tertiary effects, and they must also recognise that additional effects due to the chain reactions caused by them can arise later on after the implementation of energy efficiency measures.

The findings from viewing non-energy benefits through the measures perspective also contributes with factors that are important to understand non-energy benefits in detail in order to grasp, measure and estimate their effects. Hence, the measures perspective also contributes to gaining knowledge on which non-energy benefits an energy efficiency implementation might possibly yield together with relations between non-energy benefits and when in time the effects will arise. All these aspects are important and can offer guidance on how to observe and map the non-energy benefits of energy efficiency improvements aiming at specific energy-using processes, which are important in investigating and utilising non-energy benefits.

The diversity of and relations among the non-energy benefits that can be generated as effects of implementing energy efficiency measures in compressed air systems are important for other reasons as well. Gaining knowledge on what energy efficiency improvements might bring to industrial firms beyond energy savings may increase interest in adopting energy efficiency measures in compressed air systems. From the results presented in Chapter 6, the summarised views of the users, experts and suppliers of compressed air systems indicated that measures to improve energy efficiency in compressed air systems seem to be hindered mainly by economic and organisational factors. According to the respondents, similar factors were also stated as drivers for the implementation of energy efficiency measures in compressed air systems. Therefore, recognising the myriad of non-energy benefits and applying that information when making decisions on future implementations could be a means of removing barriers. For example, non-energy benefits such as capital avoidance (e.g. delaying new investments), reduced labour requirements and reduced maintenance lower costs in various ways that may contribute to reducing economic barriers such as access to capital. On the other hand, such information could also drive the adoption of energy efficiency measures for compressed air systems by shortening payback periods, thereby increasing profitability. In addition, shorter payback periods and lower expenditures are characteristics of energy efficiency measures that positively affect their adoption rate (Fleiter et al., 2012). Further, the larger non-energy benefits, the greater adoption of energy efficiency measures (Fleiter et al., 2012), which is in accordance with Trianni et al. (2014) who stated that many non-energy benefits in relation to energy efficiency measures increase the likelihood of the adoption of such measures.

The suppliers expressed understanding the potential of energy efficiency measures as a driver and in respect to this, non-energy benefits may contribute to that understanding. For instance, understanding the potential of energy efficiency measures can help to overcome the informational barriers that were stressed by Cagno and Trianni (2014) in 
relation to the measures in compressed air systems. Furthermore, since the characteristics of energy efficiency measures seem to affect their adoption (Fleiter et al., 2012; Trianni et al., 2014), the diversity among the non-energy benefits may also enhance the characteristics of energy efficiency measures, thereby making the measures more likely to be adopted.

By investigating energy efficiency improvements and non-energy benefits on a detailed level, as represented by the measures perspective, it can be concluded that the roles of non-energy benefits in decisions on energy efficiency depend on their characteristics and type. However, the potential of non-energy benefits to affect decisions on the implementation of energy efficiency measures is determined by the extent to which they are observed and utilised, which in turn requires that the relations between them and the time perspective are acknowledged by industrial firms.

\subsection{Investment perspective}

The studies presented in Papers I and II, which mainly took an investments perspective in investigating the non-energy benefits of implemented energy efficiency improvements in industrial firms, demonstrated variety among the perceived non-energy benefits. Furthermore, the perceived non-energy benefits were different in character and the benefits were observed in various areas both within and outside of the firms, i.e. the external environment. These results, which were the first explorative results of these studies, also indicated that there were relationships between the benefits (i.e. that one benefit leads to other benefits) and that one measure could give rise to several different benefits. These relationships indicated that the time perspective appeared to be an important aspect, i.e. that non-energy benefits can be observed right after a measure has been implemented, while other benefits appear in a longer timeframe. These findings play an important role in the observation and utilisation of the non-energy benefits, such as when benefits can be observed, how benefits will affect in the firm and by whom in the firm such effects can be perceived.

Although many non-energy benefits were observed by the industrial firms, such effects were seldom acknowledged in the firms' decisions on energy efficiency investments. In particular, very few of the non-energy benefits were monetised and taken into account in the calculations of energy efficiency investments. However, the interview results indicated that in decisions on larger investments, non-energy benefits seemed to be utilised to a higher degree in terms of the number of non-energy benefits included and the extent to which they were monetised. Even if energy cost savings are an important driver for positive decisions on energy efficiency investments (e.g. Thollander and Ottosson, 2008), this is not always enough to achieve the implementation of them (e.g. Cooremans, 2011, 2012). However, if effects of non-energy benefits are translated into monetary values and included in investment calculations, this can increase the cost savings. In such cases, non-energy benefits might be a means to overcome barriers like low rates of return 
or long payback periods previously stressed by for instance Harris et al. (2000). In addition, Fleiter et al. (2012) and Trianni et al. (2014), have showed that both short payback periods and large non-energy benefits, are characteristics which increase the adoption rate of energy efficiency measures. Hence, an increased monetisation and inclusion of non-energy benefits in investment calculations may contribute by giving driving effects of monetary character for energy efficiency measures generating such nonenergy benefits.

The type of a non-energy benefit and its inherent quantifiability seemed to explain the non-inclusion in investment calculations of energy efficiency investments. Particularly, the results indicated that inclusion was mainly hindered by a lack of information on how to measure, quantify and monetise many types of the non-energy benefits. In addition, efforts to retrieve such information were sometimes also viewed as being too much when compared to the possible gains. As suggested in Paper II, improved knowledge on such measurements, for instance by expressing the non-energy benefits in terms of how they affect the firm's cash flow, both in positive and negative ways, could be a way to increase the estimation and evaluation of non-energy benefits. Suggestions made by the respondents of the interviewed firms indicated that some of the non-energy benefits could be measured immediately after implementation. For instance, increased production could be measured immediately by measuring the output after implementation, while other less quantifiable benefits could be measured through their impact on other benefits that were easier to measure and quantify. An example of the latter is improved air quality, the effects of which can be measured by its impact on product quality and productivity. This exemplifies how, due to their individual characteristics, the different roles of nonenergy benefits can be utilised in measuring and quantifying their effects, and also how the relations among non-energy benefits generating primary, secondary and tertiary effects are applied in the evaluation or estimation of their monetary potential.

Applying a time perspective to this shows that indirect benefits will probably occur over a longer timeframe and their effects will therefore not be immediately recognised, while the effects of direct benefits might be observed and measured on a short-term basis. Hence, this raises the importance of the time perspective; i.e. considering when in time the effects of non-energy benefits will arise and become observable and measurable. The results demonstrated that the payback period was commonly applied in investment calculations. Since the time aspect seemed to be critical, the payback method-although easy to use-may perhaps not be the best method to financially evaluate investments since this calculation method does account for future values, such as the as possible values of the indirect non-energy benefits. Therefore, calculation methods, such as methods based on discounted cash flows, which take the time perspective into account, would be more suitable. The use of such methods may facilitate acknowledging and incorporation the full value of all the various types of non-energy benefits into investment calculations. The fact that benefits might arise later on after implementation should be reflected in the capital budgeting tools applied. This might enable the visualisation of non-energy 
benefits, both direct and indirect benefits, which can increase the number and value of included non-energy benefits in investment calculations and thereby positively add to the investment financially. According to the studied firms, profitability and short payback periods were important, and even critical for their approval of energy efficiency investments. Furthermore, some of the firms added that energy savings were often insufficient to justify and fulfil the criteria for approval of the investment. This speaks for the importance of translating effects of the non-energy benefits into monetary values and include those values in investment calculations, thereby increasing the financial values of energy efficiency investments and hence the probability of positive decisions being made on such investments. In addition, according to Qiu et al. (2015), firms seem to be shortsighted when assessing energy efficiency investments because such investments are associated with a perceived high risk. Acknowledging the indirect effects, i.e. that nonenergy benefits might arise later on after implementation, might contribute to lowering the supposed risk of investments in energy efficiency.

These studies' findings also showed that energy efficiency investments are not always made based on energy efficiency as the only objective. This underpins what Sandberg and Söderström (2003) previously have emphasised, which is that several reasons can contribute to motivating energy efficiency investments. Improved productivity and an improved work environment were stated by the firms as common investment motives and at the same time, improved productivity and an improved work environment were commonly observed non-energy benefits. Non-energy benefits which were difficult to quantify, or even unquantifiable, for instance improved work environment, were not included in calculations of energy efficiency investments. Nonetheless, the results of this thesis demonstrated that these intangible benefits, due to their qualitative value, were sometimes mentioned in the total evaluation of the investment as an additional value or motivation. This points to the non-energy benefits' roles as possible drivers for energy efficiency acting as motivators for the investments, which can retain or expand energy efficiency as an investment category in industrial firms. Furthermore, non-energy benefits, such as more reliable production, might lower the perceived risk of energy efficiency investments. Together with the monetised cost savings opportunities of nonenergy benefits, all these aspects corroborates Cooremans' (2011) earlier findings: nonenergy benefits may contribute to the three dimensions of competitive advantage-value, risk and costs-and thus increase the strategic nature of energy efficiency investment. Therefore, the results of studying non-energy benefits from the investment perspective further support the argument that their roles, i.e. their different characters and the relations between them, are important factors that should be considered in order to increase their potential utility in making decisions on energy efficiency investments. Depending on the type of benefit and how its value is assessed, Figure 17 shows how (i.e. in which parts) non-energy benefits can be included and thereby affect the investment process. 


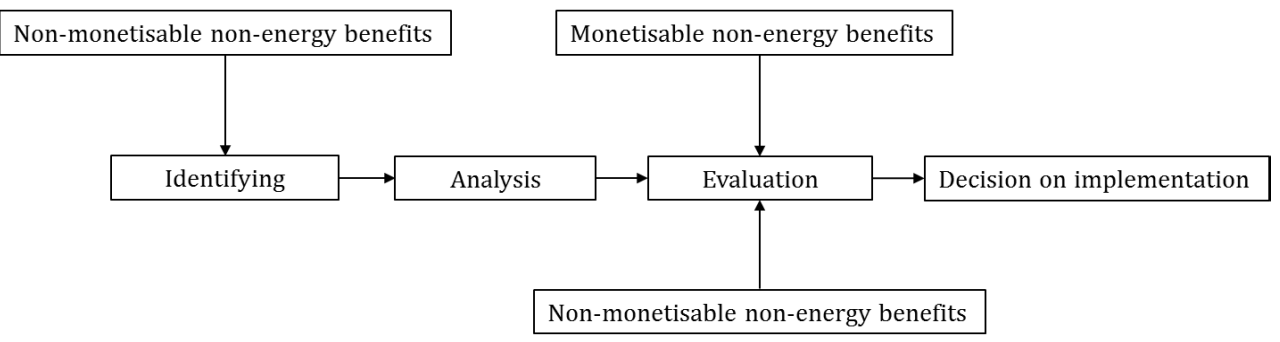

Figure 17. Non-energy benefits' possible contributions in different phases of the energy efficiency investment process.

The possibility of monetising non-energy benefits could contribute to investment decisions by including such benefits in the investment calculation. However, the results of this thesis showed that non-energy benefits were rarely monetised and included in industrial firms' investment calculations. Nevertheless, firms mentioned non-energy benefits in their commentary or arguments when evaluating investments, i.e. nonmonetised benefits were utilised and included qualitatively in the investment evaluation. Intangible and soft non-energy benefits, i.e. qualitative values, might factor into the initial stages of the investment process by raising interest in the investment by removing behavioural barriers and mitigating the lack of awareness that Trianni et al. (2016) showed impeded the initiation of the investment process. In another example, energy efficiency investments in new technology and alterations related to specific production processes were often viewed as risky projects (e.g. Rohdin et al., 2007; Thollander and Ottosson, 2008). If energy efficiency investments also generate additional effects such as more reliable production, this may contribute to overcoming the view that this type of energy efficiency improvements are risky. This may in turn contribute to energy efficiency investments not being considered without knowledge on related additional effects or getting past the first step can reach the analysis and evaluation phases. Further, in specific situations or contexts, the non-energy benefit might be of high importance to the firm; in such cases, the extra arguments might turn into objectives within the energy efficiency investments or become part of the objective. In that sense, the non-energy benefits may be the factor(s) driving the positive decision on implementation of the investment. Nonenergy benefits that translate into large monetary values might of course be seen as financial drivers.

The results of these studies showed that the analysis phase was often based on some kind of initial assessment, a pre-study. The evaluation of the pre-study could be an important opportunity to foresee and estimate any possible non-energy benefits and the value of their effects before preparing the business case.

Since one main obstacle to the utilisation of industrial non-energy benefits seems to be the barriers to inclusion of these effects in industrial firms' investment decisions on energy efficiency improvements and in particular inclusion in the investment calculation, 
knowledge on how to measure, quantify and monetise the non-energy benefits in order to overcome the barriers to the inclusion of non-energy benefits are important in order to ease the inclusion of non-energy benefits. The results of these studies demonstrate that non-energy benefits play different roles in energy efficiency investments; monetised or not, non-energy benefits contribute in the evaluation phase, including the investment calculation, or early in the investment process as an objective for the investment. Moreover, their potential impact depends on their quantifiability, type and how important their effects are to the individual firm. Hence, by considering non-energy benefits' different roles, mapping them could be improved which would support increasing the utilisation of non-energy benefits and also speak to their potential in decisions on energy efficiency investments.

\subsection{Energy management perspective}

The energy management perspective on energy efficiency and non-energy benefits sought to investigate the possible non-energy benefits of energy management activities implemented in Swedish pulp and paper mills. An extended potential for improved energy efficiency lies in the adoption of energy management procedures, i.e. that energy efficiency measures and investments in new technology are combined with energy management activities of for instance operational and managerial nature in a firm (e.g. Backlund et al., 2012; Paramonova et al., 2015). The energy management perspective hence includes both the measures and investment perspectives since the implementation of energy efficiency measures and investments are examples of energy management activities, following the framework of Schulze et al. (2016).

Although energy efficiency improvements on more detailed levels, i.e. specific measures and investments, are included in energy management procedures (Schulze et al., 2016), firms in the Swedish pulp and paper industry that have worked with energy management for several years perceived additional effects of energy management activities beyond the non-energy benefits of implemented measures alone. Organisational benefits, such as an increased interest in energy issues from top management or at other organisational levels, were perceived by the mills. For instance, support from top management has been stated as an important factor affecting successful energy management practices in Swedish industrial firms (Johansson and Thollander, 2018). Furthermore, Solnørdal and Foss (2018) have also demonstrated that drivers related to organisation and management, such as awareness of energy efficiency, performance indicators and commitment and support, are important for improving energy efficiency by energy management. The increased energy performance measurements and evaluations stated by the firms may also be beneficial in the observation and measurement of non-energy benefits. Measuring and evaluating energy data may facilitate the mapping of non-energy benefits on various levels. Finally, according to Lawrence et al. (2018), regular energy accounting and benchmarking were addressed as success factors that could boost the implementation of energy management activities. It should be noted that these findings 
are based on a limited sample from one, albeit experienced, industrial sector in one country. However, the findings indicate that the concept of non-energy benefits can be extended.

To conclude, the energy management perspective contributed a novel view on the concept of non-energy benefits. The extension of non-energy benefits as a concept, i.e. to investigate them more comprehensively in relation to energy efficiency, revealed new types of non-energy benefits. In addition, studying non-energy benefits from this aggregated and comprehensive perspective further contributed to developing a new way of investigating non-energy benefits. Since new types of non-energy benefits were observed from the energy management activities implemented, this also underpins the importance of investigating non-energy benefits through different perspectives on energy efficiency improvements. Hence, the observation and utilisation of the non-energy benefits of energy management activities can multiply their possible roles, which in turn can increase their applicability and potential in making decisions on energy efficiency improvements in general.

\subsection{Combining the perspectives}

This thesis is situated in the context of industrial energy efficiency. However, the additional effects that energy efficiency brings beyond the energy effects themselves are what have been central in the studies. In this section, the possible impacts of non-energy benefits, i.e. their roles and potential in making decisions on improving energy efficiency, will be discussed by combining the three perspectives on non-energy benefits that have been applied in the studies presented in this thesis: energy efficiency measures, energy efficiency investments and energy management activities.

Paper VI contributed the investigation of non-energy benefits by proposing a scheme for the mapping and utilisation of non-energy benefits. The scheme included the following steps: observation, measuring, quantification, monetisation and evaluation and impact assessment, and it could be applied to both the evaluation and planning of energy efficiency improvements. The empirical results presented in this thesis derived from studying non-energy benefits from three perspectives can contribute in several of the steps in the scheme. Knowledge on which non-energy benefits that may be generated by specific measures, for instance, measures for energy efficiency in compressed air systems, or energy efficiency investments, can contribute to the observation of non-energy benefits, or in the estimation of the expected effects of an implementation. In addition, the energy management perspective represents a widened view on the concept of non-energy benefits which extended the number of possible effects that might be observed by demonstrating novel types of non-energy benefits. For instance, implementations of energy management activities pointed at an increased awareness of and interest in energy efficiency issues in the industrial firms studied. This may in turn contribute to an increased awareness of the possible additional effects of energy efficiency improvements 
in general, which might lead to a larger number of non-energy benefits being observed. Further, more mapping of energy data by increased performance measurements and evaluation-another benefit of practising energy management-may facilitate the measurement and quantification of non-energy benefits. As Doyle and Cosgrave (2018) argued, complete and detailed information on energy use can facilitate the observation of energy efficiency measures' benefits.

The measures and the investment perspectives both showed that the diversity of and relations between non-energy benefits (such as primary and secondary effects) must be considered in order to understand which benefits can be observed immediately and which of them might eventually become apparent, i.e. direct and indirect non-energy effects. These aspects, the relations between them and the time perspective, are also important in the next steps-measuring, quantifying and monetising non-energy benefits-because the results indicated that the magnitude of some benefits (depending on their type) can be measured and quantified instantly (e.g. less waste), while others would have to be measured through other secondary benefits (e.g. improved work environment). Monetised non-energy benefits can be included in the investment calculation and thereby have a financial impact, while other benefits that are difficult to quantify and monetise can impact the total assessment of the investment, such as by acting as driving forces, as extra arguments for or as objectives of the implementation.

The evaluation of implemented energy efficiency improvements thus contributes knowledge on which non-energy benefits can be observed after the implementation of energy efficiency improvements on various levels. Moreover, individual contributions from each non-energy benefits perspective investigated can provide valuable insight into the mapping of non-energy benefits as a whole, which is important since observation of and mapping their effects is a requirement to gather knowledge and understandings for their utilisation in the planning of future energy efficiency improvements. Furthermore, the utilisation of non-energy benefits can be enhanced by taking into account all the possible roles that the diversity among the non-energy benefits provide, which speaks for non-energy benefits' capacity to positively impact on decisions on energy efficiency improvements in several ways. Hence, knowledge on and awareness of the non-energy benefits of previous implementations is a requirement for their utilisation, which creates a loop back to the implementation of new energy efficiency improvements on various levels, as illustrated in Figure 18. 


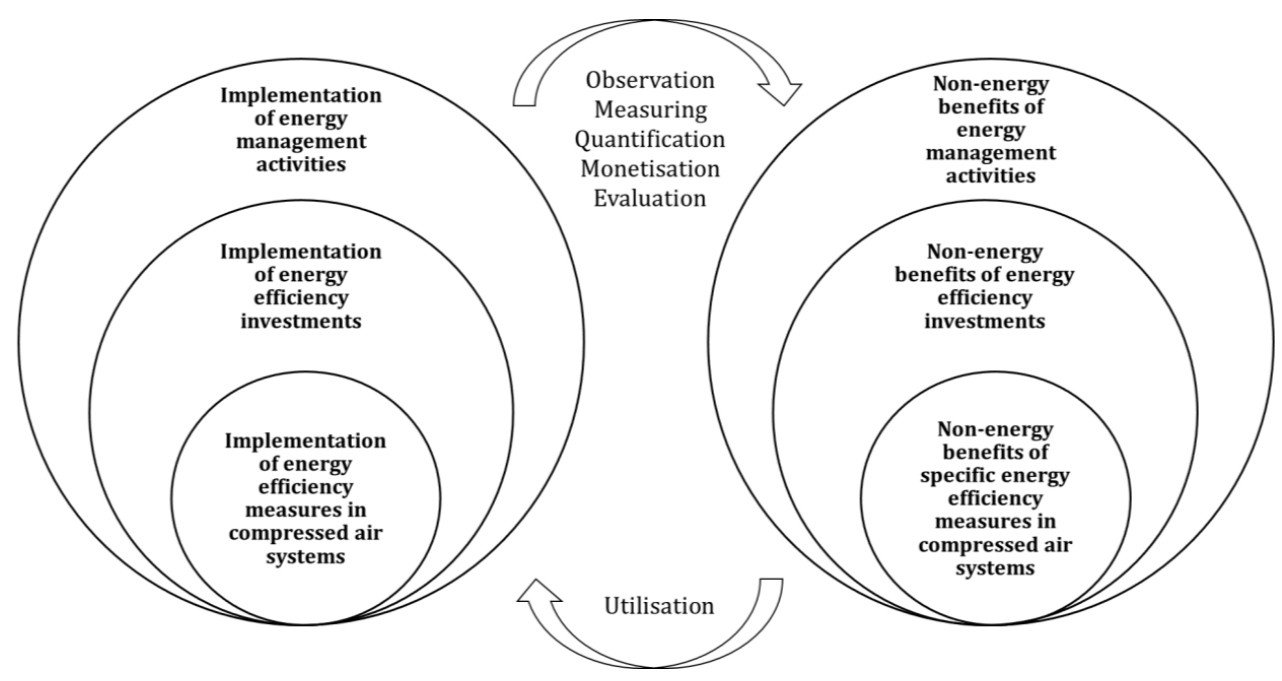

Figure 18. Implementation of energy efficiency improvements on various levels in relation to the mapping and utilisation of non-energy benefits.

It is when the knowledge from observations and evaluations of the non-energy benefits of implemented energy efficiency improvements are applied in future implementations of energy efficiency that non-energy benefits' roles and impacts can be utilised. Hence, when the roles and potential of non-energy benefits observed through different perspectives are utilised, the effects of non-energy benefits can contribute in new implementations. An improved utilisation of non-energy benefits could then be a means to motivate further implementation of energy efficiency improvements.

Findings of Paper VI demonstrated that previous research on industrial non-energy benefits to a large extent has concentrated on non-energy benefits' monetary impact. The results presented in this thesis showed that the financial aspects are important in decisions on implementations of energy efficiency improvements, but not always decisive for their approval. For instance, energy efficiency improvements are not always prioritised by industrial firms (e.g. Cooremans, 2012) and the investment process for energy efficiency investments also faces behavioural barriers and lack of awareness (Trianni et al., 2016).This speaks for the importance of paying attention to the non-energy benefits' additional roles. Knowledge of for instance production-related non-energy benefits could for instance increase the awareness of what energy efficiency might bring, but also remove barriers making energy efficiency improvements more attractive due to the relation to core business. Furthermore, previous studies have investigated nonenergy benefits on a detailed level, but results have mainly been reported on an aggregated level. Hence, the relation between industrial non-energy benefits and the specific energy efficiency improvements, i.e. exactly which non-energy benefits that are generated from a specific energy efficiency improvement, have thus many times not been 
reported. This thesis contributes with detailed knowledge on non-energy benefits of specific measures including the relations among them. Furthermore, in addition to nonenergy benefits monetary role, these studies have demonstrated additional roles among the benefits. In addition to increasing financial aspects, the roles among the benefits enabled them to for instance motivate new energy efficiency improvements or add qualitative value to the improvements. However, the results of this thesis have demonstrated that non-energy benefits can be difficult to observe, measure and quantify since these effects are very diverse and affected by the relations between them along with the time perspective. This makes it difficult to theoretically estimate the effects of nonenergy benefits. Therefore, mapping the non-energy benefits from energy efficiency improvements in different industrial processes, i.e. to retrieve empirical data on nonenergy benefits, is required to enhance the evaluations surrounding energy efficiency improvements in order to improve the decisions made about them.

Short et al. (1995) have stated that a comprehensive view on investment analysis is required in order to make the analysis as thorough as possible. Hence, by taking the nonenergy benefits' roles into account in the investment process and in decisions on energy efficiency improvements in general, including decisions on energy management activities, the perspective on such decisions is extended, along with the perspective on energy efficiency and related energy efficiency improvements. Through the acknowledgement of non-energy benefits in making decisions on energy efficiency improvements on various levels, the improvement measures' impacts will be widened to include not only the energy effects of the system regarded, but also factors beyond the measures' objectives such as the external environment, work environment, production, processes, equipment and personnel within the firm. Hence, a comprehensive view on decisions regarding energy efficiency improvements is enabled by the acknowledgement of non-energy benefits. Including non-energy benefits in relation to various perspectives and levels of energy efficiency, i.e. including additional effects beyond energy effects, might be a way to increase the competitiveness of energy efficiency investments and other types of energy efficiency improvements. In addition, the results of this this thesis demonstrated new types of non-energy benefits of implementing energy management practices. For instance, increased interest for energy issues from top management and other levels in the firms' organisations. These increased interest can contribute to higher level of awareness of all the effects that energy management might bring but also what improved industrial energy efficiency in general can lead to.

Throughout the studies, the question on how to define a non-energy benefit was raised several times. A general reflection based on the research presented in this thesis is that the definition seems quite dependent on the context, i.e. the context influences how an effect is perceived and its value. For instance, effects on the indoor climate will naturally be smaller and less important in firms that normally have a comfortable indoor climate, for instance, a pharmaceuticals producer, while the situation might be the opposite in another firm, such as a foundry. Similarly, if firms' production-related processes are 
highly efficient and reliable, non-energy benefits such as increased production reliability and improved productivity, might not be observed or less valued due to their minor effects in such context. The context may also influence possible non-energy benefits from energy management practices; for instance the maturity of the mill's work with energy management might have impact on non-energy effects. How a non-energy benefit is defined also relates to if and how knowledge on non-energy benefits of one type of energy efficiency measure may be transferred to implementation of the same measure in other industrial contexts. Industrial processes are often be adjusted to specific conditions in individual firms. Hence, perceived non-energy benefits and the value of their effects may therefore vary between different industrial firms and contexts.

The findings of the studies presented in this thesis address the importance of combining a comprehensive view with different perspectives in studies on non-energy benefits. A comprehensive perspective must be applied to capture and map the non-energy benefits due their spread and their effects on various processes, areas and actors. This has to be considered in relation to the utilisation of non-energy benefits and also taken into account in methods for estimation and evaluation of non-energy benefits' effects because measurements, quantifications and monetisation, for instance, cannot be done every time. This would be time-consuming and may not be worth the effort when compared to the possible savings, which seemed to be a main barrier to the inclusion of non-energy benefits in investment decisions. Even if specific non-energy benefits are studied or should be utilised, a comprehensive view must be applied in order to capture all the effects of them due to the benefits' diversity and their appearance on various levels and in areas in and outside the firm. However, this diversity is beneficial from the perspective of their different roles due to their different types and their effects on different processes, areas and actors-both inside and outside the firm. In addition, studying non-energy benefits from the perspective of energy management demonstrated new types of benefits which increase the number of possible additional effects of energy efficiency improvements. Further, this multiply the roles of non-energy benefits which can contribute to increasing their potential. The investigation of non-energy benefits from three perspectives on energy efficiency, as conducted in this thesis, has contributed valuable insights into future implementations of energy efficiency improvements. These insights are of importance since knowledge of this kind contributes to understanding the total effects and values of energy efficiency improvements. This, in turn, may increase the adoption of such improvements. Improved industrial energy efficiency is required to reach energy targets and thereby reduce $\mathrm{CO}_{2}$ emissions and alleviate climate impacts. In this regard, non-energy benefits may offer opportunities and attractive arguments to motivate further improvements and, as required by Spiesshofer (2014), serve as "clear examples of energy efficiency" in industry.

To conclude, several non-energy benefits were observed from various kinds of implemented energy efficiency improvements in relation to all three perspectives applied in these studies which demonstrates an awareness of non-energy benefits among the 
studied industrial firms and interviewed respondents. In addition, the investment perspective revealed that, although to a less extent, non-energy benefits were acknowledged by industrial firms in various ways in their decisions on energy efficiency improvements, which speaks for the utilisation of non-energy benefits. Assumed that the non-energy benefits contributed to positive decisions on those implementations, the results of this thesis give support to the proposition posed at the beginning of these studies, which is that awareness and the utilisation of non-energy benefits can contribute to improved industrial energy efficiency. 


\section{Conclusions}

In this chapter, the final conclusions are drawn and presented. The conclusions are structured according to the research questions posed in the introduction chapter of this thesis.

Based on the results of these studies and the discussion of the results from the three perspectives applied in this thesis, following conclusions are provided:

What are the perceived non-energy benefits of implemented energy efficiency measures, energy efficiency investments and energy management activities in the industrial firms studied?

In this thesis, non-energy benefits have been studied through different perspectives on energy efficiency improvements: energy efficiency measures, energy efficiency investments and energy management activities, and the results revealed an existence of different types of non-energy benefits perceived in relation to all the three perspectives.

The results of this thesis demonstrated that the implementation of energy efficiency measures in systems for compressed air can give rise to several non-energy benefits in various parts of the compressed air system, for instance reliable production, less wear and tear on equipment and a stable pressure, and also offer benefits outside the system such as an improved work environment. Studying the non-energy benefits of specific energy efficiency improvement measures conducted through the case of compressed air showed that improving the energy efficiency of one energy-using process and even one single measure can generate several non-energy benefits of various types. In addition, one non-energy benefit also generated other types of non-energy benefits, i.e. primary nonenergy benefits generated secondary, tertiary effects and further effects. As a consequence, non-energy benefits were observed directly after implementation, and the effects could also arise within a longer timeframe, demonstrating the existence of both direct and indirect non-energy benefits.

The studies on the non-energy benefits of energy efficiency investments in industrial firms indicated that the firms studied had observed non-energy benefits of various kinds as a consequence of the energy efficiency investments they implemented. The most commonly observed effects were benefits in relation to operations and maintenance, 
work environment and production. The implementation of one energy efficiency investment could generate several non-energy benefits of different types. In addition, relations between the non-energy benefits generated for instance secondary and tertiary non-energy benefits, and the importance of the time perspective, giving direct and indirect non-energy benefits, were also shown for the non-energy benefits of energy efficiency investments.

Furthermore, except non-energy benefits of implemented energy efficiency measures and investments, the studies also indicated non-energy benefits on a higher level in the form of the additional effects of working with energy management practices. The perception among the studied pulp and paper firms was that due to the energy management activities conducted, interest in energy efficiency issues had increased at various levels within the organisation. However, other important benefits of their energy management practices were observed: improvements to the external environment, increased energy performance measurement and evaluation and economic benefits such as cost reductions beyond energy cost reductions and increased capital for energy efficiency investment.

In sum, the results of the thesis have shown a variety of industrial non-energy benefits perceived as the consequences of implementing energy efficiency improvements on various levels, from the benefits of specific energy efficiency improvement measures to the benefits of implementing energy management activities. Furthermore, the extended view including energy management activities led to the recognition of novel non-energy benefits.

How are non-energy benefits utilised and how could they be utilised in decisions aiming at improving energy efficiency in the industrial firms studied?

From the studies presented in this thesis, it can be concluded that the non-energy benefits perceived constitute a diverse collection of effects affecting for instance processes, equipment, people and areas inside the industrial firm, but also affecting the external environment in positive ways. This spread among the non-energy benefits enabled the benefits to be included in the decisions on energy efficiency improvements in various ways depending on the type of benefit and how its value was assessed. Even though several non-energy benefits were observed as consequences of improving energy efficiency, such effects were seldom utilised and included in decisions on energy efficiency improvements in a structured way. However, non-energy benefits seemed to be utilised to a higher degree in decisions on larger investments. Monetising non-energy benefits could contribute to investment decisions by including them in the investment calculation. However, the results of this thesis showed that few non-energy benefits were monetised and included in industrial firms' investment calculations, but firms utilised non-energy benefits in the form of comments or as extra argumentation in investment evaluations, i.e. non-monetised benefits were utilised and included qualitatively in the investment evaluations. Furthermore, in specific situations or contexts, the non-energy benefits could 
be of high importance for the firm; in such cases, the extra arguments became an objective of the energy efficiency investment or served as part of the objective. Hence, the nonenergy benefits' quantifiability, type and importance depicted in which part of the investment process or decision chain benefits had their impact. The different types and characters among the non-energy benefits also provide them with roles which enabled them to act as possible drivers or as facilitators for overcoming barriers. For instance, monetised non-energy benefits can increase profitability and thereby reducing financial barriers. On the other hand, non-monetised non-energy benefits of qualitative nature were shown to motivate energy efficiency improvements, i.e. drive such implementations. The results also indicated that non-energy benefits' different roles could be utilised in overcoming obstacles to measuring their effects, for instance by evaluating the benefits' impact on the cash flow or by utilising the relations between the benefits.

The results of this thesis also showed that the acknowledgement of not just the primary non-energy benefits, but also the related effects, such as secondary and tertiary nonenergy benefits, would be a way to increase the utilisation of non-energy benefits in decisions on energy efficiency improvements. In particular, the utilisation of non-energy benefits that arise later on after implementations can be improved by the use of calculation methods which consider the time perspective, i.e. includes both direct and indirect benefits. This improved utilisation can increase the number and value of included non-energy benefits in decisions on energy efficiency improvements.

Studying non-energy benefits from the energy management perspective extended the view on non-energy benefits as a concept which revealed new types of non-energy benefits. Utilisation of such non-energy benefits increase the number of possible roles among the non-energy benefits which can increase their potential in decisions on energy efficiency improvements.

What are the individual contributions of the three perspectives that have been applied in studying the non-energy benefits of energy efficiency improvements?

In this thesis, non-energy benefits have been studied from three different perspectives. The overall findings pointed in the same direction: different types of non-energy benefits of implemented energy efficiency measures and investments and energy management activities were perceived in various areas in relation to industrial firms. However, each of the perspectives contributed individually to the overall results.

The results of the measures perspective-the case of compressed air-contributed detailed insights, and several opportunities for improving the energy efficiency of the process for compressed air were shown. The measures were directed at the various subparts of the systems or aimed at improving energy efficiency in general for systems of compressed air. Furthermore, some measures implemented in one part of the system were also shown to affect other parts, indicating relationships between the measures. 
Implementing energy efficiency measures in compressed air generated many different non-energy benefits in various parts of the system or outside the system. Moreover, the case of compressed air demonstrated relations among non-energy benefits as well, and it showed that one measure could give rise to several different non-energy benefits. As a consequence, non-energy benefits could arise within a longer timeframe, demonstrating the existence of direct and indirect non-energy benefits. The findings indicated that specific energy efficiency measures in compressed air systems were hindered by mainly economic and organisational factors. On the other hand, such factors were also viewed as driving forces. Since the non-energy benefits perceived were of different types, if utilised by industrial firms, they might impact and contribute in decisions on energy efficiency in various ways, such as by increasing the financial value of measures or raising the interest in such measures in general in industrial firms.

Several non-energy benefits of different types were also perceived in relation to the energy efficiency investments implemented in industrial firms. In addition, relations between the non-energy benefits and the importance of the time perspective, were also shown for the non-energy benefits of energy efficiency investments. However, non-energy benefits were seldom utilised in decisions on energy efficiency investments, mainly due to a lack of information on how to measure and quantify non-energy benefits. To overcome such barriers, it was suggested that intangible non-energy benefits could be measured through their effects on other benefits and by acknowledging that some effects of non-energy benefits are observed over a longer timeframe. Exploiting the diversity of non-energy benefits, the potential of non-energy benefits lies in utilising their different roles: increasing the financial value of energy efficiency investments by their inclusion in calculations; adding qualitative value to decisions on energy efficiency investments; or as motivations for the implementation of energy efficiency investments.

The perspective of energy management activities revealed that the implementation and practice of energy management in industrial firms yielded new types of non-energy benefits, such as increased awareness of energy efficiency issues on several levels in the organisation of industrial firms. The findings demonstrated that the concept of nonenergy benefits can be widened to include effects that extend beyond those of the implemented energy efficiency measures and investments.

What are the implications of combining the results of the three perspectives applied in studying the non-energy benefits of energy efficiency improvements?

Studying non-energy benefits from each of the three different perspectives provided insights of different kinds. The studies presented in this thesis contribute with an comprehensive view on industrial non-energy benefits by adding a detailed perspective as well as an extended perspective to the investment perspective. The three perspectives offered individual input into the mapping of non-energy benefits, which provided a more comprehensive approach in mapping the effects of non-energy benefits, which is 
important for their utilisation in the planning of future energy efficiency improvements. Hence, acknowledging all possible roles among the non-energy benefits by combining the results from each perspective offered a comprehensive view of the decisions on energy efficiency improvements; the consideration of the non-energy benefits' of energy efficiency improvements provided a widened view which included the whole systemnot only the energy effects. Moreover, the potential of non-energy benefits in decisionmaking on industrial energy efficiency improvements lies in the utilisation of all types of non-energy benefits and highlighting all the roles that the non-energy benefits may play. In particular, if knowledge on non-energy benefits and their roles are utilised in planning and implementations of new energy efficiency improvements, non-energy benefits can impact the decisions on them. 


\section{Further work}

In this chapter, suggestions for future research are addressed.

During the studies and in particular during the work on this thesis, several suggestions to address in future studies emerged. The studies presented in this thesis are based on limited samples. Since the context seemed to be important for observation and evaluation of non-energy benefits, further studies on the perception of non-energy benefits among firms in other industrial contexts are required. Furthermore, studying one single process, compressed air, contributed with detailed knowledge. However, even if compressed air is a commonly used industrial process, it represents a limited share of all industrial processes and knowledge on non-energy benefits in relation to compressed air may not be transferable to other industrial processes. Therefore, future studies need to explore the non-energy benefits of the specific energy efficiency measures of other industrial energy-using processes and technologies.

The results of this thesis showed that even if industrial firms have observed several nonenergy benefits, these types of effects were seldom monetised and utilised in investment evaluations. The reasons stated for this non-inclusion were difficulties in measuring the benefits and a lack of information on how to translate the effects into monetary terms. Therefore, even if non-energy benefits seem to be affected by the industrial context in which they are observed, it is suggested that future studies address the development of general methods for the quantification and monetisation of industrial non-energy benefits in order to overcome the obstacles to utilising non-energy benefits. This also address the requirement of further knowledge on non-energy benefits in relation to specific measures, but also knowledge on non-energy benefits in relation to industrial processes, investments and activities in different contexts to recognise their effects and improve their future utilisation. In order to utilise the different roles among the non-energy benefits, further knowledge on barriers and drivers to energy efficiency are required. In particular, barriers to and drivers for specific energy efficiency measures and energy management activities.

Furthermore, the investigation of non-energy benefits through the energy management perspective demonstrated novel but explorative results. Since the Swedish pulp and paper firms which were studied in this thesis, have practiced energy management for many years, these firms' perceptions on non-energy benefits were important for these 
studies. Although several years of experience from practising energy management, the Swedish pulp and paper sector represents a limited group of firms from one type of industrial sector. Therefore, further knowledge on non-energy benefits of energy management practices and the perceptions among firms belonging to other industrial sectors can provide additional insights on the topic.

One way to increase the awareness and utilisation of non-energy benefits would be to include non-energy benefits in the design of policy instruments and energy efficiency programmes directed towards industrial energy efficiency. Since the results of this thesis demonstrated that non-energy benefits are observed from energy efficiency improvements through various perspectives, non-energy benefits might be included in different types of policy instruments and programmes aiming at improving energy efficiency, for instance, informative instruments or economic instruments for energy audits. However, this requires more knowledge on the non-energy benefits of specific energy efficiency measures of industrial energy-using processes. According to Kluczek and Olszewski (2017), energy audits might also serve as a tool to observe and map nonenergy benefits. The inclusion of non-energy benefits in informative policy instruments might be a way to increase general awareness of the non-energy benefits that industrial energy efficiency improvements might bring. Knowledge on how to include non-energy benefits in the design of various policy instruments and programmes for industrial energy efficiency is therefore a topic to address in future studies. 


\section{References}

Abadie, L., M., Ortiz, R., A., Galarraga, I. (2012). Determinants of energy efficiency investments in the US. Energy Policy, 45, 551-566.

Ahrne, G., Svensson, P. (2015). Handbook in qualitative methods. [Handbok i kvalitativa metoder.] - in Swedish. Liber AB, Stockholm, Sweden.

Andersson, E., Nehler, T. (2018). Energy management in Swedish pulp and paper industry - benchmarking and non-energy benefits. In Proceedings ECEEE Industrial Summer Study - Leading the low-carbon transition, 313-322.

Anderson, S., T., Newell, R., G. (2004). Information programs for technology adoption: The case energy-efficiency audits. Resource and Energy Economics, 26, 27-50.

Apeaning, R., W., Thollander, P. (2013). Barriers to and driving forces for industrial energy efficiency improvements in African industries - a case study of Ghana's largest industrial area. Journal of Cleaner Production, 84, 53, 204-213.

Backlund, S., Thollander, P., Palm, J., Ottosson, M. (2012a). Extending the energy efficiency gap. Energy Policy, 51, 392-396.

Backlund, S., Broberg, S., Ottosson, M., Thollander, P. (2012b). Energy efficiency potentials and energy management practices in Swedish firms. ECEEE Industrial Summer Study.

Bergquist, A.-K., Söderholm, K. (2015). Sustainable energy transition: The case of the Swedish pulp and paper industry. Energy Efficiency, 9, 1179-1192.

Björk, C., Gralén, K., Räftegård, O., Åberg, B. (2003). Den tryckluftslösa fabriken. Eskilstuna, Sverige: Statens energimyndighet.

Björkman, T., Cooremans, C., Nehler, T., Thollander, P. (2016). Energy Management: a driver to sustainable behavioural change in companies. In Proceedings ECEEE Industrial Efficiency Summer Study, 379-387.

Blass, V., Corbett, C., J., Delmas, M., A., Muthulingam, S. (2014). Top management and the adoption of energy efficiency practices: Evidence from small and medium-sized manufacturing firms in the US. Energy, 65, 560-571.

Blomqvist, E., Thollander, P. (2015). An integrated dataset of energy efficiency measures published as linked open data. Energy Efficiency, 8 (6), 1125-1147.

Brooks, R., M. (2016). Financial Management - Core Concepts. Pearson Educational Limited, Essex, England.

Brunke, J.-C., Johansson, M., Thollander, P. (2014). Empirical investigation of barriers and drivers to the adoption of energy conservation measures, energy management practices and energy services in the Swedish iron and steel industry. Journal of Cleaner Porduction, 84, 509-525.

Bryman, A. (2011). Social science methods. [Samhällsvetenskapliga metoder.] - in Swedish. $2^{\text {nd }}$ ed., Liber, Malmö, Sweden.

Bryman, A., Bell, E. (2011). Business Research Methods. $3^{\text {rd }}$ ed., Oxford University Press. 
Bunse, K., Sachs, J., Vodicka, M. (2009). Evaluation energy efficiency improvements in manufacturing processes. Chapter in: Advances in production management systems 2009, Vallespir, B. and Alix, T., (Eds.): IFIP AICT 338:19-26.

Caffal, C. (1995). Energy management in industry. Centre for the Analysis and Dissemination of Demonstrated Energy Technologies (CADDET). Analysis Series 17, Sittard, The Netherlands.

Cagno, E., Trianni, A. (2013). Exploring drivers for energy efficiency within small- and medium-sized enterprises: First evidences from Italian manufacturing enterprises. Applied Energy. 104, 276-285.

Cagno, E., Worrell, E., Trianni, A., Pugliese, G. (2013). A novel approach to industrial energy efficiency. Renewable and Sustainable Reviews, 19, 290-308.

Cagno, E., Trianni, A. (2014). Evaluating the barriers to specific industrial energy efficiency measures: an exploratory study in small and medium-sized enterprises. Journal of Cleaner Production, 82, 70-83.

Cagno, E., Trianni, A., Moschetta, D. (2016). Only non-energy benefits when adopting an EEM? Cases from industry. In Proceedings of the ECEEE Industrial Summer Study, Berlin, Germany, 12-14 September, 281-292.

Carbon Trust (2011). Energy Management. A Comprehensive Guide to Controlling Energy Use.

Christiansen, I., S., Gudbjerg, E., Dyhr-Mikkelsen, K. (2016). New robes for NEB research Open and expanding data. In Proceedings of the ECEEE Industrial Summer Study, Berlin, Germany, 12-14 September, 417-26.

Cooremans, C. (2011). Make it strategic! Financial investment logic is not enough. Energy Efficiency, 4 (4), 473-492.

Cooremans, C. (2012). Investment in energy efficiency: do the characteristics of investments matter? Energy Efficiency, 5, 497-518.

Creswell, J., W. (2009). Research design: Qualitative, Quantitative, and Mixed Methods Approaches. 3rd ed., SAGE Publications, Thousand Oaks, California.

Creswell, J., W. (2013). Qualitative Inquiry \& Research Design: Choosing among Five Approaches. 3rd ed., SAGE Publications, Thousand Oaks, California.

Denzin, N., K., Lincoln, Y., S. (2013). Collecting and interpreting qualitative materials. $4^{\text {th }}$ ed., SAGE Publications, Thousand Oaks, California.

Doyle, F., Cosgrave, J. (2018). An approach to optimising compressed air systems in production operations. International Journal of Ambient Energy, 39 (2), 194-201.

EC (2009a). Decision 406/2009/EC. Decision No 406/2009/EC of the European Parliament and of the Council of 23 April 2009 on the effort of Member States to reduce their greenhouse gas emissions to meet the Community's greenhouse gas emission reduction commitments up to 2020. https://eur-lex.europa.eu/legalcontent/EN/TXT/?uri=CELEX:32009D0406. Retrieved 2018-11-01.

EC (2009b). Directive 2009/28/EC. Directive 2009/28/EC of the European Parliament and of the Council of 23 April 2009 on the promotion of the use of energy from renewable sources. https://eur-lex.europa.eu/legalcontent/EN/TXT/PDF/?uri=CELEX:32009L0028\&from=E. Retrieved 2018-11-01.

EC (2012). Energy Efficiency Directive. European Commission, Directive 2012/27/EU. https://eur-lex.europa.eu/legalcontent/EN/TXT/?qid=1399375464230\&uri=CELEX:32012L0027. Retrieved 2018-11-01.

EC (2016a). Proposal for a Directive of the European Parliament and of the Council amending Directive 2012/27/EU on energy efficiency. Brussels, European 
Commission. https://eur-lex.europa.eu/resource.html?uri=cellar:efad95f3-b7f511e6-9e3c-01aa75ed71a1.0009.02/DOC_1\&format=PDF. Retrieved 2018-10-31.

EC (2016b). Good practice in energy efficiency. Proposal for a Directive of the European Parliament and of the Council amending. Brussels, European Commission. https://eur-lex.europa.eu/legalcontent/EN/TXT/?qid=1490870135947\&uri=CELEX:52016SC0404. Retrieved 2018-11-04.

EC (2018). STATEMENT/18/4155. Brussels, European Commission. http://europa.eu/rapid/press-release_STATEMENT-18-4155_en.htm.

EA (2016). Energy agreement. Framework agreement between the Social Democratic Party, the Moderate Party, the Green Party, the Centre Party and the Christian Democrats. Government Offices of Sweden, Stockholm, Sweden. https://www.regeringen.se/artiklar/2016/06/overenskommelse-om-densvenska-energipolitiken/. Retrieved 2019-02-02.

Eurostat (2018). Sustainable development in the European Union. Monitoring report on progress towards the SDGS in an EU context. https://ec.europa.eu/eurostat/documents/3217494/9237449/KS-01-18-656EN-N.pdf/2b2a096b-3bd6-4939-8ef3-11cfc14b9329. Retrieved 2018-11-01.

De Groot, H., Verhoef, E., Nijkamp, P. (2001). Energy saving by firms: decision-making, barriers and policies. Energy Economics, 23, 717-40.

Finman, H., J. A. Laitner, 2001. Industry, energy efficiency and productivity improvements. Proceeding of the 2001 Summer Study on Energy Efficiency in Industry, 561-570.

Fleiter, T., Hirzel, S., Worrell, E. (2012). The characteristics of energy-efficiency measures - a neglected dimension. Energy Policy 51, 502-513.

Freed, M. and Felder, F., A. (2017). Non-energy benefits: Workhouse or unicorn of energy efficiency programs? The Electricity Journal, 30, 43-46.

Gordon, F., Peters, J., Harris, J., Scales, B. (1999). Why is the treasure still buried? Breaching the barriers to compressed air system efficiency. In Proceedings of the ACEEE Summer Study on Energy Efficiency in Industry, Saratoga Spring, NY, USA, 15-18 June, 709-718.

Gudbjerg, E., Dyhr-Mikkelsen, K., Andersen, C., M. (2016). Spreading the word - An online non-energy benefit tool. In Proceedings of the ECEEE Industrial Summer Study, Berlin, Germany, 12-14 September, 171-78.

Hall, N. P. and Roth, J. A. (2003). Non-energy benefits from commercial and industrial energy efficiency programs: Energy efficiency may not be the best story. Proceeding of the 2003 International Energy Program Evaluation Conference, 689702.

Harris, J., Anderson, J., Shafron, W. (2000). Investment in energy efficiency: a survey of Australian firms. Energy Policy, 28, 867-876.

Hasanbeigi, A., Menke, C., du Pont, P. (2010). Barriers to energy efficiency improvement and decision-making behavior in Thai industry. Energy Efficiency, 3: 33-52.

Hirst, E. and Brown, M. (1990). Closing the efficiency gap: barriers to the efficient use of energy. Resources, Conservation and Recycling, 3 (4), 267-81.

ICF (2015). Study on Energy Efficiency and Energy Saving Potential in Industry and on Possible Policy Mechanisms. ICF Consulting Limited, London. Prepared by ICF Consulting Ltd under contract to European Commission Directorate-General Energy.

IEA (2012). Spreading the net: The multiple benefits of energy efficiency improvements. Insight Series 2012. International Energy Agency, Paris, OECD/IEA. 
IEA (2014). Capturing the multiple benefits of energy efficiency. International energy agency, Paris, OECD/IEA.

IEA (2015). Key world statistics. International Energy Agency (IEA), OECD/IEA, France.

IEA (2018). Energy Efficiency 2018. Analysis and outlooks to 2040. Market Report Series. OECD/IEA, France.

IPCC (2018). Sixth Assessment Report (AR6). Summary for policymakers. The Intergovernmental Panel on Climate Change, IPCC. http://report.ipcc.ch/sr15/pdf/sr15_spm_final.pdf. Retrieved 2018-11-01.

Jackson, J. (2010). Promoting energy efficiency investments with risk management tools. Energy Policy 38, 3865-3873.

Jaffe, A.B. and Stavins R.N. (1994). The energy-efficiency gap What does it mean? Energy Policy, 22 (10), 804-810.

Jaffe, A.B. and Stavins R.N. (1994). The energy paradox and the diffusion of conservation technology Resource and Energy Economics, 16 (2), 91-122.

Jakob, M. (2006). Marginal costs and co-benefits of energy efficiency investments. The case of the Swiss residential sector. Energy Policy, 34 (2 SPEC. ISS.), 172-187.

Johansson, P-E., Thollander, P., Moshfegh, B. (2011). Towards increased energy efficiency in industry - a manager's perspective. Proceedings World Energy Renewable Congress 2011, Sweden.

Johansson, M., T., Thollander, P. (2018). A review of barriers to and driving forces for improved energy efficiency in Swedish industry - Recommendations for successful in-house energy management. Renewable and Sustainable Energy Reviews, 82 , 618-628.

Kluczek, A. and Olszewski, P. (2017). Energy audits in industrial processes. Journal of Cleaner Production, 142, 3437-3453.

Knoop, K. and Lechtenböhmer, S. (2017). The potential for energy efficiency in the EU Member States - A comparison of studies. Renewable and Sustainable Energy Reviews, 68 (2), 1097-1105.

Krutwig, M. C., Starosta, K. D. (2017). Characterization, classification and assessment of non-energy benefits of energy efficiency measures. In: Proceedings of the 30th International Business Information Management Association Conference, IBIMA 2017 - Vision 2020: Sustainable Economic development, Innovation Management, and Global Growth, 2017; 2697-707.

Kvale, S. and Brinkmann S. (2009). The qualitative research interview [Den kvalitativa forskningsintervjun] - in Swedish. Studentlitteratur. Lund, Sweden.

Lawrence, A., Thollander, P., Karlsson, M. (2018). Drivers, barriers, and success factors for improving energy management in the pulp and paper industry. Sustainability, $10(6)$ doi:10.3390/su10061851.

Laitner, J. A., Ruth M. B., Worrell, E. (2001). Incorporating the productivity benefits into the assessment of costeffective energy savings potential using conservation supply curves. Proceeding of the 2001 Summer Study on Energy Efficiency in Industry: 597-608.

Lee, K.-H. (2015). Drivers and barriers to energy efficiency management for sustainable development. Sustainable Development, 23 (1), 16-25.

Lilly, P. and Pearson D. (1999). Determining the full value of industrial efficiency programs. Proceedings ACEEE Summer Study on Energy Efficiency in Industry, 349-362. 
Lung, R. B., McKane, A., Leach R. and Marsh D. (2005). Ancillary savings and production benefits in the evaluation of industrial energy efficiency measures. Proceedings ACEEE Summer Study on Energy Efficiency in Industry.

May, G., Stahl, B., Taisch, M., Kiritsis, D. (2018). Energy management in manufacturing: From literature review to a conceptual framework. Journal of Cleaner Production, 167, 1464-1489.

Mills, E., Rosenfeld, A. (1996). Consumer non-energy benefits as a motivation for making energy-efficiency improvements. Energy, 21 (7-8), 707-720.

Mundaca, L. (2008). Markets for energy efficiency: Exploring the implications of an EUwide 'Tradable White Certificate' scheme. Energy Economics, 30 (6), 3016-3043.

Neal Elliott, R., Pye, M. (1998). Investing in industrial innovation: a response to climate change. Energy Policy, 26 (5), 413-423.

Nehler, T. (2016). The non-energy benefits of industrial energy efficiency - investments and measures. Lic. Thesis No. 1760, Linköping Studies in Science and Technology, Linköping University.

Nehler, T. (2018a). Linking energy efficiency measures in industrial compressed air systems with non-energy benefits - A review. Renewable and Sustainable Energy Reviews, 89, 72-87.

Nehler, T. (2018b). A systematic literature review of methods for improved utilisation of the non-energy benefits of industrial energy efficiency. Energies, 11(12).

Nehler, T., Rasmussen, J. (2016). How do firms consider non-energy benefits? Empirical findings on energy-efficiency investments in Swedish industry. Journal of Cleaner Production, 113, 472-482.

Nehler, T., Parra, R., Thollander, P. (2018). Implementation of energy efficiency measures in compressed air systems: barriers, drivers and non-energy benefits. Energy Efficiency, 11 (5), 1281-1302.

Olve, N-G., Samuelson, L., A. (2008). Controllerhandboken. Liber, Malmö, Sweden.

Paramonova, S., Thollander, P., Ottosson, M. (2015). Quantifying the extended energy efficiency gap - evidence from Swedish electricity-intensive industries. Renewable and Sustainable Energy Reviews, 51, 472-483.

Patton, M., Q. (2015). Qualitative Research Methods \& Evaluation Methods. 4th ed., SAGE Publications, Thousand Oaks, California.

Pye, M., McKane, A. (2000). Making a stronger case for industrial energy efficiency by quantifying non-energy benefits. Resources, Conservation and Recycling. 28, 171183.

Qiu, Y., Wang, Y.D., Wang, J. (2015). Implied discount rate and payback threshold of energy efficiency investment in the industrial sector. Applied Economics, 47 (21), 22182233.

Rasmussen, J. (2014). Energy-efficiency investments and the concepts of non-energy benefits and investment behaviour. In Proceedings ECEEE Industrial Summer Study - Retool for a Competitive and Sustainable Industry, 733-744.

Rasmussen, J. (2017). The additional benefits of energy efficiency investments-a systematic literature review and a framework for categorisation. Energy Efficiency, 10 (6), 1401-1418.

Rohdin, P., Thollander, P. (2006). Barriers to and driving forces for energy efficiency in the non-energy intensive manufacturing industry in Sweden. Energy, 31, 18361844.

Rohdin, P., Thollander, P., Solding, P. (2007). Barriers to and drivers for energy efficiency in the Swedish foundry industry. Energy Policy 35 (1), 672-677. 
Rosenqvist, J., P. Thollander, P. Rohdin, M. Söderström. (2012). Industrial Energy Auditing for Increased Sustainability - Methodology and Measurements.

Sa, A., Thollander, P., Cagno, E. (2017). Assessing the driving factors for energy management program adoption. Renewable and Sustainable Energy Reviews, 74, 538-547.

Sandahl, G., Sjögren, S. (2003). Capital budgeting methods among Sweden's largest groups of companies. The state of the art and a comparison with earlier studies. International Journal of Production Economics, 84 (1), 51-69.

Sandberg, P., Söderström, M. (2003). Industrial energy efficiency: The need for investment decision support from a manager perspective. Energy Policy, 31 (15), 1623-1634.

Schulze, M., Nehler, H., Ottosson, M., Thollander, P. (2016). Energy management in industry - a systematic review of previous findings and an integrative conceptual framework. Journal of Cleaner Production, 112 (5), 3692-3708.

SEA (2017). Energiläget 2017. ET2017:12. Statens energimyndighet.

SEA (2015). Energiläget 2015. ET2015:08. Statens energimyndighet.

SEA (2018). Energiläget 2018. ET2018:8. Statens energimyndighet.

SFS 2004:1196, Lag om program för energieffektivisering. Swedish Parliament, Stockholm.

Short, W., Packey, D. J., Holt, T. (1995). A manual for the economic evaluation of energy efficiency and renewable energy technologies. National Renewable Energy Laboratory, Colorado, U.S.

Skumatz, L., A., Dickerson, C., A. (1997). Recognizing All Program Benefits: Estimating the Non-Energy Benefits of PG\&E's Venture Partner Pilot Program (VPP). Energy Evaluation Conference, Chicago, August 1997.

Sivill, L., Manninen, J., Hippinen, I., Ahtila, P. (2013). Success factors of energy management in energy-intensive industries: Development priority of energy performance measurement. International Journal of Energy Research, 37 (8), 936-951.

Solnørdal, M., T., Foss, L. (2018). Closing the Energy Efficiency Gap-A Systematic Review of Empirical Articles on Drivers to Energy Efficiency in Manufacturing Firms. Energies, 11, 518.

Sorrell, S., Schleich, J., Scott, S., O’Malley, E., Trace, F., Boede, E., Ostertag, K. Radgen, P. (2000). Reducing barriers to energy efficiency in public and private organizations. http://www.sussex.ac.uk/Units/spru/publications/reports/barriers/finaltoc.pdf Retrieved 2016-10-06.

Sorrell, S., O’Malley, E., Schleich, J., Scott, S. (2004). The economics of Energy Efficiency, Cheltenham, UK: Edward Elgar Publishing.

Spiesshofer, U. (2014). Industrin måste energieffektivisera. Dagens industri, January 22nd. Stern, P., Aronson, E. (1984). Energy use: the human dimension. New York. Freeman.

Svensson, A., Paramonova, S. (2017). An analytical model for identifying and addressing energy efficiency improvement opportunities in industrial production systems Model development and testing experiences from Sweden. Journal of Cleaner Production, 142 (4), 2407-2422.

Söderström, M. (1996). Industrial electricity use characterized by unit processes a tool for analysis and forecasting. In proceedings of UIE XIII Congress on Electricity Applications, Birmingham June 16-20, 77-85.

Söderström, M., Carlsson, P., Hall, O. (1994). Enhetsprocesser - Ett sätt att strukturera industrins energianvändning. Linköping, Tech. Rep., Linköping University and Sydkraft Konsult. 
Thollander, P., Ottosson, M. (2008). An energy-efficient Swedish pulp and paper industry - exploring barriers to and driving forces for cost-effective energy efficiency investments. Energy Efficiency, 1 (1), 21-34.

Thollander, P., Ottosson, M. (2010). Energy management practices in Swedish energyintensive industries. Journal of Cleaner Production, 18, 1125-33.

Thollander, P., Palm, J. (2013). Improving Energy Efficiency in Industrial Energy Systems: An Interdisciplinary Perspective on Barriers, Energy Audits, Energy Management, Policies, and Programs. Springer, London.

Thollander, P., Karlsson, M., Rohdin, P., Söderström, M., Rosenqvist, J. (2012). A standardized energy audit tool for improved energy efficiency in industrial SMEs. In proceedings of ECEEE 2012 Summer study on energy efficiency in industry, Arnhem, the Netherlands, September 11-14, 659-667.

Thollander P, Backlund S, Trianni A, Cagno E. (2013). Beyond barriers - A case study on driving forces for improved energy efficiency in the foundry industries in Finland, France, Germany, Italy, Poland, Spain, and Sweden. Applied Energy 2013, 111, 636-43.

Tranfield, D., Denyer, D., Smart, P. (2003). Towards a Methodology for Developing Evidence-Informed Management Knowledge by Means of Systematic Review. British Journal of Management, 14 (3), 207-222.

Trianni, A., Cagno, E. (2012). Dealing with barriers to energy efficiency and SMEs: Some empirical evidences, Energy, 37, 494-504.

Trianni, A., Cagno, E., De Donatis, A. (2014). A framework to characterize energy efficiency measures. Applied Energy, 118, 207-220.

Trianni, A., Cagno, E., Thollander, P., Backlund, S. (2013). Barriers to industrial energy efficiency in foundries: A European comparison. Journal of Cleaner Production, 40, 161-76.

Trianni, A., Cagno, E., Farné, S. (2016). Barriers, drivers, and decision-making process for industrial energy efficiency: a broad study among manufacturing small and medium-sized enterprises. Applied Energy, 162, 1537-1551.

Trianni, A., Cagno, E., Nicosia, M. (2018). Compressed air systems: factors affecting the adoption of measures for improved efficiency. In Proceedings ECEEE Industrial Summer Study - Leading the low-carbon transition, 171-180.

Trost, J., Hultåker, O. (2016). Enkätboken. Fifth ed. Studentlitteratur, Lund.

UN (2015). Transforming our world: the 2030 Agenda for Sustainable Development. UN (United http://www.un.org/ga/search/view_doc.asp?symbol=A/RES/70/1\&Lang=E Retrieved 2019-02-04.

UNFCCC (2015). Adoption of the Paris agreement. UN (United Nations). https://unfccc.int/resource/docs/2015/cop21/eng/109r01.pdf. Retrieved 201902-04.

Venmans, F. (2014). Triggers and barriers to energy efficiency measures in the ceramic, cement and lime sectors. Journal of Cleaner Production, 69, 133-142.

Ürge-Vorsatz, D., Metz, B. (2009). Energy efficiency: How far does it get us in controlling climate change? Energy Efficiency, 2 (2), 87-94.

Ürge-Vorsatz, D., Novikova, A., Köppel, S., Boza-Kiss, B. (2009). Bottom-up assessment of potentials and costs of $\mathrm{CO} 2$ emission mitigation in the buildings sector: Insights into the missing elements. Energy Efficiency, 2 (4), 293-316.

Weber, L. (1997). Some reflections on barriers to the efficient use of energy. Energy Policy 25 (10), 833-835. 
Worrell, E., Martin, N., Price, L., Ruth, M., Elliott, N., Shipley, A., Thorn, J. (2002). Emerging Energy-efficient Technologies for Industry, Energy Engineering, 99 (2), 36-55.

Worrell, E., Laitner, J., Ruth, M., Finman, H. (2003). Productivity benefits of industrial energy efficiency measures. Energy, 28 (11), 1081-1098.

Yin, R., K. (2014). Case Study Research: Design and Methods, 5th ed., SAGE, Thousand Oaks, California. 


\section{Papers}

The papers associated with this thesis have been removed for copyright reasons. For more details about these see:

http://urn.kb.se/resolve?urn=urn:nbn:se:liu:diva-156297 


\section{FACULTY OF SCIENCE AND ENGINEERING}

Linköping Studies in Science and Technology, Dissertation No. 1980, 2019 Department of Management and Engineering

Linköping University

SE-581 83 Linköping, Sweden

www.liu.se 